\title{
Synthetic approaches to the
}

\section{incorporation of gallium and germanium into inorganic polymer structures}

by

\author{
Andrew Timothy Durant

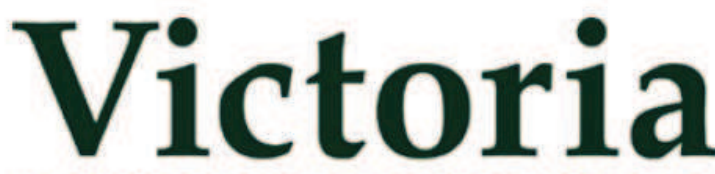 \\ UNIVERSITY OF WELLINGTON \\ Te Whare Wānanga \\ o te Üpoko o te Ika a Māui

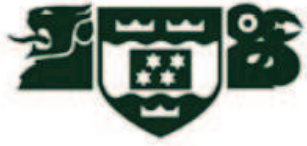

A thesis

Submitted to the Victoria University of Wellington

in fulfilment of the requirements for the degree of Master of Science in Chemistry

Victoria University of Wellington

2009 


\section{Abstract}

New sol-gel and solid-state synthesis methods and combinations of these were developed for the preparation of several new inorganic polymers related to aluminosilicate inorganic polymers, attempting to substitute gallium and germanium for aluminium and silicon. Gallium could successfully substitute for aluminium, but germanium could not be substituted for silicon by these methods.

Gallium silicate and gallium aluminosilicate inorganic polymers were synthesised from mixtures of $\mathrm{KGaO}_{2}, \mathrm{KAIO}_{2}, \mathrm{KOH}$ solutions with finely divided $\mathrm{SiO}_{2}$ (silica fume) using a combination of sol-gel and solid-state techniques. The products of these reactions were studied by X-ray powder diffraction (XRD), solid-state ${ }^{27} \mathrm{Al}$, ${ }^{29} \mathrm{Si},{ }^{71} \mathrm{Ga}$ and ${ }^{39} \mathrm{~K}$ nuclear magnetic resonance with magic-angle spinning (MAS NMR) and scanning electron microscopy (SEM).

For the synthesis of these mixed gallium-aluminium silicate inorganic polymers, the optimal $\mathrm{SiO}_{2}:\left(\mathrm{Ga}_{2} \mathrm{O}_{3}+\mathrm{Al}_{2} \mathrm{O}_{3}\right)$ ratio was found to be 7 and the $\mathrm{Ga}$ :Al ratio could range from $100 \% \mathrm{Ga}$ to $100 \% \mathrm{Al}$, with all intermediate ratios yielding inorganic polymers. The products showed all the characteristics of a true inorganic polymer, being X-ray amorphous and containing gallium and/or aluminium in tetrahedral coordination states. ${ }^{29} \mathrm{Si}$ MAS NMR showed the occurrence of $\mathrm{Si}(3 \mathrm{Ga})$ and $\mathrm{Si}(2 \mathrm{Ga})$ sites when gallium was present, and $\mathrm{Si}(3 \mathrm{Al})$ and $\mathrm{Si}(2 \mathrm{Al})$ sites when aluminium was present. Unreacted silica was also detected in these compounds by ${ }^{29}$ Si NMR and spherical silica particles were observed by SEM.

Heat treatment of gallium silicate, gallium aluminosilicate and aluminosilicate inorganic polymers synthesised by variations of the sol-gel method was monitored by thermal analysis methods (DSC-TGA) which revealed a water loss at $75^{\circ} \mathrm{C}$ and $160^{\circ} \mathrm{C}$ followed by a phase transition at $950^{\circ} \mathrm{C}$. At this temperature the inorganic polymers crystallised to $\mathrm{KGaSi}_{2} \mathrm{O}_{6}$ and $\mathrm{KAISi}_{2} \mathrm{O}_{6}$. 
The thermal behaviour of these samples was found to be different at $1200^{\circ} \mathrm{C}$; the high-temperature products derived from the gallium silicate inorganic polymers remained as crystalline $\mathrm{KGaSi}_{2} \mathrm{O}_{6}$ and retained their shape, while gallium aluminosilicate and aluminosilicate inorganic polymers melted and slumped, losing their shape and becoming X-ray amorphous.

Attempts to substitute germanium for silicon in the inorganic polymer structure were unsuccessful. A sol-gel approach using $\mathrm{GeO}_{2}$ produced crystalline $\mathrm{K}_{6} \mathrm{Ga}_{6}\left(\mathrm{GeO}_{4}\right)_{6}\left(\mathrm{H}_{2} \mathrm{O}\right)_{7}$. In an alternative solid-state approach, potassium germanate was synthesised and subsequently reacted with $\mathrm{KGaO}_{2}$ in a solidstate reaction to form partially amorphous hydraulic precursors; however, these did not set on the addition of water. A solid-state reaction of potassium germanate with $\mathrm{KGa}_{5} \mathrm{O}_{8}$ formed a partially amorphous precursor powder that set with the addition of water. However, the cured product was not amorphous, but proved to be crystalline $\mathrm{K}_{6} \mathrm{Ga}_{6}\left(\mathrm{GeO}_{4}\right)_{6}\left(\mathrm{H}_{2} \mathrm{O}\right)_{7}$.

In another approach, a sol-gel reaction of $\mathrm{NaAlO}_{2}$ solution and $\mathrm{GeO}_{2}$ with $\mathrm{KOH}$ solution set to an X-ray amorphous but brittle product. ${ }^{27} \mathrm{Al}$ MAS NMR showed this to contain aluminium in both tetrahedral and octahedral coordination states. When $\mathrm{KAIO}_{2}$ was used instead of $\mathrm{NaAlO}_{2}$, the products were crystalline. The study of the structure of these germanium compounds is hindered by the inaccessibility of the germanium nuclide to MAS NMR.

Nevertheless, the ability to synthesise a new category of materials by these new methods opens up the possibility of their potential applications as fluorescent materials and as components of optoelectronic devices. 


\section{Acknowledgements}

Professor Kenneth J D MacKenzie - supervisor

Sean O'Connor - lab partner

Industrial Research Ltd - NMR and furnace facilities

Hideki Maekawa, Tohoku University, Japan - gallium NMR

Herbert Wong, IRL - aluminium, silicon and potassium NMR

David Flynn, VUW - electron microscopy

Teresa Gen and Jackie King, VUW - lab support

Funding from the following sources is greatly appreciated and acknowledged:

William Georgetti Scholarship

Todd Foundation Award for Excellence

Freemasons University Scholarship

J L Stewart Scholarship

Curtis-Gordon Research Scholarship

Victoria Graduate Award

IRL Research Grant 


\section{Contents}

1 Introduction and literature survey 4

1.1 Inorganic polymers 5

1.2 New synthetic methods $\quad 9$

1.2.1 Sol-gel synthesis $\quad 9$

1.2.2 Solid-state synthesis 10

1.2.3 Potassium inorganic polymers 11

1.3 Gallium and germanium oxides $\quad 12$

2 Experimental 18

2.1 Methods of characterisation 18

2.1.1 Powder X-ray Diffraction 18

2.1.1.1 XRD apparatus 19

2.1.2 NMR Spectroscopy 20

2.1.2.1 NMR apparatus $\quad 23$

2.1.2.2 NMR sample preparation $\quad 24$

2.1.3 Scanning electron microscopy 24

2.1.3.1 SEM apparatus $\quad 26$

2.1.3.2 SEM sample preparation 26

2.1.4 DSC-TGA 27

2.1.4.1 DSC-TGA apparatus $\quad 27$

2.2 Reagents 28

3 Sample syntheses and characterisation 29

3.1 Sol-gel synthesis of Ga-Ge inorganic polymer analogues $\quad 29$

3.1.1 Synthesis of $\rho-\mathrm{Al}_{2} \mathrm{O}_{3} \quad 29$

3.1.2 Sol-gel synthesis 30

3.1.3 Molar ratios 31

3.1.4 XRD 32

3.1.5 Problems with the sol-gel synthesis 34

3.1.6 Synthesis of $\mathrm{KGaO}_{2}$

3.1.7 Sol-gel reaction of $\mathrm{KGaO}_{2}$ and $\mathrm{GeO}_{2} \quad 38$ 
3.1.8 Forming a $\mathrm{KGaO}_{2}$ solution $\quad 40$

3.1.9 Summary 41

3.2 Solid-state synthesis of $\mathrm{Ga}-\mathrm{Ge}$ inorganic polymers 42

3.2.1 $\mathrm{KGaO}_{2}$ and $\mathrm{GeO}_{2}$

3.2.2 Synthesis of potassium germanate 43

3.2.3 Synthesis of mixed-oxide precursor 45

3.2.4 Addition of water 47

3.2.5 Reducing alkali content 48

3.2.6 Potassium germanate melt 49

3.2.7 $\mathrm{KGaO}_{2}$ and germanate melt $\quad 50$

3.2.8 Gallium NMR 52

3.2.9 Synthesis of $\mathrm{KGa}_{5} \mathrm{O}_{8}$

3.2.10 Summary 56

3.3 Synthesis of gallium silicate inorganic polymers 57

3.3.1 Dissolving silica $\quad 57$

3.3.2 Water content 58

3.3.3 Synthesis 58

3.3.4 XRD 61

3.3.5 Effect of the $\mathrm{SiO}_{2}: \mathrm{Ga}_{2} \mathrm{O}_{3}$ ratio 61

3.3.6 Setting conditions 62

3.3.7 Water stability 64

3.3.8 Thin films 64

3.3.9 Silica 65

3.3.10 Silicon NMR 65

3.3.11 Gallium NMR 67

3.3.12 SEM 69

3.3.13 Structure conclusion $\quad 75$

3.3.14 Addition of potassium germanate 75

3.3.15 Summary 78

3.4 Synthesis of gallium aluminosilicate inorganic polymers $\quad 79$

3.4.1 Synthesis of $\mathrm{KAIO}_{2} \quad 79$ 
3.4.2 Synthesis $\quad 81$

3.4.3 XRD 84

3.4.4 Aluminium NMR $\quad 85$

3.4.5 Silicon NMR $\quad 85$

3.4.6 Gallium NMR $\quad 87$

3.4.7 Potassium NMR 88

3.4.8 SEM 90

3.4.9 Summary 93

3.5 Sol-gel reactions of aluminate and germanium dioxide $\quad 94$

3.5.1 Synthesis 94

3.5.2 Characterisation 94

3.5.3 $\mathrm{KAIO}_{2} \vee \mathrm{NaAlO}_{2} \quad 97$

$\begin{array}{ll}3.5 .4 \text { Summary } & 100\end{array}$

4 Effect of heat on potassium gallium silicate and potassium gallium $\begin{array}{ll}\text { aluminosilicate inorganic polymers } & 101\end{array}$

4.1 Sequential firings of gallium silicate inorganic polymers 101

4.2 DSC-TGA 103

4.3 Silicon NMR 111

4.4 Aluminium and gallium NMR 114

4.5 Summary 117

5 Summary and conclusions 118

$\begin{array}{ll}\text { References } & 123\end{array}$ 


\section{Introduction and literature survey}

The aim of this project was to synthesise gallium-germanium analogues of an aluminosilicate inorganic polymer (geopolymer), and characterise their structures by diffraction and spectroscopic techniques. The thermal behaviour of these new compounds was also investigated.

Geopolymers are inorganic polymer materials with ceramic-like properties which are synthesised and hardened by curing at ambient temperatures. Most of the applications of geopolymers up to now have been low-technology, such as an environmentally-friendly alternative to Ordinary Portland Cement(OPC); storage and disposal of heavy metal, fluoride, and radioactive wastes; removing impurities from waterways; and fireproof and refractory materials. The unique features of these aluminosilicate inorganic polymers are an X-ray amorphous network of aluminium and silicon atoms in solely tetrahedral coordination with oxygen, with alkali metal cations balancing the aluminium charge. They can be considered as an amorphous equivalent of geological feldspars. [1]

In contrast, gallium and germanium oxides are compounds that are typically used in materials with high-technology applications. The position of gallium and germanium, below aluminium and silicon, in the periodic table, suggests they will have a similar chemistry, and can therefore be substituted for aluminium and silicon in the geopolymer structure. Such substitutions have already been demonstrated, for example in mullite compounds[2], albite melts[3] and zeolites.[4, 5] Such a material potentially has some interesting properties and applications, and would be totally new in inorganic polymer chemistry. Although germanium glasses are known, products from these starting materials are usually crystalline, and there does not appear to be a precedent for attempting to make a non-crystalline product.

Central to this study will be the use of powder X-ray diffraction and multinuclear solid-state nuclear magnetic resonance - a technique crucial to research on such typically amorphous materials - to probe the structure of the products. 


\subsection{Inorganic Polymers}

Alkaline aluminosilicate cementitious systems were developed in Soviet Ukraine in the 1950's as a cheap construction material, referred to as 'soil silicates'. [6, 7] Inorganic polymers were pioneered by Joseph Davidovits, whose inspiration for the search of such materials was the need for a fireproof insulation material, to replace inflammable organic foam insulation, which posed a serious fire hazard, hampering efforts to extinguish fires in Parisian buildings.[8] Davidovits holds several patents for his invention, which he called a geopolymer.[9-12]

The original term 'geopolymer' was used to describe the product of a reaction of a dehydroxylated aluminosilicate clay with alkali silicate under highly alkaline conditions. These starting materials are mixed together to form a paste which hardens in a few hours at ambient temperature, and achieves maximum strength much more rapidly than Ordinary Portland Cement (OPC). More recently the word geopolymer has been used to describe a wide variety of materials made from a range of minerals and waste products, such as fly-ash from coal-fired power plants. In such cases the chemical composition can be complex and uncertain.

Aluminosilicate inorganic polymers have attracted increasing attention over the last two decades as a possible alternative to Ordinary Portland Cement (OPC). The reason for this is the environmental impact of OPC, which contributes the greenhouse gas, carbon dioxide, to the atmosphere, both from its chemistry of production and via the high energy requirement of its production. Conversely, inorganic polymers are not made of carbonate materials, and are formed at much lower temperatures, resulting in a reduced negative impact on the environment. Inorganic polymers have been reported to have compressive strengths of up to $80 \mathrm{MPa}$, making them stronger in some cases than OPC.[7]

The properties of aluminosilicate inorganic polymer materials are affected by the composition ratios $\mathrm{SiO}_{2}: \mathrm{Al}_{2} \mathrm{O}_{3}, \mathrm{Al}_{2} \mathrm{O}_{3}: \mathrm{M}_{2} \mathrm{O}, \mathrm{H}_{2} \mathrm{O}: \mathrm{M}_{2} \mathrm{O}$ and $\mathrm{H}_{2} \mathrm{O}: \mathrm{SiO}_{2}, \mathrm{pH}$, and 
curing temperature.[13] Water content in particular must be controlled to ensure a strong hard product, and the $\mathrm{pH}$ value of the mixture must be above 13 . Inorganic polymers can cure at ambient temperature, but cure faster at slightly elevated temperatures around $60^{\circ} \mathrm{C}$, forming a stronger material.

The setting of inorganic polymers can be made rapid by the addition of calcium, lithium or arsenate, or retarded by the addition of borate.[14, 15]

The octahedral aluminium layer of the clay lattice must be accessible for reaction with the silicate, and therefore 1:1 layer aluminosilicate clays are used. 2:1 aluminosilicates have the aluminium layer sandwiched between silica sheets, rendering it unavailable for the reaction. Mechanochemical grinding can allow a 2:1 lattice layer clay to react, however the usual aluminosilicate used is the 1:1 layer dehydroxylated kaolin clay, metakaolinite. This has aluminium in 4, 5 and 6 fold coordination with oxygen.[16]

The conventional inorganic polymer synthesis begins with dissolution of the aluminosilicate source into silicate ions and $\mathrm{Al}(\mathrm{OH})_{4}^{-}$species. The rate of this dissolution is dependant on $\mathrm{pH}$, which generally needs to be greater than 13.[1] Small aluminosilicate subunit oligomers are formed in the initial stages of the geopolymerisation reaction, forming a paste that thickens as the aluminosilicate subunits condense to form the geopolymer structure. The viscosity of the mixture increases rapidly at this point.[17] As polymerisation of the aluminosilicate units continues, the water content of the resulting gel is reduced, a process called syneresis.

The geopolymerisation process proceeds under kinetic control[18, 19], but the mechanism of the setting process is complicated and not fully understood. Silicate species are not linear and the polymerisation mechanism of polymeric silicate species is entirely different to an organic system.[20] The particle size of the aluminate source can influence the properties of the inorganic polymer, such as setting time and compressive strength. The use of milled metakaolin powders 
have been shown to improve such properties and also improve the homogeneity of the inorganic polymer microstructure.[21]

The structure of an inorganic polymer is a $3 \mathrm{D}$ network of $\mathrm{SiO}_{4}$ and $\mathrm{AlO}_{4}$ tetrahedra , similar to that of alkali aluminosilicate glasses.[22] Davidovits[23] proposed a network structure made up of units he termed polysialate, polysialate-siloxo and polysialate-disiloxo (figure 1).[10]

The charge imbalance created by anionic $\mathrm{AlO}_{4}$ tetrahedra is balanced by alkali cations, typically sodium and/or potassium (figure 2).

\begin{tabular}{|c|c|}
\hline $\begin{array}{c}\text { PS } \\
\text { Poly(sialate) }\end{array}$ & $\begin{array}{cc} & (-) \\
1 & 1 \\
(-S i-O-A l-O- \\
1 & 1 \\
0 & 0 \\
1 & 1\end{array}$ \\
\hline $\begin{array}{c}\text { PSS } \\
\text { Poly(sialate-siloxo) }\end{array}$ & $\begin{array}{ccc} & (-) & \\
1 & 1 & 1 \\
(-S i-O-A l-O-S i-O-) \\
\text { 1 } \\
0 & 1 & 1 \\
1 & 1 & 1\end{array}$ \\
\hline $\begin{array}{c}\text { PSDS } \\
\text { Poly(sialate-disiloxo) }\end{array}$ & $\begin{array}{cccc} & (-) & \\
1 & 1 & 1 & 1 \\
\text { (-Si-O-Al-O-Si-O- Si-O-) } \\
1 & 1 & 1 & 1 \\
0 & 0 & 0 & 0 \\
1 & 1 & 1 & 1\end{array}$ \\
\hline
\end{tabular}

Figure 1: Types of polysialates[7]

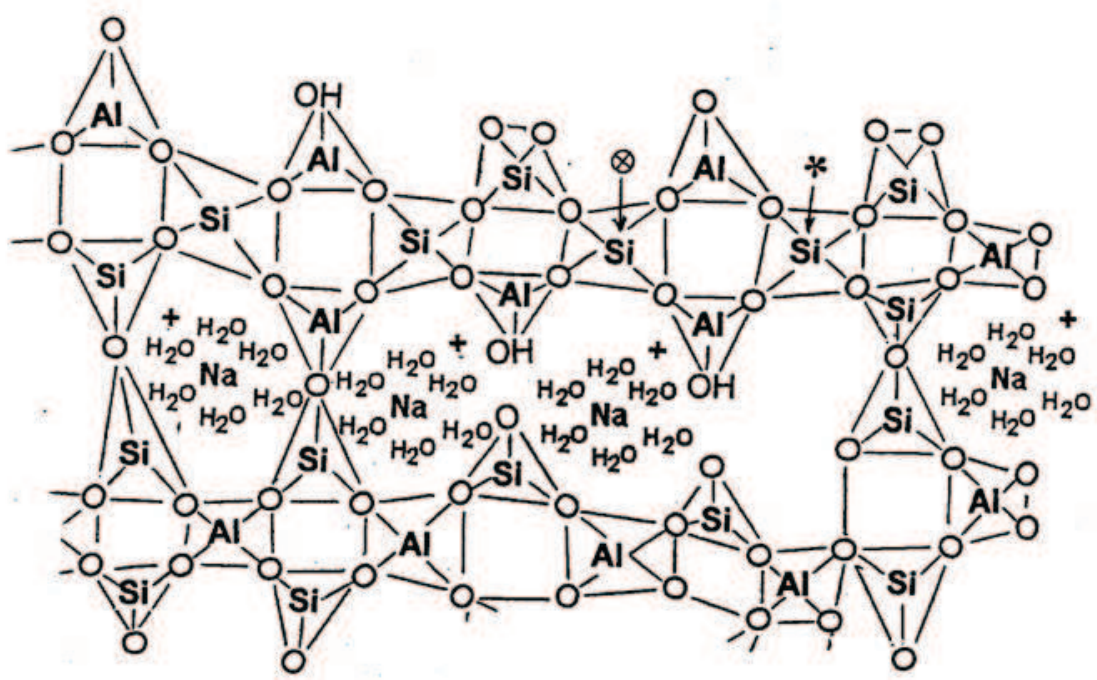

Figure 2: A suggested 'structure' of a geopolymer consistent with XRD and NMR evidence[24] 
Water is coordinated to alkali cations in structural pores, and can be removed by heating the geopolymer to approximately $250-500^{\circ} \mathrm{C}$. The matrix is both microporous and nanoporous, and more silicaceous geopolymers have a decreased porosity. The micropores are probably caused by water loss in a fashion similar to cement.

'Foamed' inorganic polymers are formed when the $\mathrm{SiO}_{2}: \mathrm{Al}_{2} \mathrm{O}_{3}$ ratio is very high. These have a high alkali and water content, and on heating to around $250^{\circ} \mathrm{C}$ the water is lost causing them to foam and making them potentially useful as insulating materials.[25]

Aluminosilicate inorganic polymers with typical $\mathrm{SiO}_{2}: \mathrm{Al}_{2} \mathrm{O}_{3}$ ratios can also be foamed by being subjected to a vacuum before setting. The product is strong with large visible pores.[26]

Inorganic polymers are both strong and hard but lack toughness, and as a result can break catastrophically. To improve toughness and cause graceful breakage the matrix can be reinforced with fibres. This has already been done using inorganic fibres such as basalt, wollastonite, glass, carbon fibre, and silicon carbide and also metallic fibres.[27, 28]

It may also be possible to improve the physical properties of a galliumgermanium inorganic polymer analogue in a similar fashion, although the toughness of such a product is unlikely to be of great significance for the envisaged electronic or optoelectronic applications. 


\subsection{New Synthetic Methods}

\subsubsection{Sol-gel synthesis}

The impetus for this project came from some recent developments in the methods for making regular aluminosilicate geopolymers. These are conventionally formed by reaction between a solid aluminosilicate, metakaolin, and alkali silicate solution under highly alkaline conditions. Metakaolin is the dehydroxylated form of the 1:1 layer lattice aluminosilicate mineral kaolinite.[22, 24] However, to make a gallium-germanium analogue by this method would require a solid gallogermanate starting material akin to metakaolinite, which is not known in nature.

In 2007 two new syntheses were developed that do not require a solid aluminosilicate starting material.

The first uses silica fume as the silicon source and sodium aluminate as the aluminium source. These were reacted together in an alkaline solution, in an essentially sol-gel type process.[29] Often in sol-gel preparations water is used in excess, but this is not the case in this reaction as water content influences the product outcome. The purpose of this was to use a simpler chemical system, which could be used to study the mechanism of geopolymer formation.

$$
\mathrm{SiO}_{2}+\mathrm{NaAlO}_{2}+\mathrm{NaOH}+\mathrm{H}_{2} \mathrm{O} \longrightarrow \text { Geopolymer Product }
$$

The product sets at $40^{\circ} \mathrm{C}$ with a crushing strength of $26 \mathrm{MPa}$, is X-ray amorphous and contains solely 4-coordinated Al. Its ${ }^{29} \mathrm{Si}$ MAS NMR spectrum indicates the presence of some unreacted $\mathrm{SiO}_{2}(-109 \mathrm{ppm})$ in addition to the typical $\mathrm{Si}$ resonance of a geopolymer (-87, $-97 \mathrm{ppm})$.[29] These partially dissolved silica particles may act as fillers, which lower the porosity and contribute to the compressive strength. 


\subsubsection{Solid-state synthesis}

Later in 2007, another new method for making inorganic polymers was reported.[30] This is a solid-state synthesis that does not require an alkali silicate solution, but involves direct calcination of kaolin clay with sodium or potassium hydroxides. The product is a hydraulic powder; on addition of water it forms a paste, which hardens at ambient temperature. XRD and NMR confirm it has the characteristics of the geopolymer structure, but also contains a small amount of crystalline phases.[30] The product is weaker than a conventional geopolymer, with a compressive strength of $4 \mathrm{MPa}$.[30]

This method has been successfully used to synthesise an aluminosilicate inorganic polymer with lithium as the charge balancing alkali cation.[26] This is difficult to prepare by the conventional method because of the poor solubility and weak alkalinity of $\mathrm{LiOH}$ solution. In this solid state synthesis, halloysite clay was reacted with $\mathrm{LiOH}$ at $550^{\circ} \mathrm{C}$, forming a hydraulic precursor powder. When wetted, the product sets at $40^{\circ} \mathrm{C}$ to a compound containing solely tetrahedrally coordinated $\mathrm{Al}$ and has a ${ }^{29} \mathrm{Si}$ MAS NMR spectrum consistent with aluminosilicate geopolymers, but is not fully X-ray amorphous.[26]

Both of these methods, sol-gel and solid-state, are potential synthetic routes for making gallium and germanium geopolymer analogues, as the gallium and germanium can come from different sources. Gallium oxide and germanium oxide were the starting materials used. The solid-state method also potentially allows the synthesis of compounds that are insoluble in water. 


\subsubsection{Potassium Inorganic Polymers}

Conventional aluminosilicate geopolymers were originally made using sodium silicate and sodium hydroxide because these were cheaper than the potassium equivalent, and cost is an important consideration for a low-technology bulk structural material. However, more recently potassium has been suggested to produce geopolymers with better physical properties.[7]

Sodium gives rise to zeolite formation in the product.[7] Potassium geopolymers display remarkable thermal stability, with little change in structure until $1000^{\circ} \mathrm{C}$.[31] Sodium geopolymers react to form nepheline at $800^{\circ} \mathrm{C}-900^{\circ} \mathrm{C}$ and display lower stability than potassium geopolymers at temperatures from $30^{\circ} \mathrm{C}$ to $90^{\circ} \mathrm{C}$ and high humidity, undergoing a reaction to form zeolites.[18, 32]

Potassium was chosen as the charge balancing cation for most of the inorganic polymer synthesis in this project. The larger size of the potassium ion may help stabilise the larger gallium and germanium tetrahedra. Gallium oxide is more soluble in potassium hydroxide and potassium gallate solutions have considerably lower viscosities than sodium gallate solutions, aiding processing.[33]

The use of potassium hydroxide increases the rate of silica dissolution and favours the formation of more polymerised silica species in solution compared to other alkali cations.[34]

The charge balancing alkali cation influences the conductivity of aluminosilicate inorganic polymers, and is likely to also affect such measurements of the products of this project. The magnitude of the conductivity appears to be related to ion size, decreasing from $\mathrm{Li}^{+}>\mathrm{Na}^{+}>\mathrm{K}^{+}$. This suggests the mechanism of conductance may be due to movement of these ions through the matrix.[35, 36] 


\subsection{Gallium and Germanium Oxides}

Gallium occurs below aluminium in group 13 of the periodic table and resembles aluminium in its chemical properties. It occurs, to a small extent, in all naturally occurring aluminium minerals.[15] Both aluminuim and gallium have similar ionic radii (57 pm and $62 \mathrm{pm}$ respectively), which allows mixed crystal formation, and many gallium compounds- particularly oxides - are isomorphous with the corresponding aluminium compounds.[37]

Gallium oxide has been suggested as a main component of gas sensors due to its semi-conducting properties and as a phosphor due to its luminescent properties.[38] It has a wide band gap of $4.8 \mathrm{eV}$.[38]

A considerable amount of earlier research on gallates and germanates found in the literature is in Russian. Most of this work appears to involve the development of luminescent materials, such as gallates with formula $\mathrm{MGa}_{5} \mathrm{O}_{8}$, and compounds formed within the ternary system, $\mathrm{M}_{2} \mathrm{O}-\mathrm{Ga}_{2} \mathrm{O}_{3}-\mathrm{GeO}_{2}$, where $\mathrm{M}=\mathrm{Li}, \mathrm{Na}$, K.[39] The luminescence of these materials was both self-activated and activated by manganese, copper and terbium, however the literature does not elaborate on the specific nature of the luminescent properties. Gallium oxide can host rare earth elements, such as erbium and europium.

These compounds were made from the same starting materials that will be used for this project; $\mathrm{Ga}_{2} \mathrm{O}_{3}, \mathrm{GeO}_{2}$, and alkali carbonates, but the reaction temperatures $\left(800-1250^{\circ} \mathrm{C}\right)$ were much higher than those proposed for this project; a weakly reducing atmosphere was used, and the products were crystalline. $\mathrm{LiGaGeO}_{4}$ formation can occur in air, with $\mathrm{LiGaO}_{2}, \mathrm{LiGa}_{5} \mathrm{O}_{8}$ and $\mathrm{Li}_{2} \mathrm{O} . x \mathrm{KeO}_{3}$ (where $\mathrm{x}=4.7$ ) formed as intermediates. [39]

The corresponding sodium and potassium products also exhibit luminescence, but with lower efficiency than the lithium gallate.[39] These reported compounds 
contained more gallium than germanium, which is different to the target products of this project, where there must be more networking germanium than gallium, in order to satisfy the gallogermanate equivalent of Lowenstein's rule, where the number of silicon atoms must be greater than the number of aluminium atoms, and $\mathrm{Al}-\mathrm{O}-\mathrm{Al}$ bond sequences are forbidden.[40]

Investigations of the thermoluminescence of the complex crystalline gallates showed that after activation with manganese they possess deep level capture and were able to store a considerable amount of light. These phosphors also had a wide radiation spectrum, with a half-width luminescence of $92 \mathrm{~nm}$.[39]

There are three polymorphs of gallium oxide. $\alpha-\mathrm{Ga}_{2} \mathrm{O}_{3}$ has a hexagonal structure similar to corundum, but unlike a-aluminum oxide, it is thermodynamically unstable. $\mathrm{Y}-\mathrm{Ga}_{2} \mathrm{O}_{3}$ is isostructural with $\mathrm{Y}^{-} \mathrm{Al}_{2} \mathrm{O}_{3}$ and is as metastable as its aluminium analogue. The thermodynamically stable form of gallium oxide is $\beta$ $\mathrm{Ga}_{2} \mathrm{O}_{3}$, which has a defective spinel structure with ordered cations and valencies, and monoclinic distortion. The phase transition of $\alpha$ to $\beta$ occurs at around $1070^{\circ} \mathrm{C}$.[38] The gallium oxide used as the starting material in the present work contains the $\beta$ form, confirmed by XRD.

Manganese activated gallium oxide has potential as a luminescent material. Manganese and gallium have a reciprocal solubility in their oxide and hydroxide compounds, and mixed oxide powders have been prepared by coprecipitation.[38] The formation of solid solution phases changes the electronic and vibrational spectra of the individual compounds, and the addition of gallium results in the stabilisation of more reduced manganese species.[38]

Gallium oxide is a component in catalysts for the selective removal of nitrogen oxides from car exhaust gases, by reduction with propene.[38, 41] Zeolite-based catalysts show high catalytic activity, but suffer from deactivation under hydrothermal conditions due to dealumination from the framework. Alumina 
based catalysts have a high stability and may be a more suitable catalyst from a practical viewpoint.

Exhaust gases usually contain $\mathrm{H}_{2} \mathrm{O}$ and $\mathrm{SO}_{2}$, which can inhibit the reduction of $\mathrm{NO}$ over alumina-based catalysts.[41] $\mathrm{A} \mathrm{Ga}_{2} \mathrm{O}_{3}-\mathrm{Al}_{2} \mathrm{O}_{3}$ catalyst prepared by sol-gel method has shown good activity for $\mathrm{NO}$ reduction by propene in the presence of oxygen, $\mathrm{H}_{2} \mathrm{O}$ and $\mathrm{SO}_{2}$. Metal oxide additives, such as $\ln _{2} \mathrm{O}_{3}$ can enhance catalytic activity in this system.[27]

$\mathrm{Ga}_{2} \mathrm{O}_{3}$ on an alumina support has been used as a catalyst in the dehydrogenation of hydrocarbons.[38, 42] The reported process is the dehydrogenation of an alkyl aromatic compound, ethyl benzene, to a vinyl aromatic compound, styrene. This catalyst will also dehydrogenate ethane to ethylene. These dehydrogenation processes can be integrated into the synthesis of a vinyl aromatic compound such as styrene from a raw material base of ethane and benzene.[42] The gallium loading in this catalyst is between 0.1 and $10 \%$ by weight, calculated as gallium oxide. Variations on this theme include the addition of zinc as $\mathrm{ZnO}$, and also metals from groups 1 and 2 ( $\mathrm{Li}, \mathrm{Na}, \mathrm{K}, \mathrm{Mg}, \mathrm{Ca}$, $\mathrm{Sr}, \mathrm{Ba})$. A small amount of platinum would promote combustion during regeneration of the catalyst with air or oxygen.[42]

Gallium oxide is also used as a catalyst for the activation of methane[43], and for the vapour phase conversion of phenol and ammonia to aniline.[44]

Gallium silicate glasses have been studied as analogues of aluminosilicates[45], and show more $\mathrm{Si}-\mathrm{Ga}$ disorder than the corresponding $\mathrm{Si}-\mathrm{Al}$ disorder, and gallium may have a greater tendancy to coordinate to more than four oxygens than aluminium in such a system.[45]

A considerable amount of research has been done on the incorporation of gallium into zeolitic frameworks.[4] Common gallium sources for these syntheses 
include $\mathrm{Ga}_{2} \mathrm{O}_{3}$ and $\mathrm{Ga}\left(\mathrm{NO}_{3}\right)_{3} \cdot 9 \mathrm{H}_{2} \mathrm{O}$, and are reacted with colloidal silica. The Si:Ga ratio typically ranges from 1 to around 30.[46, 47]

Generally gallosilicate zeolites are found to have unit cell volumes larger than those of analogous aluminosilicates, but their surface adsorption capacities are lower.[48]

This gallium incorporation is usually achieved during the crystallisation process in the presence of a suitable templating agent, but there are also methods for postsynthesis galliation, such as treating the zeolite material with alkaline gallate solutions. In this method $\mathrm{Ga}^{3+}$ is substituted for $\mathrm{Si}^{4+}$, not $\mathrm{Al}^{3+}$.[49]

The aim of this substitution is to completely integrate the gallium into the framework without modifying the structure, but the synthesis conditions can be altered such that part of the gallium is deposited as oxide clusters in the porous network or on the external surface of the zeolite crystals. [4]

This non-framework gallium plays a role in many of the catalytic processes of these zeolites, such as the aromatisation of lower alkanes (Cylar process)[50] and the isomerisation of alkylaromatics.[51] The pre-treatment temperature in gallium aluminosilicate zeolites has been shown to influence the proportion of non-framework gallium species, which increased with increasing pre-treatment temperature.[52]

The geopolymer structure is thermally stable, and such a structure containing gallium oxide, and possibly doped with other metals and oxides could have potential practical uses as a catalyst in these and similar industrial processes.

Germanium and silicon also share some chemistry. Both have a diamond structure and comparable ionic radii, $53 \mathrm{pm}$ for $\mathrm{Ge}^{4+}$ and $40 \mathrm{pm}$ for $\mathrm{Si}^{4+}$. $\mathrm{GeO}_{2}$ is isostructural with $\mathrm{SiO}_{2}$, has a comparable melting point, and is compatible with 
the silica network. This has led to the development of germanium-containing zeolites[53, 54], which increases the formation of large 12-membered ring pores and channels. These materials have potential for use in the petrochemical and pharmaceutical industries, due to their ability to separate large molecules.[55] These zeolites are synthesised from $\mathrm{GeO}_{2}$ and fumed silica, with a general formula $\left(\mathrm{Si}_{96-\mathrm{x}} \mathrm{Ge}_{\mathrm{x}}\right) \mathrm{O}_{192}$ where $\mathrm{x}$ ranges from $0.1-36 .[53]$

The higher mesoporosity and a greater number of hydroxyl group defects that result from $\mathrm{Ge}$ incorporation can reduce deactivation in zeolites, enhancing catalytic activity, without altering the overall structure.[56]

The optimal Ge-O-Ge bond angle of $130^{\circ}$ is smaller than the Si-O-Si bond angle of $145^{\circ}$, and the Ge-O bond length is longer than the Si-O bond length. This can affect the structure by enhancing the probability of forming frameworks with double four-membered rings.[56] Crystallisation of these zeolites is controlled by two opposing effects; the presence of $\mathrm{Ge}$ atoms stabilises the cage, while the geometric distortions generate an overall destabilisation. An increasing germanium concentration influences zeolite growth by accelerating nucleation and crystallisation[57], and zeolites that contain germanium in the framework have a higher enthalpy of formation relative to the unsubstituted zeolite, resulting in an increased metastability.[58]

The effects of germanium on the kinetics and mechanism of zeolite growth are not well understood.[56]

Germanium is an important optical material, particularly in the infrared due to its small band gap. It is a poor dielectric and has a band structure similar to $\mathrm{SnO}_{2}$.

Germanium dioxide has a high refractive index (approximately 2) to visible light but is transparent to infrared light. It is therefore used to make infrared sensitive lenses.[56] 
Mixtures of silicon dioxide and germanium dioxide can be used to make optical fibres, and by varying the ratio of these components the refractive index can be altered.[56]

Gallium and germanium analogues of mullite structures have been reported.[2] The starting materials were $\mathrm{GeO}_{2}, \mathrm{Ga}_{2} \mathrm{O}_{3}$ and $\mathrm{Al}_{2} \mathrm{O}_{3}$ and the products were synthesised by solid-state reaction. Gallium incorporation only occurs above $1150^{\circ} \mathrm{C}$, and $\mathrm{SiO}_{2}$ could not replace $\mathrm{GeO}_{2}$ in the reactions with $\mathrm{Ga}_{2} \mathrm{O}_{3 .}$.2]

While gallium and germanium have been incorporated into zeolite frameworks, it is important to consider the fundamental differences between the syntheses of zeolites and inorganic polymers. Zeolite synthesis occurs under acidic conditions, $\mathrm{pH} 1-7$, from the addition of acid, before changing to $\mathrm{pH} 8-12$ in the second stage. In contrast inorganic polymer synthesis typically occurs under highly alkaline conditions, and a $\mathrm{pH}$ greater than 13 is required for the formation of a strong product.[1] Zeolites have a $\mathrm{SiO}_{2}: \mathrm{Al}_{2} \mathrm{O}_{3}$ ratio typically of 20-50, and occasionally between 5-100, whereas the $\mathrm{SiO}_{2}: \mathrm{Al}_{2} \mathrm{O}_{3}$ of an aluminosilicate inorganic polymer is usually between 2.7-5.2.[59] Possibly the greatest difference between the syntheses of zeolites and inorganic polymers is the amount of water used. Zeolite synthesis involves hydrothermal treatment and uses considerably more water, with $\mathrm{H}_{2} \mathrm{O}: \mathrm{SiO}_{2}$ ratios ranging from 25-50.[60] The product is typically not very sensitive to the water content during synthesis. In contrast the formation of inorganic polymers requires relatively little water, and the water content must be strictly controlled during processing and curing.

Much of the more recent literature of gallium and germanium oxides involves their use in nanoscaled compounds and materials, and the properties of these have little relevance to an extended amorphous polymer structure made of the same materials. 


\section{Experimental}

\subsection{Methods of Characterisation}

Two techniques were predominantly used to probe the structure of the products: Powder X-ray diffraction (XRD) and multinuclear solid-state nuclear magnetic resonance (NMR).

A selection of samples was also studied using scanning electron microscopy (SEM), a technique which allows observation of the surface morphology of the material, and also has the ability to map the distribution of elements in the sample, giving a guide to the level of chemical homogeneity.

Simultaneous differential scanning calorimetry (DSC) and thermogravimetric analysis (TGA) was used to investigate the thermal properties of the products and the results of firing samples.

\subsubsection{Powder X-Ray Diffraction (XRD)}

For studying inorganic polymers, XRD is used to confirm the product is amorphous, indicated by a broad hump peaking at around $30^{\circ} 2 \theta$. XRD also clearly shows the presence or absence of any crystalline phases in the product. However some inorganic polymers with good properties are not entirely amorphous and may also contain some crystalline phases containing octahedral aluminium.[40]

$\mathrm{XRD}$ is a technique particularly useful for the study of crystalline materials, and has been widely used to analyse gallium-containing zeolites, allowing changes in the cell parameters to be calculated as gallium is incorporated into the zeolite network.[60] 
However, an inorganic polymer is by definition structurally amorphous, and XRD does not yield detailed structural information. Despite this, XRD was always done for every product sample, to determine whether it is indeed non-crystalline. The evidence for this is the broad hump, centred around $30^{\circ} 2 \theta$. Another broad hump appears at around $12-14^{\circ} 2 \theta$ in all XRD patterns, originating from the Perspex sample holder used. This type of sample holder was used to avoid sharp peaks in the diffraction pattern resulting from the more common aluminium sample holder.

A fragment of each synthesized product that set was ground in a mortar and pestle and analysed by XRD using a quick survey scan of approximately 30 minutes, covering $4-80^{\circ} 2 \theta$. Samples of particular interest were then subjected to a longer 2 hour scan over the same range, which results in a cleaner background and tidier, sharper diffraction pattern.

\subsubsection{XRD Apparatus}

XRD analysis was performed using a Philips PW1730 stand alone generator, PW3710 mpd control with a PW1768/xx sample stage and a PW1050 goniometer.

Cu Ka radiation was generated from a PW2773 Cu LFF X-ray tube, operated at a voltage of $40 \mathrm{kV}$ and current of $20 \mathrm{~mA}$. 


\subsubsection{NMR Spectroscopy}

Solid-state NMR is a powerful analytical tool, crucial to the study of materials that lack a crystalline structure, and therefore cannot be studied using X-ray crystallography. ${ }^{27} \mathrm{Al}$ and ${ }^{29} \mathrm{Si}$ are two nuclei that can be studied with solid state NMR, and the development of this technique has been largely due to research on zeolites, another type of aluminosilicate, developed as catalysts for the petrochemical industry. Unlike NMR in the liquid phase, where atomic motion is fast enough to average out all the nuclei, in solids there are many different chemical environments, and this produces broad peaks in solid state NMR spectra. To counter this, the samples for solid state NMR are spun very fast at what is known as the magic angle. This angle is $54.74^{\circ}$ with respect to the direction of the magnetic field. This magic angle spinning (MAS) narrows the peaks and gives a spectrum with increased resolution that contains useful information.[61]

${ }^{27} \mathrm{Al}$ has a $100 \%$ natural abundance, and a very fast relaxation time, allowing many pulses for samples that may have a low aluminium content. The ${ }^{27} \mathrm{Al}$ nucleus has a spin, $I=5 / 2$, and has a non-spherical charge distribution. The interaction of the resulting non-zero quadrupole moment with the electric field gradient at the nucleus causes broadening in the spectra. This quadrupolar broadening is reduced by spinning the sample. It is important to have many pulses for each measurement to obtain a good spectrum, usually at least 200 . More scans give a better signal to noise ratio, making the spectrum cleaner. The spectra can be used to determine the aluminium coordination, site distortion and site occupancy.[40]

${ }^{29} \mathrm{Si}$ has a low natural abundance $(4.7 \%)$ but it is a sensitive nucleus, and is therefore suitable for NMR. It can have a long relaxation time, especially for synthetic materials. Therefore each experiment requires more time, and only allowing a few spectra to be obtained each day. These spectra can be used for fingerprinting different silicon species, identification of structural groups, 
structural disorder, and can even yield information on structural features, such as bond angles and bond lengths. [40]

The varying degree of polymerisation of silicate tetrahedral units is indicated by the ' $Q$ ' notation, where $Q$ is a silicon bonded to four oxygen atoms. A superscript number from 0 - 4 next to the $Q$ shows how many network-forming elements the silicon is bonded to through oxygen. This affects the chemical shift of the silicon, with $\mathrm{Q}^{0}$ units having shifts of around $-65 \mathrm{ppm}$, becoming increasingly negative as more network forming elements are bonded to the central silicon. $Q^{4}$ units such as fully polymerised silica have a shift of around $-110 \mathrm{ppm}$. If an aluminium atom is substituted for a silicon surrounding the central $\mathrm{Si}$ of a $\mathrm{Q}^{4}$ unit, the ${ }^{29} \mathrm{Si}$ chemical shift changes towards less negative values.[61]

For inorganic polymers the silicon units are all $Q^{4}$ but can have different chemical shifts depending on the number of aluminium atoms associated with the silica tetrahedra. A shift of the silicon peak in the direction of negative chemical shifts with respect to tetramethyl silane (TMS) indicates there are fewer aluminium atoms around the silica. The number of aluminium atoms bonded through oxygen to the central silicon is denoted in brackets. A peak between -83 and $-90 \mathrm{ppm}$ is assigned to $\mathrm{Si}(4 \mathrm{Al})$; between -86 and $-93 \mathrm{ppm}$ is $\mathrm{Si}(3 \mathrm{Al})$; -93 to $-98 \mathrm{ppm}$ is $\mathrm{Si}(2 \mathrm{Al}) ;-98$ to $-105 \mathrm{ppm}$ is $\mathrm{Si}(1 \mathrm{Al})$; and -103 to $-115 \mathrm{ppm}$ is $\mathrm{Si}(0 \mathrm{Al})$.[62]

A typical solid state NMR spectrum for an aluminosilicate geopolymer shows tetrahedral aluminium coordination, statistically prevalent $\mathrm{Si}(3 \mathrm{Al})$ silicon sites for sodium geopolymers, and predominantly $\mathrm{Si}(4 \mathrm{Al})$ silicon sites for potassium geopolymers.[63]

It has been suggested that substitution of aluminium by gallium in crystalline gallosilicate materials can cause a shift of about 3 ppm to higher ppm. [64] However there is currently no systematic study available of the range of silicon shifts in gallosilicate compounds.[61] 
Gallium MAS NMR spectroscopy is the preferred tool for the characterisation of solids containing gallium. There are two NMR active nuclei, ${ }^{71} \mathrm{Ga}$ and ${ }^{69} \mathrm{Ga}$, with natural abundances of $40 \%$ and $60 \%$ respectively. Both have a spin of $3 / 2$ and have good sensitivity, however ${ }^{71} \mathrm{Ga}$ is the most common nuclide reported in the literature. Well-resolved Ga NMR spectra are more difficult to acquire than Al NMR spectra due to the quadrupolar broadening of the Ga nuclei being 11 times that of aluminium.[61] High magnetic field strengths are required to minimise the average second-order line broadening, and high spinning frequencies are required to reduce the chemical shift anisotropy effects on line-width, and to prevent overlap of peaks and spinning side bands. Chemical shifts are recorded relative to a solution of $\mathrm{Ga}^{3+}$ ions, typically 1 molar gallium nitrate solution. Tetrahedral framework gallium is indicated by a peak at $+155 \mathrm{ppm}$. [4]

${ }^{71} \mathrm{Ga}$ NMR has been used to study alkaline gallium silicate solutions.[65]

The germanium nuclide, ${ }^{73} \mathrm{Ge}$, has a spin of $9 / 2$ and a natural abundance of $7.7 \%$, but there is no reported literature on germanium NMR, and it has been suggested anecdotally that this cannot presently be done, with resulting spectra yielding no useful information, due to a very broad line-width. The relaxation time may also be too slow to be practical. As a result germanium NMR was not possible for this project.

${ }^{39} \mathrm{~K}$ has a natural abundance of $93.1 \%$ and has a central transition with a relative receptivity comparable to ${ }^{13} \mathrm{C}$. However, studies using solid-state ${ }^{39} \mathrm{~K}$ NMR are limited as it has a small magnetic moment and a quadrupolar nucleus. Some systematic studies of a few potassium compounds have been made, but the spectra of minerals tend to be broad and featureless. Different potassiumcontaining silicates can be distinguished by comparing the centre-of-gravity of the broad resonance. If potassium is hydrated the peak is sharper, and this is used to identify structural and exchangeable sites within mineral structures.[61] 
${ }^{39} \mathrm{~K}$ NMR experiments require an echo pulse, which effectively delays collection of information outside the 'deadtime'. This is a term used to describe probe and electronic effects that prevent the spectrometer from recording the NMR signal.[66]

${ }^{39} \mathrm{~K}$ NMR has been used to study the thermal properties of aluminosilicate inorganic polymers. As the inorganic polymer is heated to $1300^{\circ} \mathrm{C}$ the centre-ofgravity position of the peak shifts from $-47 \mathrm{ppm}$ to $-120 \mathrm{ppm}$, which is similar to the potassium position of the anhydrous feldspar leucite, $\mathrm{KAISi}_{2} \mathrm{O}_{6}$.[61]

\subsubsection{NMR apparatus}

${ }^{29} \mathrm{Si},{ }^{27} \mathrm{Al}$ and ${ }^{39} \mathrm{~K}$ solid-state nuclear magnetic resonance spectroscopy with magic angle spinning was carried out at $11.7 \mathrm{~T}$ using a BRUKER Avance 500 spectrometer and Doty MAS probes spun at approximately $6 \mathrm{kHz}$ for silicon and $10-12 \mathrm{kHz}$ for aluminium.

${ }^{29} \mathrm{Si}$ NMR was carried out at a frequency of $99.926 \mathrm{MHz}$, using a $6 \mu \mathrm{s}$ ( $\pi / 10)$ pulse and a 30 second delay. The spectra were referenced to tetramethyl silane (TMS).

${ }^{27} \mathrm{Al}$ NMR was carried out at a spectrometer frequency of $130.224 \mathrm{MHz}$, using a $1 \mu \mathrm{s}$ ( $\pi / 10$ pulse for solution) and a one second delay. The spectra were referenced to a 1 molar solution of aluminium nitrate.

${ }^{71} \mathrm{Ga}$ MAS NMR was carried out at $14 \mathrm{~T}$ using a JEOL ECA-600 spectrometer, with a $1.5 \mu$ s 90 degree pulse width and a 2 second delay. 4000 scans were made of each sample. The average sample mass was $99.6 \mathrm{mg}$. 


\subsubsection{NMR sample preparation}

Samples were ground and dried. Samples were spun in a small rotor with two spinning caps, one at each end of the rotor. Rotors for ${ }^{27} \mathrm{Al}$ MAS NMR are made of $\mathrm{Si}_{3} \mathrm{~N}_{4}$ and rotors for ${ }^{29} \mathrm{Si}$ MAS NMR are made of $\mathrm{ZrO}_{2}$.

A cap was removed from one end of the rotor and a small amount of sample was loaded into the open end of the rotor, and packed down. Any loose material was removed and the cap was replaced. A small mark was made on the bottom end of the rotor after each experiment to ensure the rotor was always inserted correctly into the probe. The rotor was inserted into the probe and was spun by applying first the bearing gas flow and then the drive gas flow. Once the sample was spinning (this was detected audibly) the probe was inserted into the spectrometer and tuned, and the experiment begun.

\subsubsection{SEM}

Scanning electron microscopy uses electrons instead of light photons to 'image' the sample, and allows visualization of objects too small to be observed with light microscopy. Its operating principle is similar to a cathode ray tube (CRT) by scanning a beam of electrons across a sample. It is not an optical instrument as there is no image forming lens. Instead focus is achieved by bringing the beam to its crossover point on the surface of the sample.

There are two modes of viewing: secondary electron imaging, and backscatter electron imaging. Secondary electrons are produced when an electron from the incident beam excites an electron in the sample, losing energy in an inelastic collision. The excited electron moves towards the surface where it escapes to the detector. The electron is of low energy (less than $50 \mathrm{eV}$ ) and only travels 1-3 nm through the sample, so only electrons near the surface can be detected. The result is a 3D picture of the surface of the sample. Surface topography allows different amounts of signal to reach the detector, producing a 'shadow', the angle of which is determined by the position of the detector, but the view is directly down on the sample. 
Backscattered electrons are produced from an elastic collision between incident electrons and nuclei in the sample. The electrons bounce back in the direction they came from, and the detector is vertically above the sample in the axis of the beam. Chemical elements with high atomic number scatter more electrons, and appear brighter, or more intense in the image, whereas lighter elements are paler. The electrons have a higher energy (around $30 \mathrm{keV}$ ), and can be freed from deeper in the sample.

A higher accelerating voltage produces a stronger signal and the image is therefore brighter, but results in lower resolution. The image resolution is lower for backscattered electron imaging, whereas the lower voltage of secondary electron imaging produces high resolution images.

Another important tool in the SEM is energy dispersive X-ray spectroscopy (EDS). An inelastic collision between the primary electron beam and an inner orbital electron results in the emission of an electron from that atom. A higher energy electron in the atom drops down to replace the lost electron and the energy released from this event is an X-ray. Each element has a family of characteristic X-rays associated with it. Detection of these X-rays allows for positive identification of an element in the sample. Certain events are only possible in atoms of sufficient atomic weight, and elements lighter than carbon are not easily detected. The resolution of EDS is poor because electrons can travel a long distance through the sample to escape. Heavier elements give a higher resolution.

EDS can be combined with backscatter imaging to produce an X-ray microanalysis 'map' of the current view of the sample. This can be used to detect where different elements are concentrated in a material, and individual element maps can be overlaid to show the distribution of particular elements, which elements are associated with each other, and the level of chemical homogeneity of the sample at different orders of magnification. 


\subsubsection{SEM apparatus}

The scanning electron microscope used was a JEOL JSM-6500F with a Schottky-type field emission gun (T-FE gun) and a $\mathrm{Zr} / \mathrm{O}$ tungsten emitter. The backscatter electron imaging detector was a retractable JEOL SM-54031. Accelerating voltage was $15 \mathrm{kV}$, probe current set at 15, and a working distance of $10 \mathrm{~mm}$. A JEOL EX-23000BU ED x-ray analyser was used for EDS measurements.

\subsubsection{SEM Sample Preparation}

Some samples that had been ground and dried for powder XRD analysis were also investigated by SEM. A very small amount of powdered sample was scattered onto sticky conductive carbon tape, which was adhered to an aluminium stub. The sample was pressed down firmly onto the carbon tape, and any loose material was blown off with dry compressed air.

The sample was sputter coated with a thin layer of platinum (approximately 8 $\mathrm{nm})$. This renders the surface of the sample conductive, which is important to prevent charging on the surface during viewing, and prevents thermal damage to the sample. Platinum coating allows the surface of the sample to be viewed at high magnification with good resolution, and is thin enough for backscatter imaging and EDS mapping. 


\subsubsection{Differential Scanning Calorimetry and Thermogravimetric Analysis (DSC-TGA)}

Differential scanning calorimetry measures the temperature and heat flows associated with phase transitions in materials as they are heated. This thermal analysis technique gives information about physical and chemical changes that involve changes in heat capacity and exothermic and endothermic processes, and is useful for studying the crystalline transition temperature of inorganic polymers. The difference in energy inputs into the sample and a reference material are measured as the sample is heated or cooled according to a controlled temperature programme.

Thermogravimetric Analysis (TGA) is a technique for measuring changes in mass as function of temperature. The change in mass can be used to characterise the composition of a material. For inorganic polymers this technique can be used to determine the temperature at which hydration water is lost, and whether it is lost in discrete stages as the temperature is increased.

These two techniques can be run simultaneously on the same instrument, and the results are presented on the same graph.

\subsubsection{DSC-TGA apparatus}

The instrument used was a TA Instruments SDT Q600 V8.2 Build 100.

Samples were weighed and loaded into platinum crucibles. The heating rate was $10^{\circ} \mathrm{C} /$ minute in air with an airflow of $50 \mathrm{~mL} /$ minute. 


\subsection{Reagents}

For the syntheses reported in the following chapter, the reagents were:

Silica fume, $\mathrm{SiO}_{2}\left(94 \%, 5 \% \mathrm{ZrO}_{2}\right)$. Doral Fused Materials Pty. Ltd.

Gallium oxide, $\mathrm{Ga}_{2} \mathrm{O}_{3}(99.99+\%)$. Aldrich 215066

Germanium oxide, $\mathrm{GeO}_{2}$ (99.99\%). Aldrich 483703

Aluminium hydroxide, $\mathrm{Al}(\mathrm{OH})_{3}$ (anhydrous). $\mathrm{BDH} 48 \mathrm{I} 216$

Potassium carbonate, $\mathrm{K}_{2} \mathrm{CO}_{3}$ (anhydrous). $\mathrm{BDH} 101964 \mathrm{H}$

Potassium hydroxide, KOH. Pure Science 100-KOH EN9014

Sodium hydroxide, $\mathrm{NaOH}$. Pure Science 100-1027 NN1515

Sodium aluminate, $\mathrm{NaAlO}_{2}$. Ajax Chemicals 1559

Fumed silica, $\mathrm{SiO}_{2}$ (99.8\%). Aldrich 381276 


\section{Sample Syntheses and characterisation}

All reported reactions, although performed on a small scale due to the expense of reagents, are reproducible and several samples were made for each reaction.

\subsection{Sol-gel synthesis of gallium and germanium inorganic polymer analogues}

The first step in developing the synthesis of a Ga-Ge analogue was to simplify the reported synthesis of the related aluminosilicate sol-gel inorganic polymer, by using $\mathrm{Al}_{2} \mathrm{O}_{3}$ instead of $\mathrm{NaAlO}_{2}$. The rationale for this was that the original starting materials available for synthesising these analogues were $\mathrm{Ga}_{2} \mathrm{O}_{3}$ and $\mathrm{GeO}_{2}$.

\subsubsection{Synthesis of $\rho-\mathrm{Al}_{2} \mathrm{O}_{3}$}

There are several forms of alumina and it is important for a reactive form to be used. Corundum, $\alpha-\mathrm{Al}_{2} \mathrm{O}_{3}$, is a common form of alumina, but is highly crystalline and the most thermodynamically stable form of alumina, and therefore less reactive in a sol-gel reaction. Corundum contains aluminium solely in octahedral coordination. A suitable alumina type is $\rho-\mathrm{Al}_{2} \mathrm{O}_{3}$, which is much less crystalline than corundum, and therefore more reactive. A synthesis of $\rho-\mathrm{Al}_{2} \mathrm{O}_{3}$ was attempted by heating $\mathrm{Al}(\mathrm{OH})_{3}$ (the mineral gibbsite):

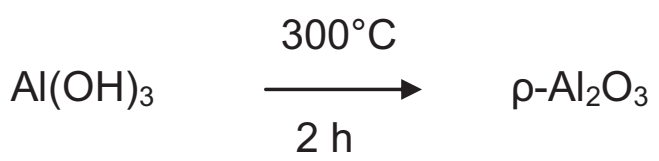

$\mathrm{XRD}$ of the product of this reaction shows an amorphous phase with peaks from boehmite, $\mathrm{AlO}(\mathrm{OH})$. This indicates the gibbsite was not entirely dehydroxylated at this temperature. However firing the gibbsite at a higher temperature was avoided, as it would likely generate a less reactive aluminium oxide species. 


\subsubsection{Sol-gel synthesis}

The reactive-alumina product (" $\mathrm{p}-\mathrm{Al}_{2} \mathrm{O}_{3}$ ") was then substituted for sodium aluminate in the sol-gel aluminosilicate inorganic polymer synthesis:

$$
\text { " } \mathrm{p}-\mathrm{Al}_{2} \mathrm{O}_{3} \text { " }+\mathrm{SiO}_{2}+\mathrm{NaOH}+\mathrm{H}_{2} \mathrm{O} \longrightarrow \text { Product }
$$

The mixture was cured in an oven at $40^{\circ} \mathrm{C}$ for 48 hours. The mixture set to a hard material which is X-ray amorphous. ${ }^{29}$ Si MAS NMR showed two resonances that have merged but are distinguishable (figure 3). A peak at -99.6 ppm indicates a $\mathrm{Si}(1 \mathrm{Al})$ environment, and a peak at -107 indicates free unreacted $\mathrm{SiO}_{2}$.

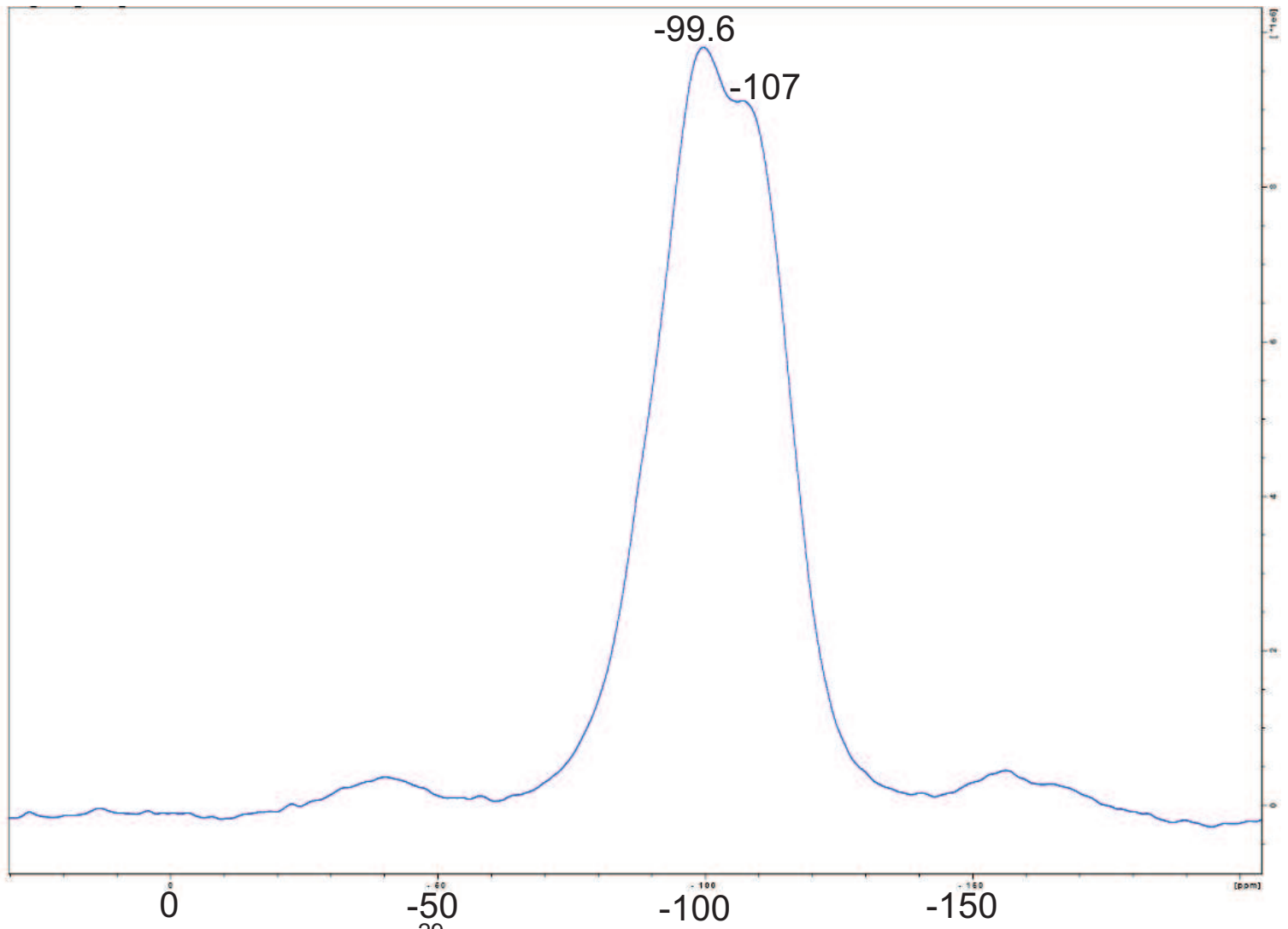

${ }^{29} \mathrm{Si}$ shift (ppm) w.r.t. TMS

Figure 3: $11.7 \mathrm{~T}^{29} \mathrm{Si}$ MAS NMR of the set product of a sol-gel reaction of " $\mathrm{\rho}-\mathrm{Al}_{2} \mathrm{O}_{3}$ " and $\mathrm{SiO}_{2}$.

${ }^{27} \mathrm{Al}$ NMR shows that both tetrahedral and octahedral aluminium sites are present in almost equal proportions in the product, and it therefore does not have the typical aluminium coordination characteristics of a geopolymer. Despite this, a replication of this method substituting $\mathrm{Ga}_{2} \mathrm{O}_{3}$ for $\mathrm{Al}_{2} \mathrm{O}_{3}$ and $\mathrm{GeO}_{2}$ for $\mathrm{SiO}_{2}$ was attempted, using similar molar ratios. Combinations of $\mathrm{Ga}_{2} \mathrm{O}_{3}+\mathrm{SiO}_{2}$ and $\mathrm{Al}_{2} \mathrm{O}_{3}+$ $\mathrm{GeO}_{2}$ were also reacted using 50:50 mixtures of $\mathrm{Al}_{2} \mathrm{O}_{3}: \mathrm{Ga}_{2} \mathrm{O}_{3}$ and $\mathrm{SiO}_{2}: \mathrm{GeO}_{2}$. 


\subsubsection{Molar ratios}

New materials in ceramics are often defined in terms of molar ratios of various oxides, and this is true also for inorganic polymers. The optimum values of the important ratios for aluminosilicate inorganic polymers vary according to different literature sources, but the general consensus gives the optimum ratios as:[59, 67]

$\mathrm{SiO}_{2}: \mathrm{Al}_{2} \mathrm{O}_{3} \quad 3.2-4.8$

$\mathrm{M}_{2} \mathrm{O}: \mathrm{Al}_{2} \mathrm{O}_{3} \quad 0.6-1.4$

$\mathrm{H}_{2} \mathrm{O}: \mathrm{M}_{2} \mathrm{O} \quad 6-16$

( $\mathrm{M}=$ the charge balancing alkali cation)

It is therefore expected that similar ratios will be required when substituting $\mathrm{GeO}_{2}$ for $\mathrm{SiO}_{2}$ and $\mathrm{Ga}_{2} \mathrm{O}_{3}$ for $\mathrm{Al}_{2} \mathrm{O}_{3}$ to produce analogous materials with the characteristic geopolymer structure. However, the original sol-gel method using aluminate and silica fume was based on a reported $\mathrm{SiO}_{2}: \mathrm{Al}_{2} \mathrm{O}_{3}$ ratio of 8.2, considerably greater than the usual ratio for this parameter in normal geopolymer syntheses.[29] Despite this, that product was of good strength (26 MPa). 
Molar rations of some of the Ga-Ge samples synthesised by the sol-gel method:

1) $\mathrm{Ga}_{2} \mathrm{O}_{3}+\mathrm{GeO}_{2}+\mathrm{NaOH}+\mathrm{H}_{2} \mathrm{O}$

2) $\mathrm{Ga}_{2} \mathrm{O}_{3}+\mathrm{SiO}_{2}+\mathrm{NaOH}+\mathrm{H}_{2} \mathrm{O}$

3) $\mathrm{Ga}_{2} \mathrm{O}_{3}+\mathrm{Al}_{2} \mathrm{O}_{3}+\mathrm{SiO}_{2}+\mathrm{NaOH}+\mathrm{H}_{2} \mathrm{O}$

4) $\mathrm{Ga}_{2} \mathrm{O}_{3}+\mathrm{Al}_{2} \mathrm{O}_{3}+\mathrm{GeO}_{2}+\mathrm{NaOH}+\mathrm{H}_{2} \mathrm{O}$

5) $\mathrm{Ga}_{2} \mathrm{O}_{3}+\mathrm{GeO}_{2}+\mathrm{SiO}_{2}+\mathrm{NaOH}+\mathrm{H}_{2} \mathrm{O}$

6) $\mathrm{Ga}_{2} \mathrm{O}_{3}+\mathrm{Al}_{2} \mathrm{O}_{3}+\mathrm{GeO}_{2}+\mathrm{SiO}_{2}+\mathrm{NaOH}+\mathrm{H}_{2} \mathrm{O}$

\begin{tabular}{|c|c|c|c|c|c|c|}
\hline Sample \# & 1 & 2 & 3 & 4 & 5 & 6 \\
\hline $\mathrm{GeO}_{2}: \mathrm{Ga}_{2} \mathrm{O}_{3}$ & 3.85 & - & - & 6.89 & 1.79 & 3.80 \\
\hline $\mathrm{SiO}_{2}: \mathrm{GeO}_{2}$ & - & - & - & - & 1.00 & 1.00 \\
\hline $\mathrm{Al}_{2} \mathrm{O}_{3}: \mathrm{Ga}_{2} \mathrm{O}_{3}$ & - & - & 1.00 & 1.00 & - & 1.00 \\
\hline $\mathrm{SiO}_{2}: \mathrm{Ga}_{2} \mathrm{O}_{3}$ & - & 3.74 & 7.47 & - & - & - \\
\hline $\mathrm{Na}_{2} \mathrm{O}: \mathrm{GeO}_{2}$ & 0.88 & - & - & 0.46 & 0.92 & 0.71 \\
\hline $\mathrm{Na}_{2} \mathrm{O}: \mathrm{SiO}_{2}$ & - & 0.43 & 0.36 & - & - & - \\
\hline $\mathrm{H}_{2} \mathrm{O}: \mathrm{Na}_{2} \mathrm{O}$ & 19.77 & 8.81 & 8.90 & 20.14 & 16.36 & 18.13 \\
\hline $\mathrm{H}_{2} \mathrm{O}: \mathrm{GeO}_{2}$ & 17.81 & - & - & 9.30 & 15.11 & 12.90 \\
\hline $\mathrm{H}_{2} \mathrm{O}: \mathrm{SiO}_{2}$ & - & 3.83 & 3.87 & - & - & - \\
\hline
\end{tabular}

Table 1: Selected molar ratios of some of the Ga-Ge samples synthesised by the sol-gel method.

After the same curing conditions as previously used, all samples set to a white solid, and those made using silica had a shiny surface, whereas those made with germanium dioxide were matt.

\subsubsection{XRD}

XRD showed an amorphous phase with superimposed crystalline peaks of varying intensities, arising from both unreacted starting materials and unintended products. Therefore a partial polymerisation has occurred, but competing reactions have produced an unwanted crystalline product, sodium gallogerminate hydrate (pdf file number 04-009-7325). 
The XRD also indicated some unreacted $\mathrm{GeO}_{2}$ starting material. The reactions involving $\mathrm{SiO}_{2}$ generally produced more of the amorphous phase, with less intense crystalline phase peaks on top of the amorphous phase in the diffraction pattern (figure 4).

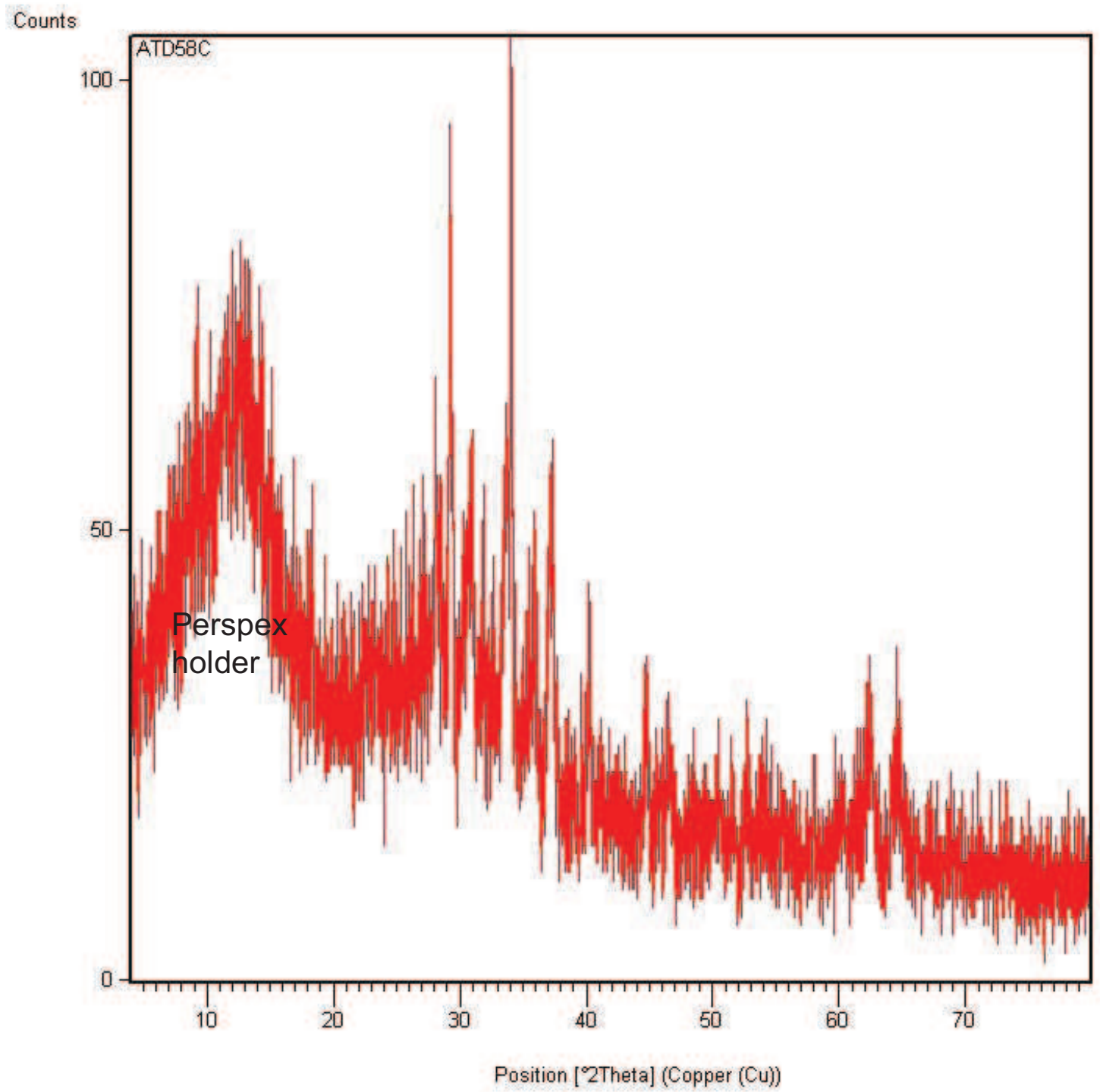

Figure 4: XRD of the set product of a sol-gel reaction of $\mathrm{SiO}_{2}$ and $\mathrm{Ga}_{2} \mathrm{O}_{3}$. The crystalline phase is unreacted $\mathrm{Ga}_{2} \mathrm{O}_{3}$ (pdf 00-006-0509). 


\subsubsection{Problems with the sol-gel synthesis}

$\mathrm{GeO}_{2}$ seemed to require more water than $\mathrm{SiO}_{2}$ (table 1), otherwise it rapidly forms a hard paste on addition of $\mathrm{NaOH}$. Other samples were made using potassium hydroxide, $\mathrm{KOH}$, instead of $\mathrm{NaOH}$ to test whether less water could be used. Again, different $\mathrm{GeO}_{2}: \mathrm{Ga}_{2} \mathrm{O}_{3}$ ratios were tested, from 3.26 - 6.52. This ratio range was used as it encompasses both typical aluminosilicate geopolymer ratios and also the higher ratios reported in the aluminate sol-gel method.[29] These samples behaved in a similar fashion to the earlier $\mathrm{NaOH}$ samples, but did not require as much water to be added to allow mixing. The $\mathrm{H}_{2} \mathrm{O}: \mathrm{K}_{2} \mathrm{O}$ ratio was approximately 10.47 , relatively lower than the $18.13-20.14$ range for $\mathrm{H}_{2} \mathrm{O}: \mathrm{Na}_{2} \mathrm{O}$ in samples using $\mathrm{GeO}_{2}$ and $\mathrm{NaOH}$. These samples did set, but XRD showed they are not amorphous and contain unreacted $\mathrm{GeO}_{2}$ and $\mathrm{Ga}_{2} \mathrm{O}_{3}$.

The solubility of the gallium oxide is potentially a problem for this method. It appears to only partially dissolve giving a white slurry, and the opaque appearance is due to undissolved $\mathrm{Ga}_{2} \mathrm{O}_{3}$ particles. Gallium oxide is insoluble in water, but soluble in strongly alkaline solutions, with a maximum solubility of 90.2 g.dm ${ }^{-3}$.[68] But despite the high alkalinity, the restriction on water content in the mixtures described prevents all the oxide from dissolving.

The major problem with this sol-gel method appears to be due to the behaviour of $\mathrm{GeO}_{2}$ in basic aqueous solutions being different to $\mathrm{SiO}_{2}$. Germanium has a high affinity for $\mathrm{OH}$ groups.[69] In this environment germania nanoparticles form[70] with a $\mathrm{Ge}_{8} \mathrm{O}_{12}(\mathrm{OH})_{8}$ octamer structure. Similar cubic octamers are also known in silicate chemistry, and the presence of such species can increase the rate of silica dissolution depending on the cation present in the solution.[71]

At a critical aggregation concentration corresponding to a $1: 1 \mathrm{GeO}_{2} / \mathrm{OH}^{-}$molar ratio the germania nanoparticles form aggregates.[56] This was observed during the reaction as the $\mathrm{GeO}_{2}$ forming gritty lumps on addition of $\mathrm{NaOH}$ solution. As a result more water was added to aid the processing of the reaction, as the $\mathrm{GeO}_{2}$ alkali mixture needs to be a wetted paste for good mixing. The addition of extra 
water affects the ratios of $\mathrm{H}_{2} \mathrm{O}: \mathrm{Na}_{2} \mathrm{O}, \mathrm{H}_{2} \mathrm{O}: \mathrm{GeO}_{2}$ and $\mathrm{H}_{2} \mathrm{O}: \mathrm{Ga}_{2} \mathrm{O}_{3}$ (and the corresponding ratios when silica and alumina are also used). The water content and therefore these ratios - are important in making a regular aluminosilicate geopolymer, and are likely to affect the nature of a Ga-Ge analogue product. The addition of water may also be the cause of other crystalline phases forming in the products.

Since the initial approach of adapting the sol-gel method to the synthesis of a gallium germinate/silicate inorganic polymer - by attempting to use $\mathrm{Ga}_{2} \mathrm{O}_{3}$ as a starting material - was less successful than hoped, the approach was changed to create a gallium-containing starting material that was more like the aluminium source used in the original sol-gel method.

\subsubsection{Synthesis of $\mathrm{KGaO}_{2}$}

Potassium gallate, $\mathrm{KGaO}_{2}$, was prepared by solid-state reaction from a mixture of gallium oxide, $\mathrm{Ga}_{2} \mathrm{O}_{3}$ (figure 5) and potassium carbonate, $\mathrm{K}_{2} \mathrm{CO}_{3}$, following a method reported for the synthesis of $\beta$-gallates[72]. with a molar composition of $\mathrm{K}_{2} \mathrm{O}: \mathrm{Ga}_{2} \mathrm{O}_{3}=1: 1$. The two powders were ground together under ethanol, and the solvent was allowed to evaporate off. The mixture was calcined in air at $900^{\circ} \mathrm{C}$ for 5 hours.

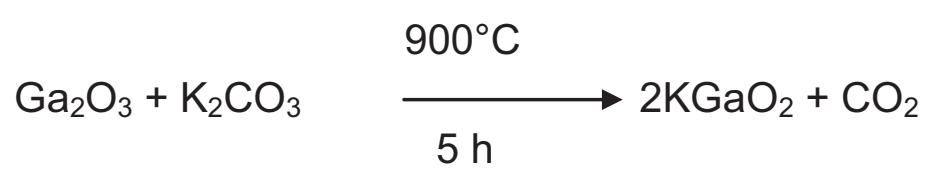

$\mathrm{KGaO}_{2}$ is very hygroscopic and rapidly forms a gel, therefore every attempt was made to keep the product as dry as possible. XRD characterisation must be performed soon after the reaction, as the product becomes X-ray amorphous when it absorbs water. XRD confirmed the product was $\mathrm{KGaO}_{2}$ with no other peaks, indicating a pure product with low impurities (figure 6). 


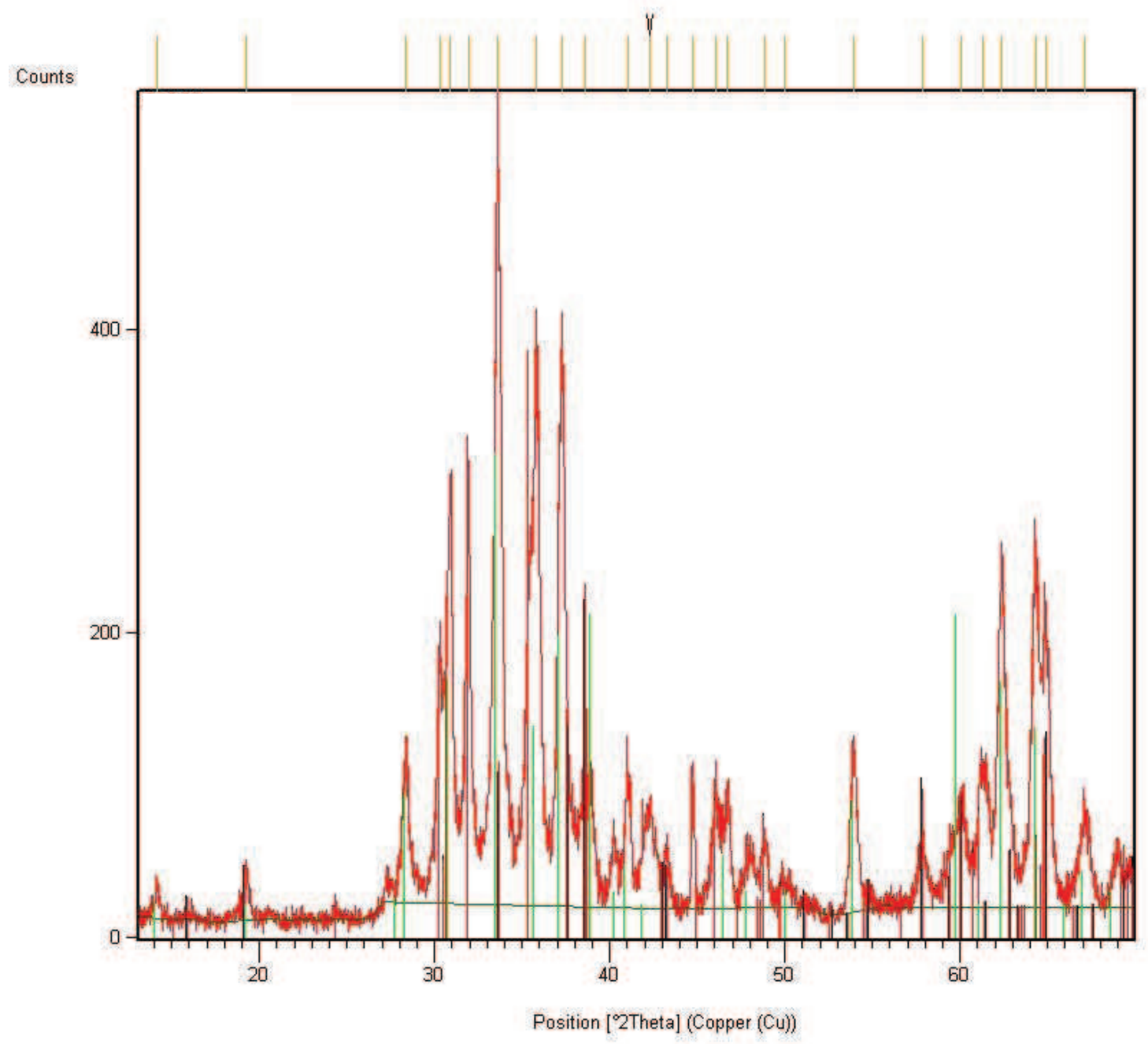

Figure 5: XRD of $\mathrm{Ga}_{2} \mathrm{O}_{3}$ starting material (pdf file number 00-006-0509). 


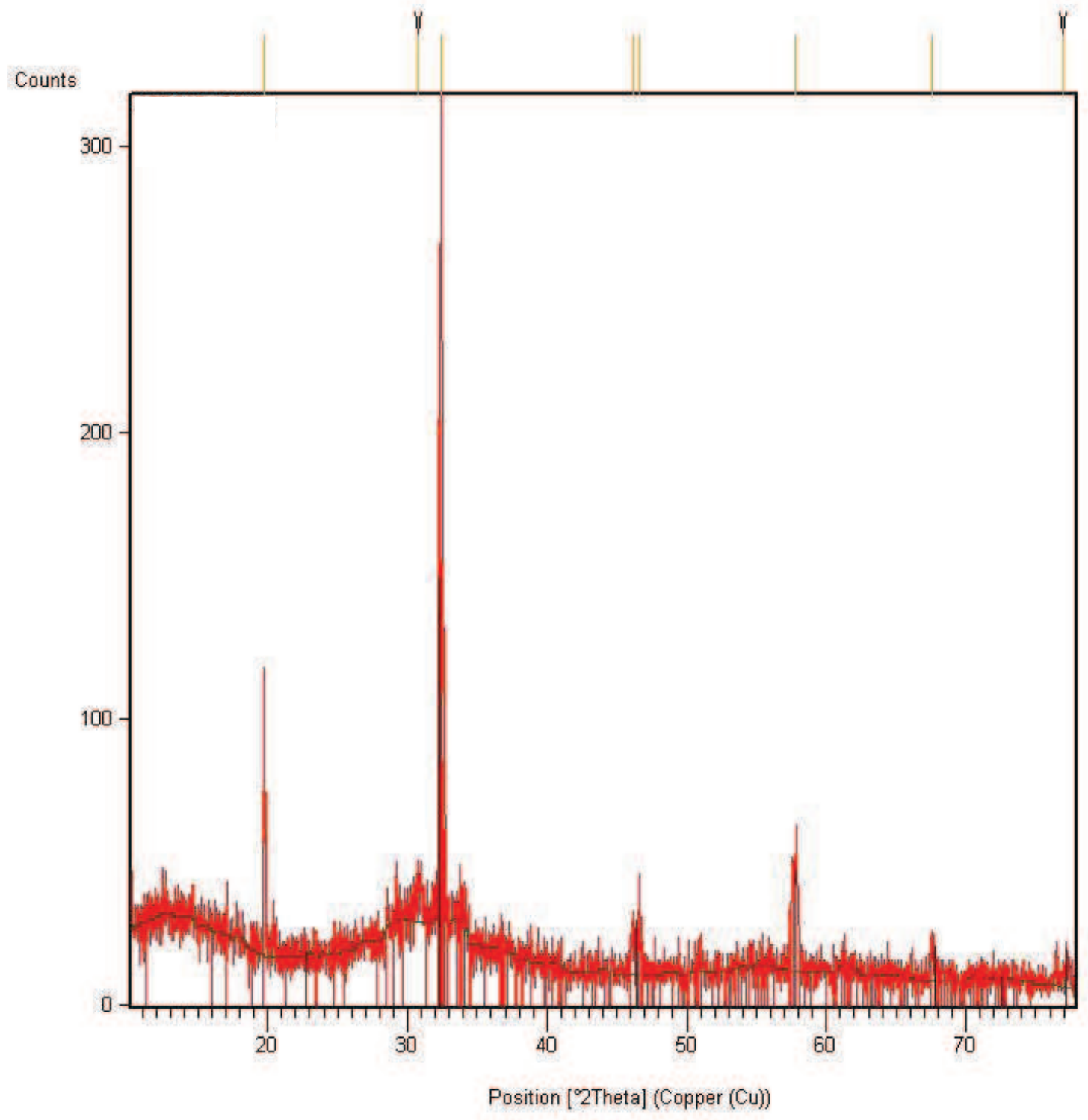

Figure 6: XRD of the product, $\mathrm{KGaO}_{2}$ (pdf 01-070-2402).

The product could not be studied using ${ }^{71} \mathrm{Ga}$ MAS NMR due to its hygroscopic property, which prevented it being spun, but it is reported that there are both tetrahedral and octahedral gallium sites in this material.[73] 


\subsubsection{Sol-gel reaction of $\mathrm{KGaO}_{2}$ with $\mathrm{GeO}_{2}$}

Wetted $\mathrm{GeO}_{2}$ was added to a solution of $\mathrm{KGaO}_{2}$ and $\mathrm{KOH}$ in the molar ratios:

$\begin{array}{ll}\mathrm{GeO}_{2}: \mathrm{Ga}_{2} \mathrm{O}_{3} & 3.04 \\ \mathrm{KOH}: \mathrm{GeO}_{2} & 0.43 \\ \mathrm{H}_{2} \mathrm{O}: \mathrm{KOH} & 10.81 \\ \mathrm{H}_{2} \mathrm{O}: \mathrm{GeO}_{2} & 4.65\end{array}$

The $\mathrm{GeO}_{2}$ was rapidly taken up by the solution, giving a white liquid of low viscosity. After mechanically stirring for approximately 30 seconds, this syrup thickened rapidly then formed clumps. The clumpy product was pressed together into a mould, where it hardened quickly. The sample was covered and left to set at room temperature. The product was a brittle white solid. The ratios indicate this method did not require as much water, and the ratios were closer to the ideal ratios of aluminosilicate geopolymers.

XRD (figure 7) showed the product was not an amorphous inorganic polymer, but was potassium gallium germanium oxide hydrate, $\left(\mathrm{K}\left(\mathrm{GaGeO}_{4}\right)_{6}\left(\mathrm{H}_{2} \mathrm{O}\right)_{7}\right.$. (pdf file number: 04-009-7324). 


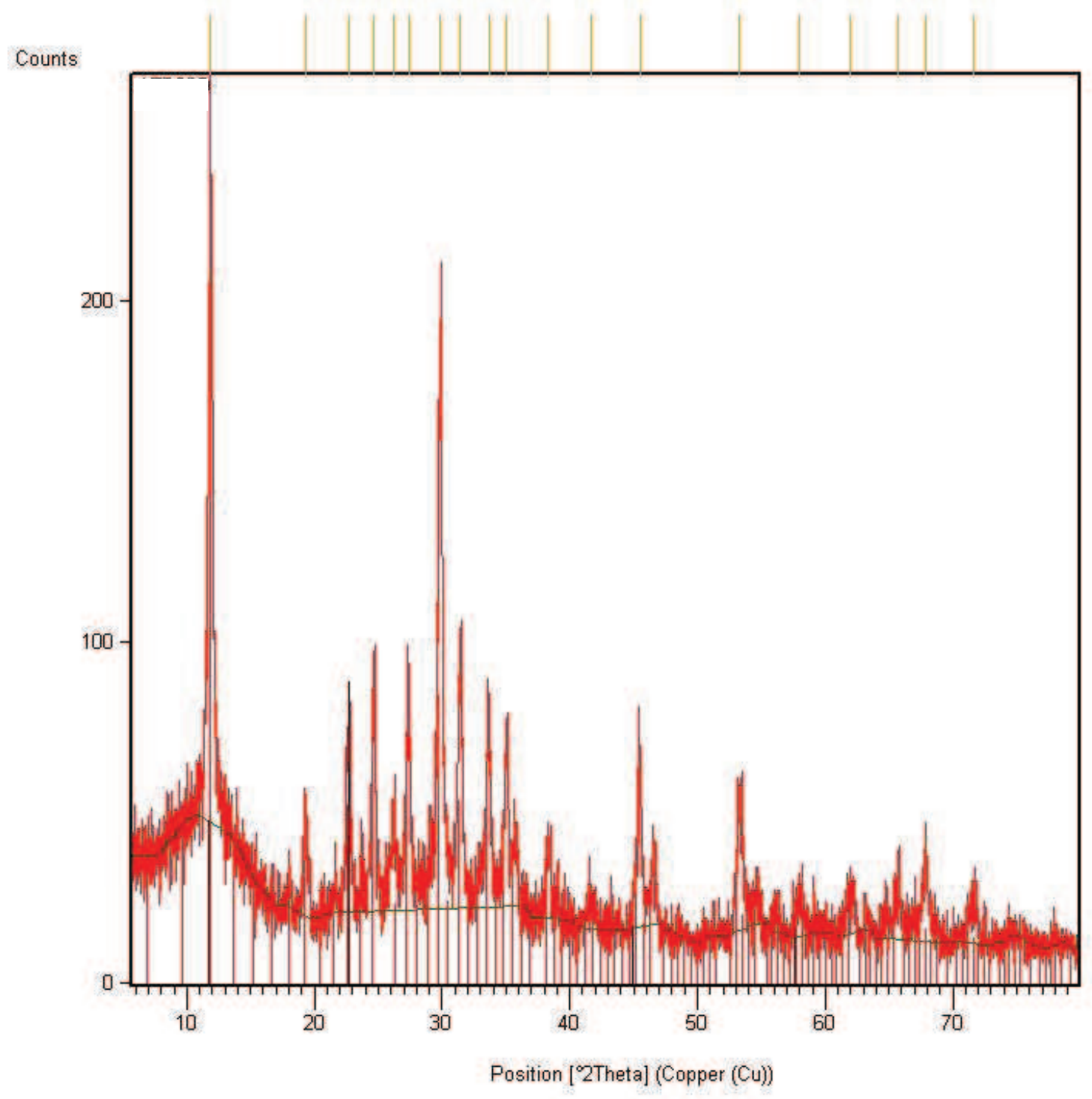

Figure 7: XRD pattern of the crystalline product, potassium gallium germanium oxide hydrate (pdf 04-009-7324). 


\subsubsection{Forming a $\mathrm{KGaO}_{2}$ solution}

This synthesis requires a $\mathrm{KGaO}_{2}$ solution to be prepared. In the initial experiments this was carried out by adding a known amount of water to a known amount of $\mathrm{KGaO}_{2}$ with a syringe. The $\mathrm{KGaO}_{2}$ would partially dissolve, but grains would remain in the solution, which would clump together on stirring. This required vigorous stirring/grinding in a mortar and pestle, and more water had to be added to coerce the gallate to dissolve into a workable solution.

Later a new method was adopted. The $\mathrm{KGaO}_{2}$ being very hygroscopic would absorb moisture from the air. The $\mathrm{KGaO}_{2}$ was weighed out as a dry powder and left in a crucible on the lab bench. After about an hour the white powder solid had absorbed enough atmospheric moisture to from a colourless gel (figure 8). The amount of water absorbed was determined from the change in initial and final total mass of the crucible and contents.

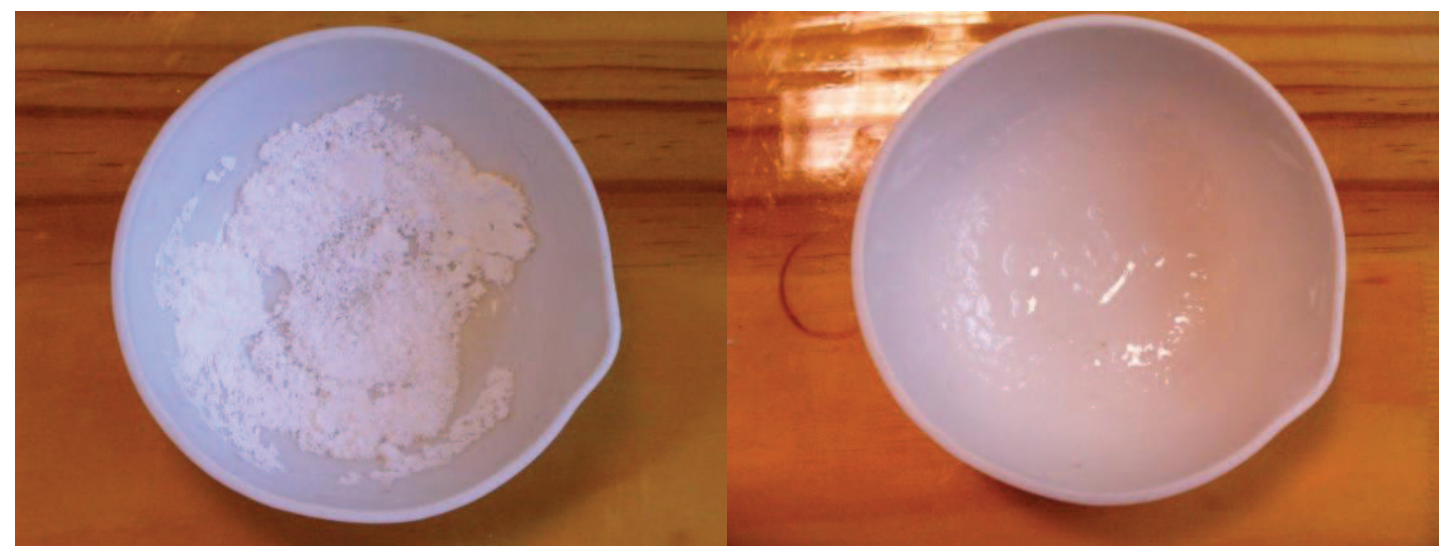

Figure 8: Photos showing dry $\mathrm{KGaO}_{2}$ (left) and two hours later... $\mathrm{KGaO}_{2}$ solution (right)

It is important to allow the $\mathrm{KGaO}_{2}$ to fully form a gel solution. If a partially dissolved solution was stirred, it would clump together, and result in the same problems posed earlier. But if the $\mathrm{KGaO}_{2}$ had fully dissolved, the gel could be easily worked with a spatula. 


\subsubsection{Summary}

A sol-gel synthesis of $\rho-\mathrm{Al}_{2} \mathrm{O}_{3}$ and $\mathrm{SiO}_{2}$ produced a strong hard material that was $\mathrm{X}$-ray amorphous, but contained aluminium in both tetrahedral and octahedral coordination states. $\mathrm{Ga}_{2} \mathrm{O}_{3}$ and $\mathrm{GeO}_{2}$ were substituted for $\mathrm{Al}_{2} \mathrm{O}_{3}$ and $\mathrm{SiO}_{2}$ in a series of sol-gel reactions covering a range of molar ratios. All mixtures set, but all the products contained crystalline phases. The $\mathrm{Ga}_{2} \mathrm{O}_{3}$ was not completely soluble in the reaction solution, and $\mathrm{GeO}_{2}$ formed aggregates when mixed with an alkaline solution. The sol-gel method was thus unsuccessful for synthesising a gallium germanium inorganic polymer. 


\subsection{Solid-state synthesis of gallium and germanium inorganic polymers}

Since $\mathrm{GeO}_{2}$ prevented the formation of an amorphous inorganic polymer by the sol-gel type method, an adaptation of the solid-state geopolymer synthesis was attempted. In the first instance a solid-state reaction between $\mathrm{KGaO}_{2}$ and $\mathrm{GeO}_{2}$ was tried.

\subsection{1 $\mathrm{KGaO}_{2}$ and $\mathrm{GeO}_{2}$}

Dry $\mathrm{KGaO}_{2}$ powder (made by solid-state reaction - see 3.1.6) and $\mathrm{GeO}_{2}$ powder were mixed under ethanol in a molar ratio $\mathrm{GeO}_{2}: \mathrm{Ga}_{2} \mathrm{O}_{3}=3.23$. The mixture was dried and fired at $600^{\circ} \mathrm{C}$ for 5 hours. The product was ground and wetted to give the ratio $\mathrm{H}_{2} \mathrm{O}: \mathrm{GeO}_{2}=2.91$. This formed a paste which was poured into a mould and cured in an oven at $50^{\circ} \mathrm{C}$ for 48 hours. The product set, but XRD showed it was crystalline (figure 9). The phases detected were $\mathrm{GeO}_{2}$ (pdf 00-036-1463) and $\mathrm{K}_{6} \mathrm{Ge}_{11} \mathrm{O}_{25}$ (pdf 00-021-0640). 


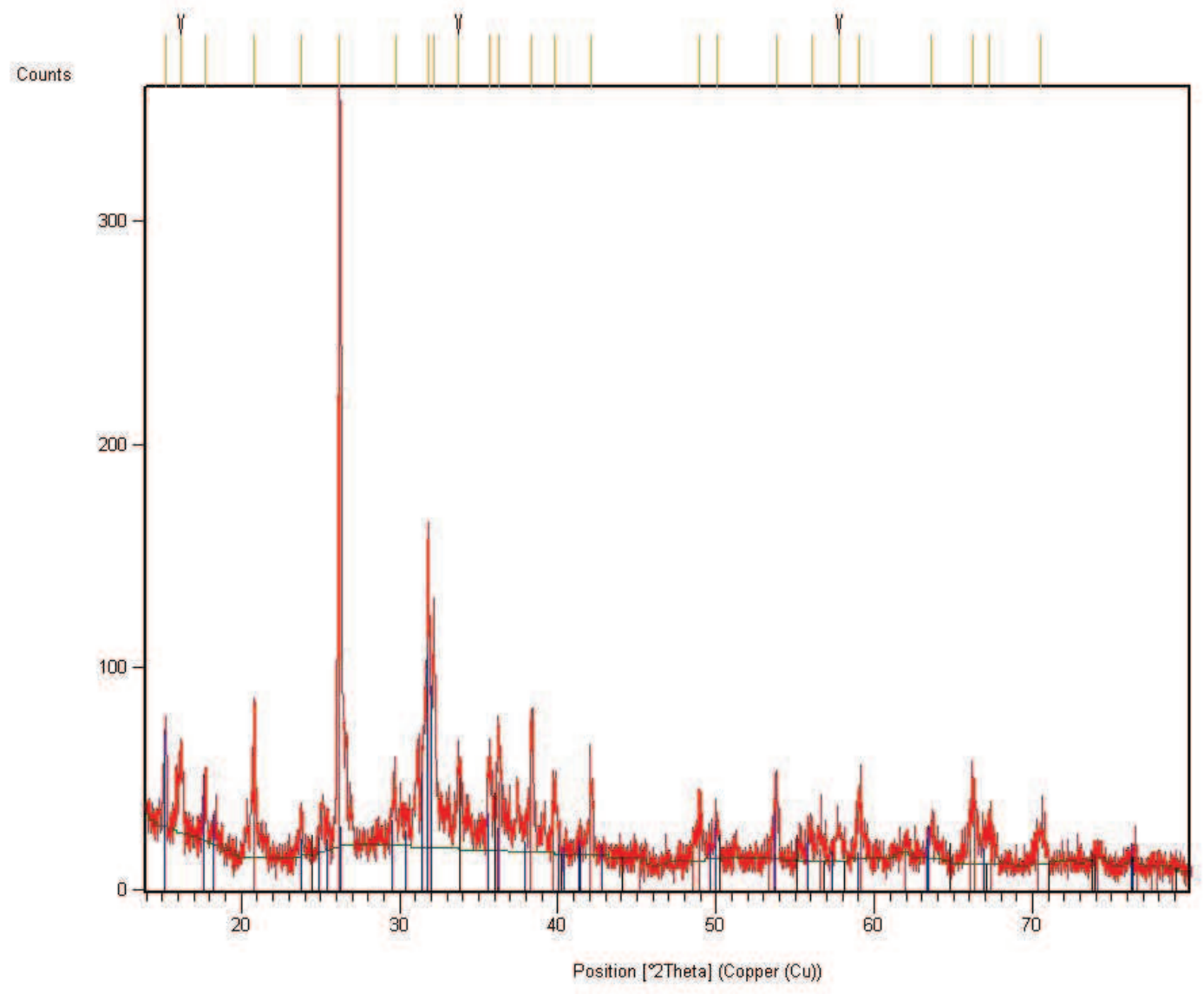

Figure 9: XRD pattern of product of solid-state synthesis reaction between $\mathrm{KGaO}_{2}$ and $\mathrm{GeO}_{2}$.

Due to the presence of unreacted $\mathrm{GeO}_{2}$ in the product, an alternative approach was made using a different germanium source.

\subsubsection{Synthesis of potassium germanate}

Potassium germanium oxide (potassium germanate) was synthesised by calcining $\mathrm{GeO}_{2}$ (figure 10) with $\mathrm{K}_{2} \mathrm{CO}_{3}(\mathrm{KOH}$ could also be used, but was harder to work with due to its hygroscopic property)

$$
\begin{aligned}
& 550^{\circ} \mathrm{C} \\
& \mathrm{GeO}_{2}+\mathrm{KOH} \underset{4 \mathrm{~h}}{\longrightarrow} \text { Potassium Germanium Oxides }
\end{aligned}
$$

Potassium germanium oxide exists as a variety of species with varying stoichiometries, such as $\mathrm{K}_{2} \mathrm{Ge}_{2} \mathrm{O}_{5}, \mathrm{~K}_{2} \mathrm{Ge}_{4} \mathrm{O}_{9}$ and $\mathrm{K}_{6} \mathrm{Ge}_{11} \mathrm{O}_{25}$, similar to a 
potassium silicate solution. The XRD pattern is therefore complex (figure 11). This creates the drawback that the ratios of the species are ill-defined, but the ratios of Ge:O:K are known from the starting materials. The potassium germanate product appears to be mildly hygroscopic, and should be kept dry.

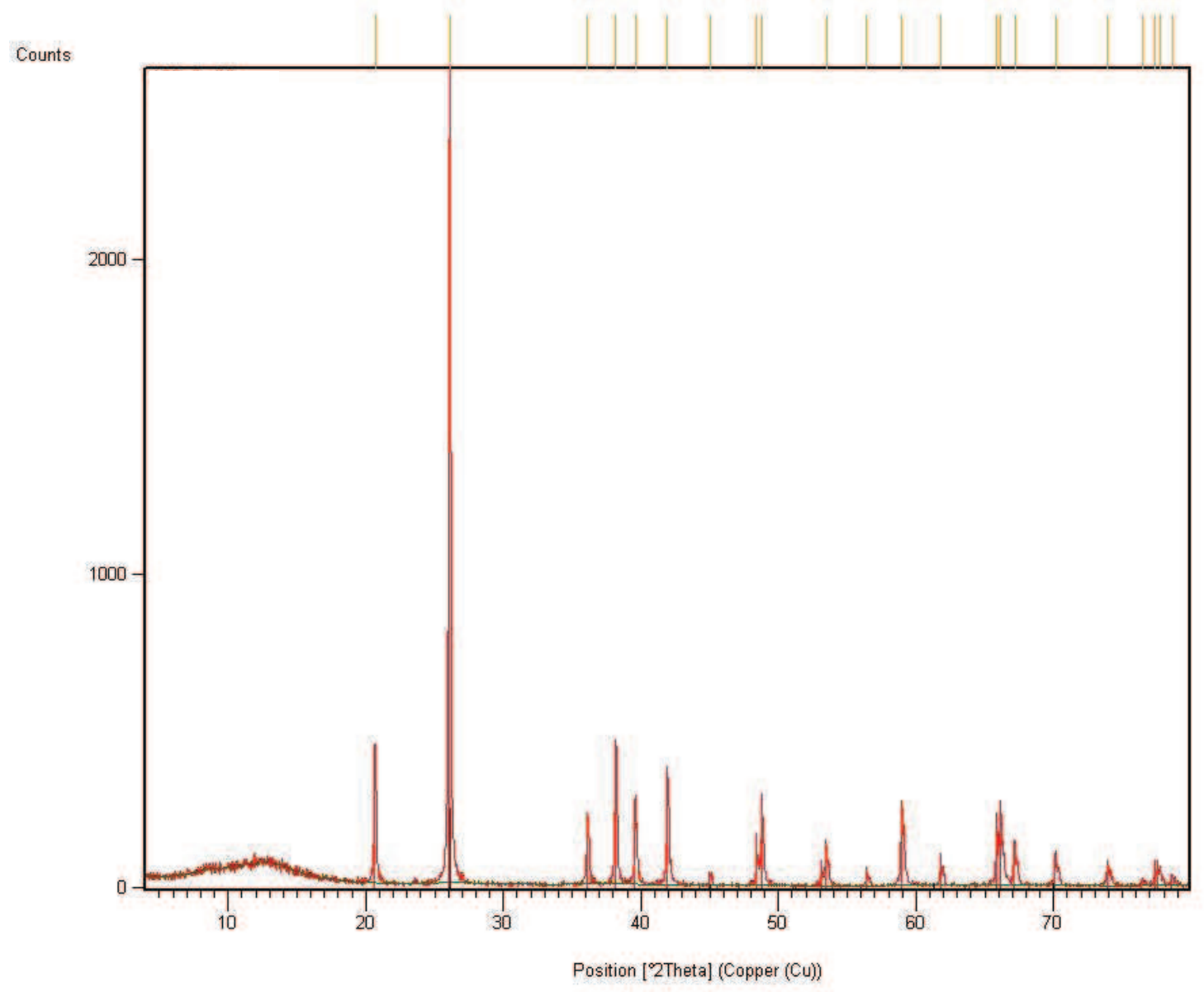

Figure 10: XRD of $\mathrm{GeO}_{2}$ starting material (pdf 00-004-0497). 


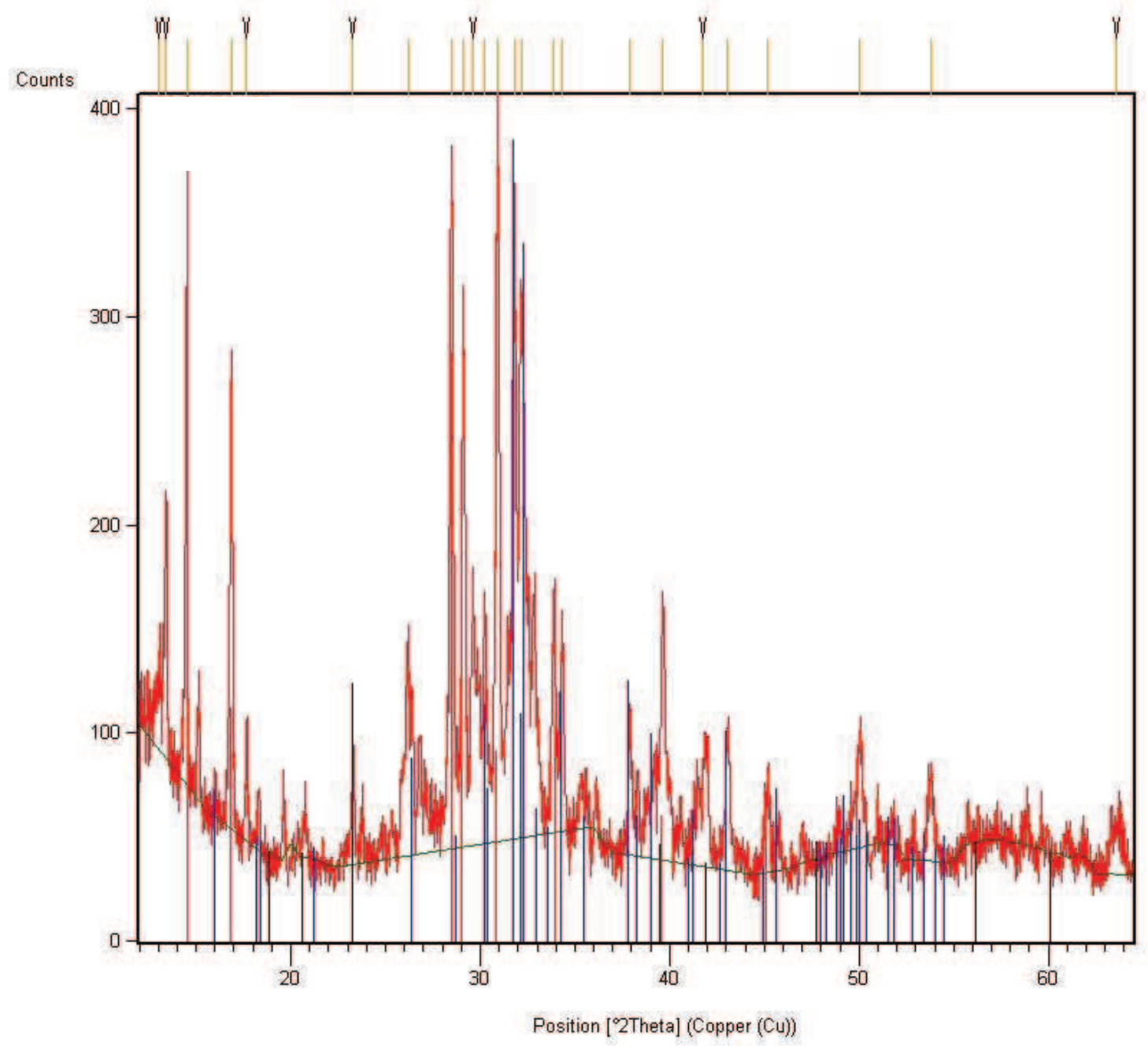

Figure 11: XRD of product, potassium germanate produced by solid-state reaction. One of the species detected was $\mathrm{K}_{2} \mathrm{Ge}_{2} \mathrm{O}_{5}$ (pdf 00-021-0638).

\subsubsection{Synthesis of mixed-oxide precursor}

The final reaction in this solid-state synthesis combines the two precursors, potassium gallate and potassium germanate, with additional hydroxide to form a mixed-oxide product:

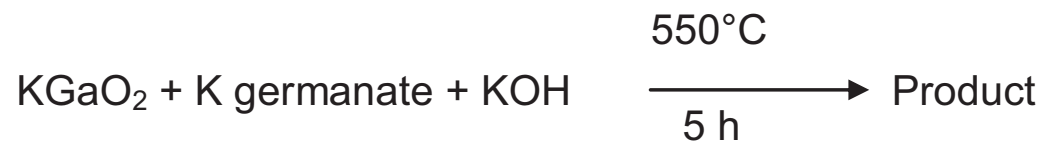

The reactants were mixed together under ethanol and dried before firing. 
The product was allowed to cool to room temperature and is then ground up to a fine powder. XRD shows the product is partially amorphous with some reflections (peaks in diffraction pattern) (figure 12). These could not be identified. The product was mildly hygroscopic, possibly due in part to unreacted $\mathrm{KGaO}_{2}$, and would be used soon after synthesis.

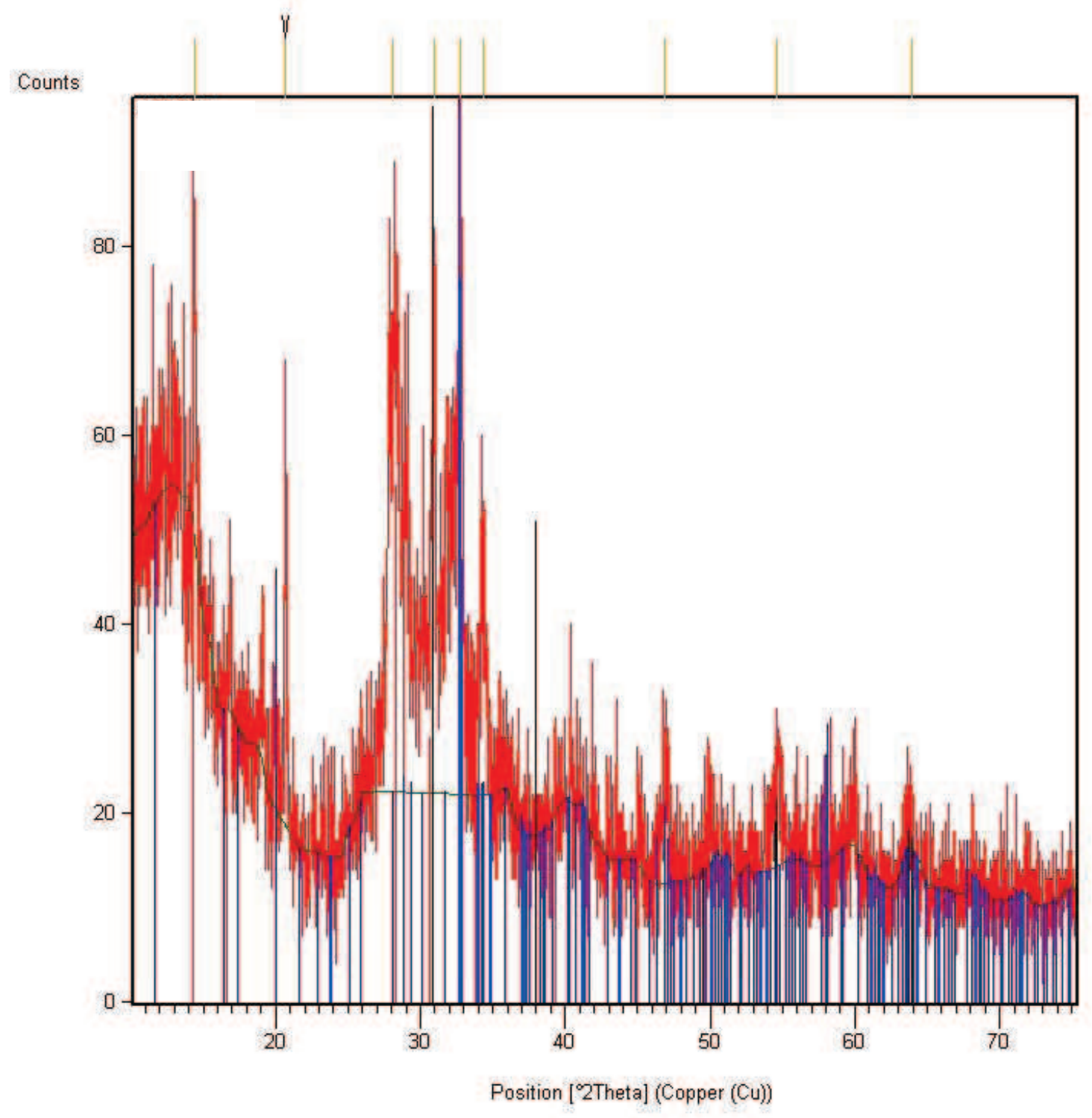

Figure 12: XRD of hydraulic K-gallate-K-germanate precursor. 


\subsubsection{Addition of water}

This powder is a hydraulic precursor, and on the addition of a small amount of water it reacts, to form a paste which was pressed into a mould and placed in a laboratory oven at $50^{\circ} \mathrm{C}$. The sample appeared to set, taking a considerably longer time to set than regular aluminosilicate geopolymers. Initially this was thought to be due to a slower reaction rate compared to aluminosilicate geopolymerisation, however it was soon evident that the product was not fully setting, but remaining as a thick paste in the mould. As a result, this product could not be characterised by XRD.

It was suspected that water content was the cause of this problem and so the reaction was repeated, but with less water added to the precursor powder. This resulted in a thicker paste. Again the sample did not set to a monolith, but instead dried to a crumbly gritty powder.

The sample must be covered when in the oven to avoid it drying out into a powder. This powder is hygroscopic, and if left exposed on the laboratory bench at room temperature it reabsorbs water, becoming soggy and eventually forming a paste. This paste does not set. This cycle of wetting, drying out and wetting again seems to be dependant on humidity.

The experiment was repeated, with the hydrated sample sealed in an airtight container, and the setting temperature lowered to $30^{\circ} \mathrm{C}$. The product still did not set, and again crumbled to a powder when removed from the oven and left uncovered.

XRD (figure 13) of these dried powdered products shows they are crystalline $\mathrm{K}_{6} \mathrm{Ga}_{6}\left(\mathrm{GeO}_{4}\right)_{6}\left(\mathrm{H}_{2} \mathrm{O}\right)_{7}$ (pdf 04-009-7324). 


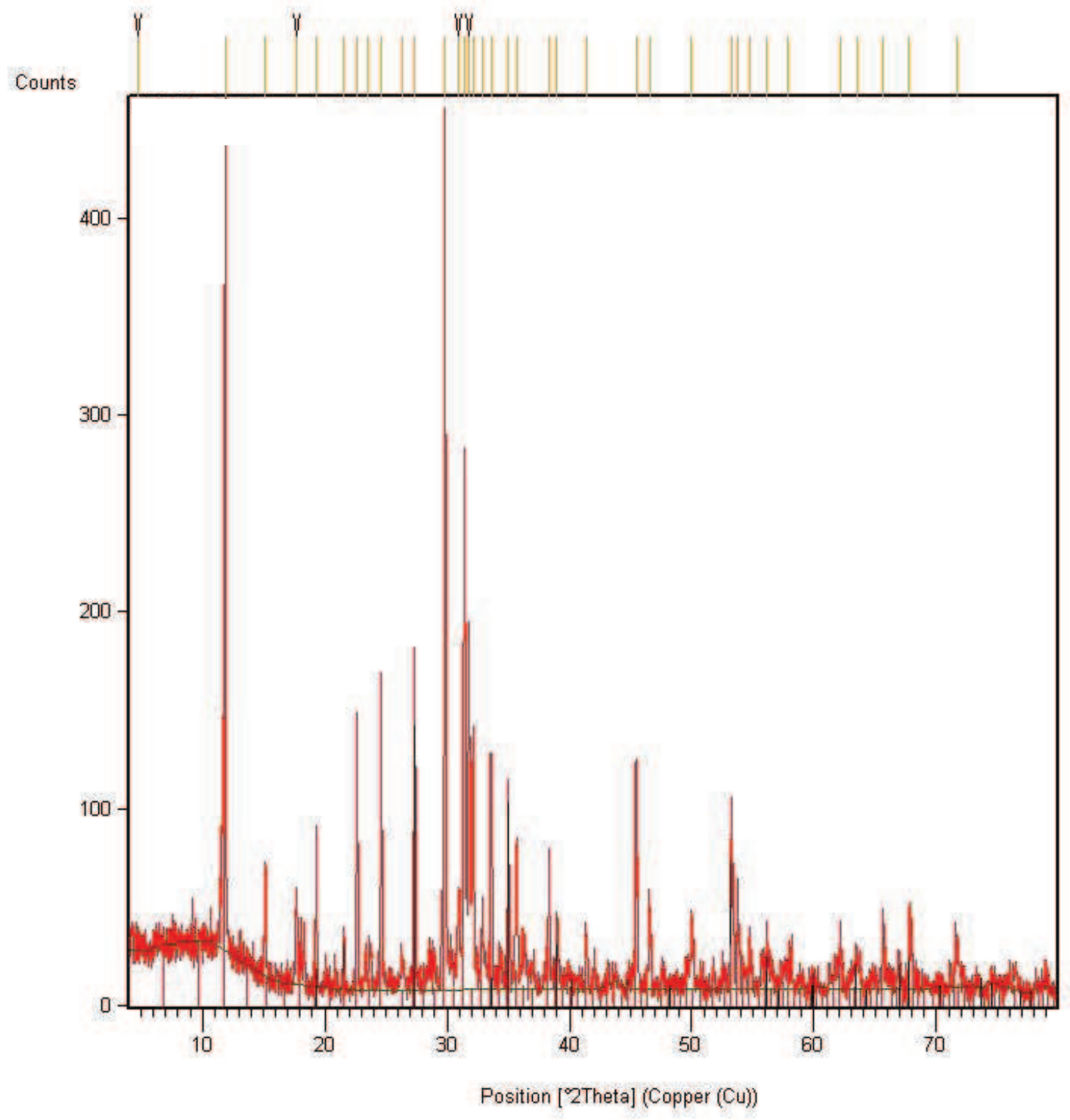

Figure 13: XRD of the crystalline product, $\mathrm{K}_{6} \mathrm{Ga}_{6}\left(\mathrm{GeO}_{4}\right)_{6}\left(\mathrm{H}_{2} \mathrm{O}\right)_{7}$ (pdf file number 04-009-7324)

\subsubsection{Reducing the alkali content}

The alkali content of these samples was higher than that of a typical geopolymer, and this may have been affecting the hydration stability of an amorphous product. The solid-state reaction was changed to reduce the amount of potassium, firstly by not including any additional $\mathrm{KOH}$. The XRD pattern of the hydraulic precursor was unchanged, still showing an amorphous phase with a 
small degree of crystallinity. Hydration of this powder with the minimum amount of water required to form a thick paste did not result in a product that set.

\subsubsection{Potassium germanate melt}

To reduce the amount of potassium even further, the synthesis of a low-alkali germanate was attempted. $\mathrm{GeO}_{2}$ and $\mathrm{K}_{2} \mathrm{CO}_{3}$ were combined with a molar ratio of $\mathrm{GeO}_{2}: \mathrm{K}_{2} \mathrm{O}=1.25$. The mixture was fired at $900^{\circ} \mathrm{C}$ for four hours. At this temperature the mixture formed a melt, which hardened once cooled, and could not be scratched with a spatula. This at first appeared to be of no use, as the glassy product could not be easily removed from the reaction crucible. But after sitting open on the laboratory bench for 24 hours, the surface of the product had softened, and was removed with a spatula. The freshly exposed surface would also soften, and consecutive softened layers were gradually removed until the product was removed from the crucible. The product is a thick colourless gel, and is likely to be a potassium germanate species, although powder XRD analysis could not be performed on the gel to confirm this. A portion of the gel was dried in an oven for 2 hours. The resulting powder was ground for XRD analysis, which showed a very poorly crystalline product or unreacted starting material, with an amorphous phase (figure 14). The species could not be determined. 


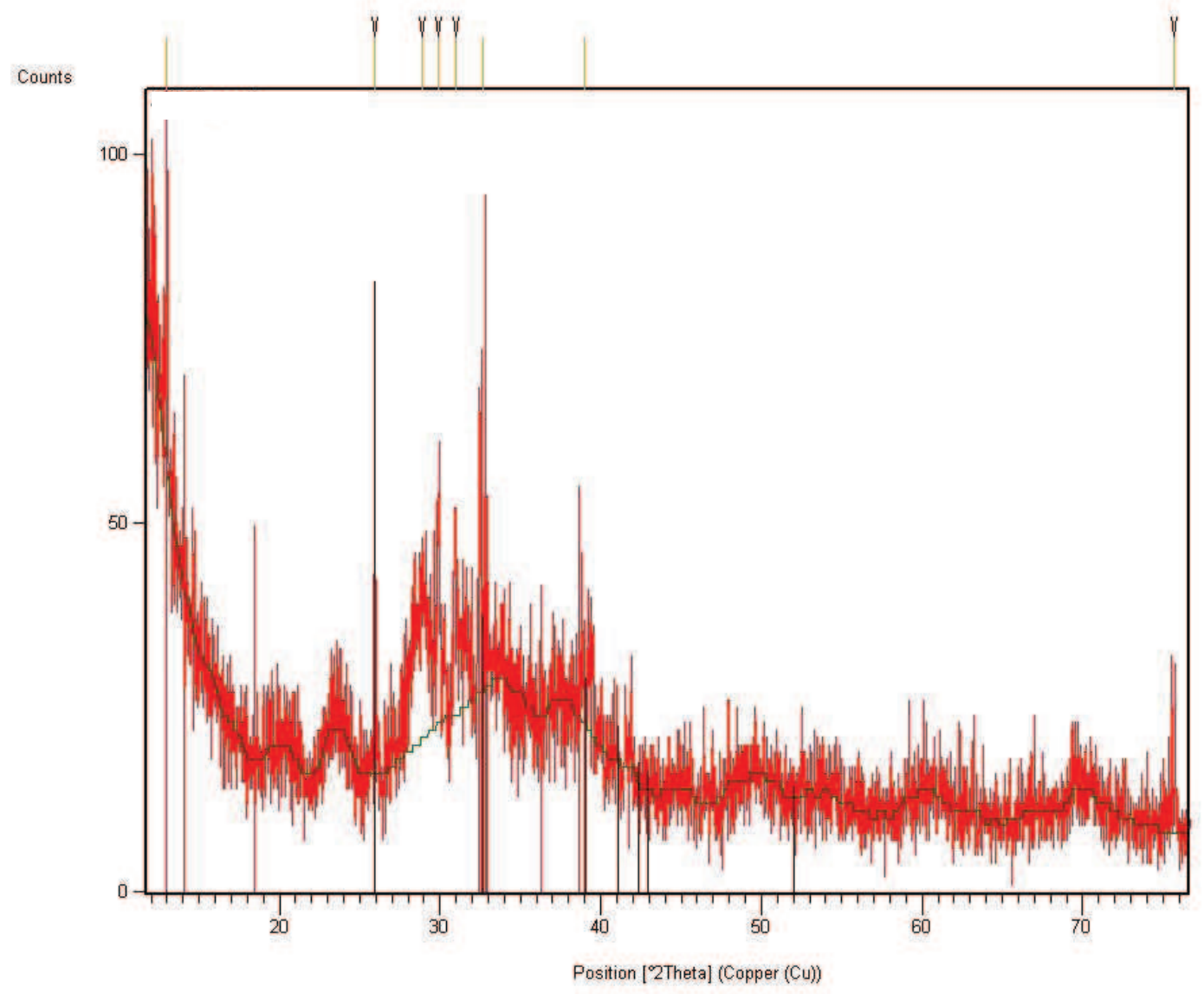

Figure 14: XRD pattern of dried potassium germanate gel.

\subsection{7 $\mathrm{KGaO}_{2}$ and potassium germanate melt}

This germanate gel was mixed with a $\mathrm{KGaO}_{2}$ gel. After mixing for 5 minutes the mixture changed from colourless to cloudy. The product was poured into a mould, which was sealed in an air-tight container, and left in an oven at $40^{\circ} \mathrm{C}$ for 48 hours. The product set, but was crystalline and therefore not an inorganic polymer. The crystalline product could not be determined by XRD (figure 15). 


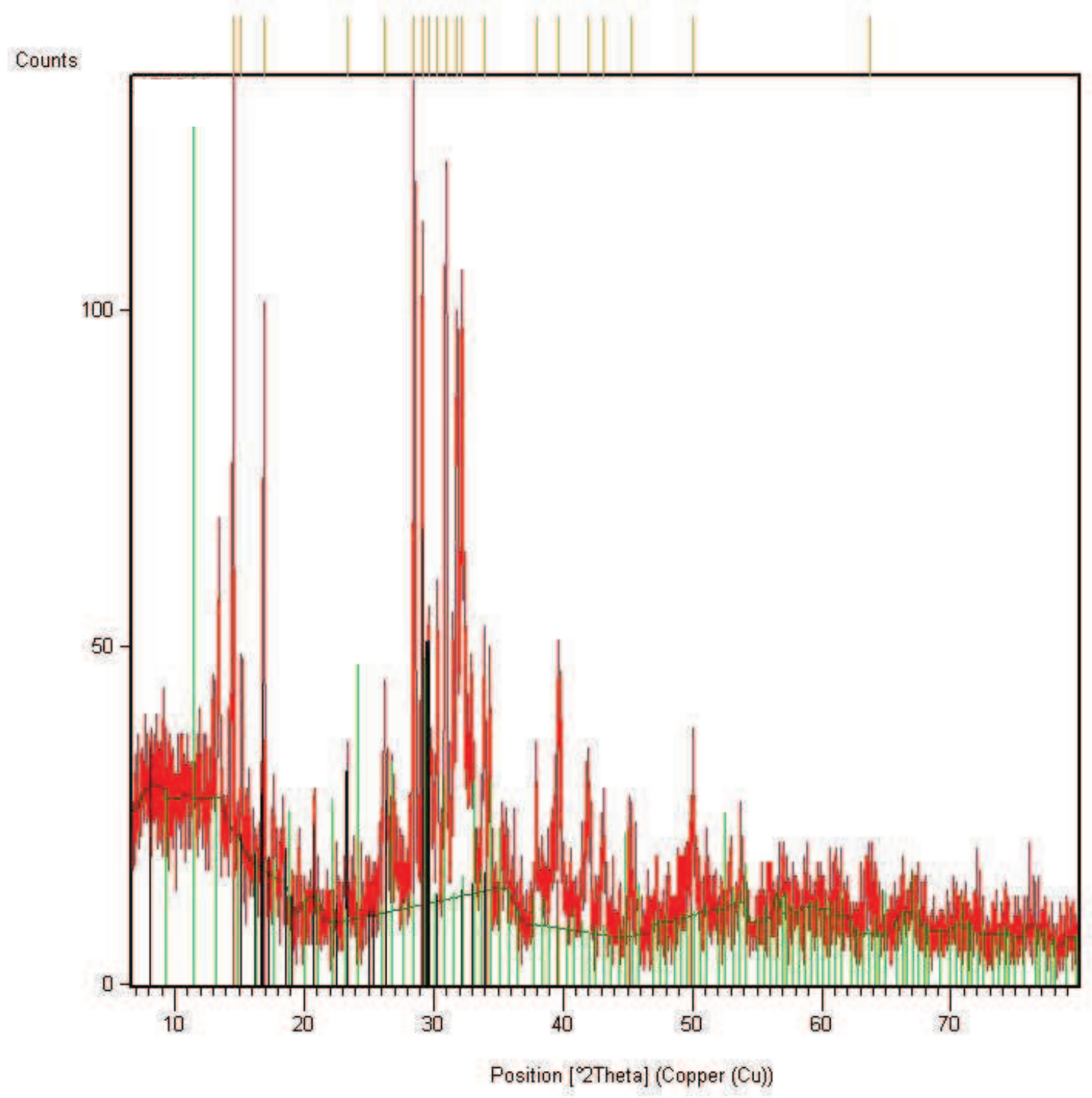

Figure 15: XRD of the crystalline product of the reaction of $\mathrm{KGaO}_{2}$ with potassium germanate gel. 


\subsubsection{Gallium NMR}

Solid-state ${ }^{71} \mathrm{Ga}$ MAS NMR of this set crystalline material shows a single resonance at $195 \mathrm{ppm}$ (figure 16). The peak is relatively sharp, indicating a uniform type of tetrahedral gallium site, which is consistent with the ordered nature of this crystalline material.

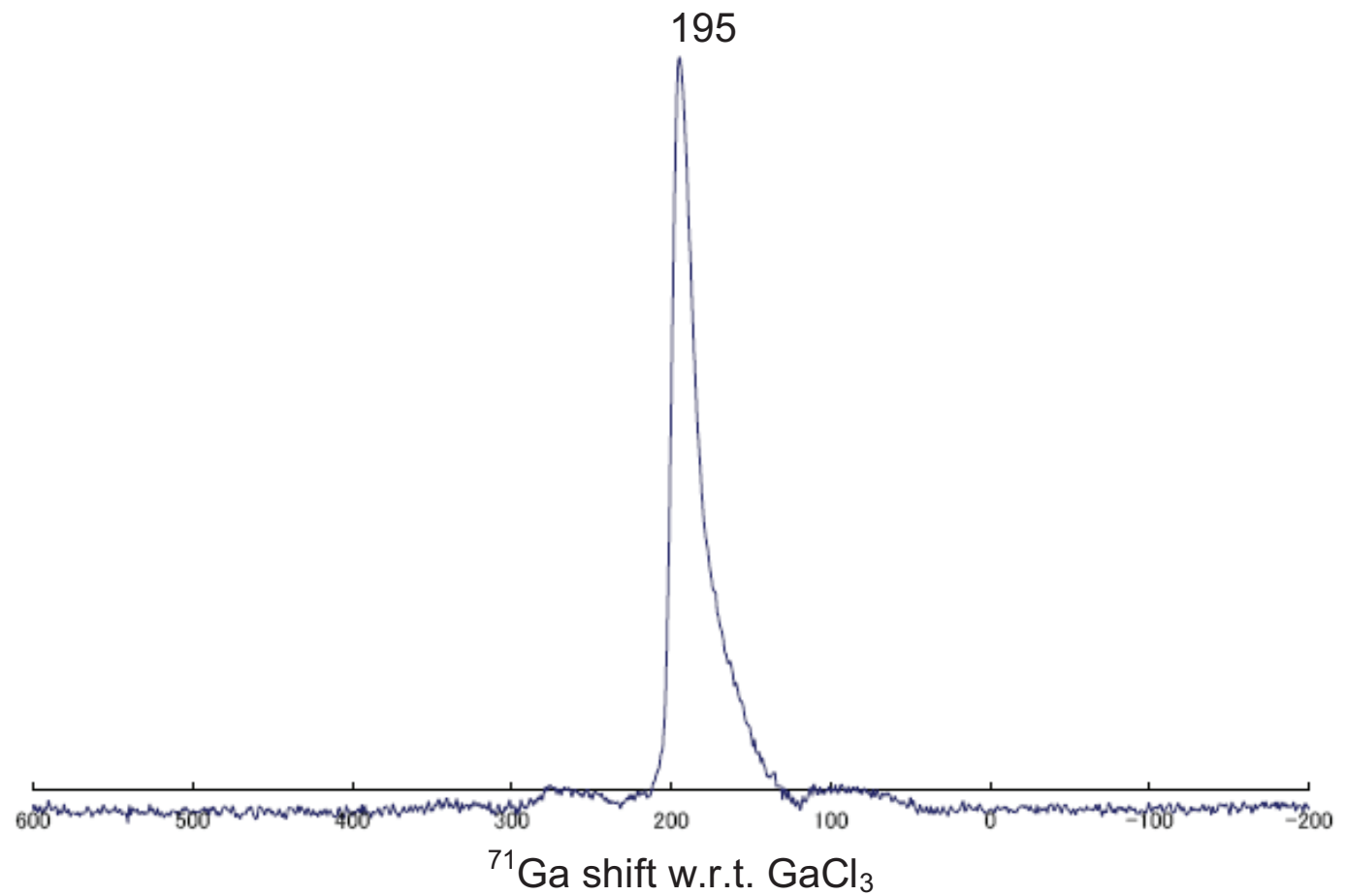

Figure 16: $14.1 \mathrm{~T}^{71} \mathrm{Ga}$ MAS NMR spectrum of a crystalline potassium gallium germanium oxide hydrate product.

\subsubsection{Synthesis of $\mathrm{KGa}_{5} \mathrm{O}_{8}$}

Since experiments repeated using a lower alkali germanate failed to produce an inorganic polymer, therefore a different approach to lowering the alkali content was taken by attempting to synthesise a low-alkali gallate by solid-state reaction. $\mathrm{Ga}_{2} \mathrm{O}_{3}$ and $\mathrm{K}_{2} \mathrm{CO}_{3}$ were mixed together under ethanol in a molar ratio of 3:1. The mixture was fired at $900^{\circ} \mathrm{C}$ for 5 hours. XRD showed the product was mostly unreacted $\mathrm{Ga}_{2} \mathrm{O}_{3}$ with a small amount of $\mathrm{KGa}_{5} \mathrm{O}_{8}$. The product was not hygroscopic and not very soluble. The solid state reaction was repeated with a $\mathrm{Ga}_{2} \mathrm{O}_{3}: \mathrm{K}_{2} \mathrm{O}$ molar ratio of $2: 1$, and fired at $950^{\circ} \mathrm{C}$ for 16 hours. The product of this reaction was confirmed by XRD to be $\mathrm{KGa}_{5} \mathrm{O}_{8}$. 
This $\mathrm{KGa}_{5} \mathrm{O}_{8}$ was mixed with the original potassium germanate in a range of ratios from $\mathrm{GeO}_{2}: \mathrm{Ga}_{2} \mathrm{O}_{3}=1.5-3.2$. The mixtures were fired at $550^{\circ} \mathrm{C}$ for 16 hours to produce mixed oxide precursors. XRD shows these to be partially amorphous (figure 17), with the sample with the higher 3.2:1 ratio being slightly more crystalline.

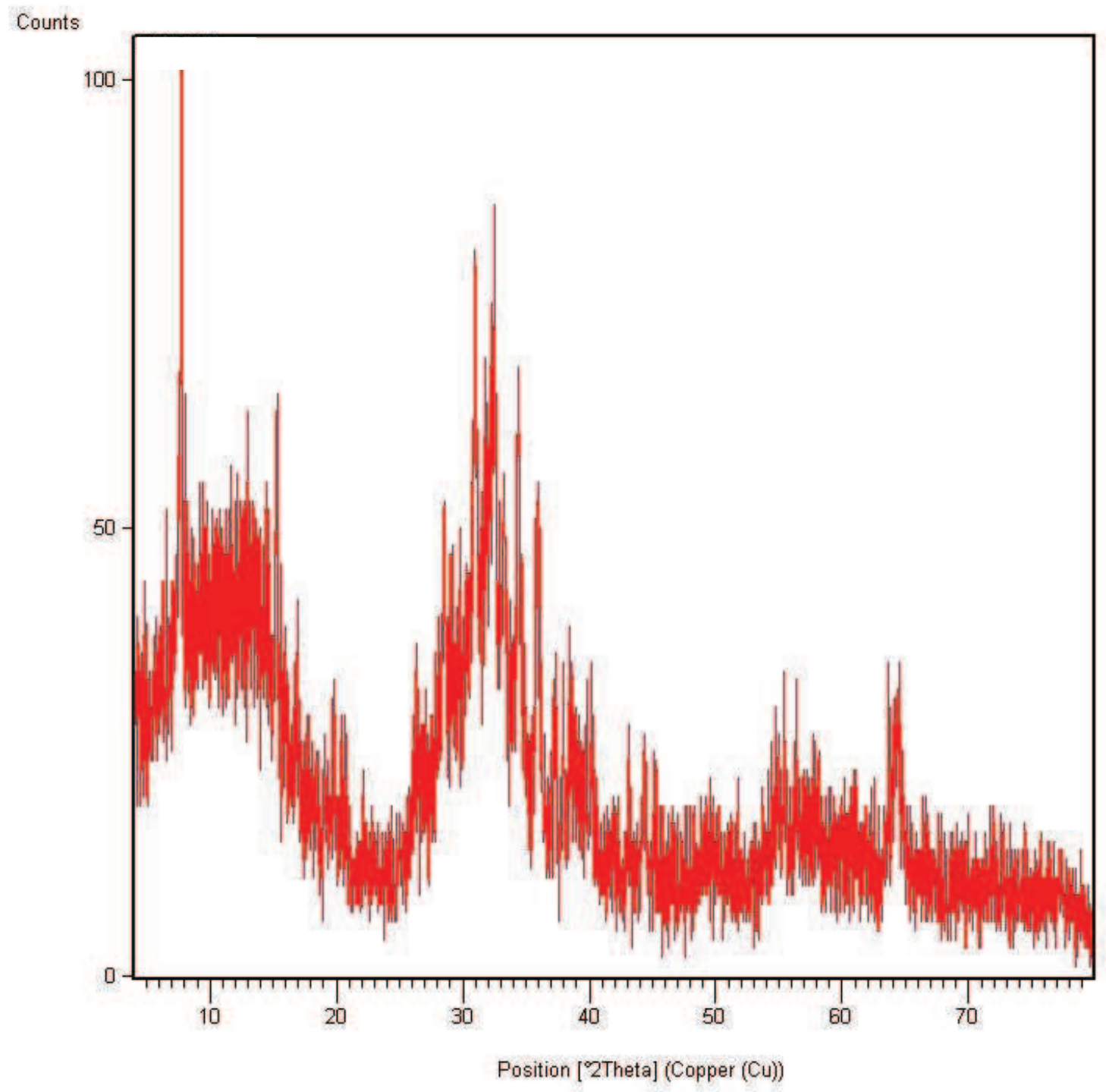

Figure 17: XRD of the mixed $\mathrm{KGa}_{5} \mathrm{O}_{8}$ - potassium germanate hydraulic precursor. 
The hydraulic precursors were wetted with the same amount of water to form a paste, poured into moulds and left to set in an oven at $50^{\circ} \mathrm{C}$ for 48 hours. All samples were hard when removed from moulds. The lower 1.5 ratio sample was deformed rather crushed than when grinding for XRD was attempted, and had not set, despite seeming hard when removed from the oven and mould.

The higher 3.2:1 ratio sample was hard and set, and could be ground to a powder. XRD showed the product was crystalline $\mathrm{K}_{6} \mathrm{Ga}_{6}\left(\mathrm{GeO}_{4}\right)_{6}\left(\mathrm{H}_{2} \mathrm{O}\right)_{7}$, but also contained unreacted hydrated potassium carbonate and some $\mathrm{K}_{2} \mathrm{Ge}_{8} \mathrm{O}_{13}$. (figure 18). 


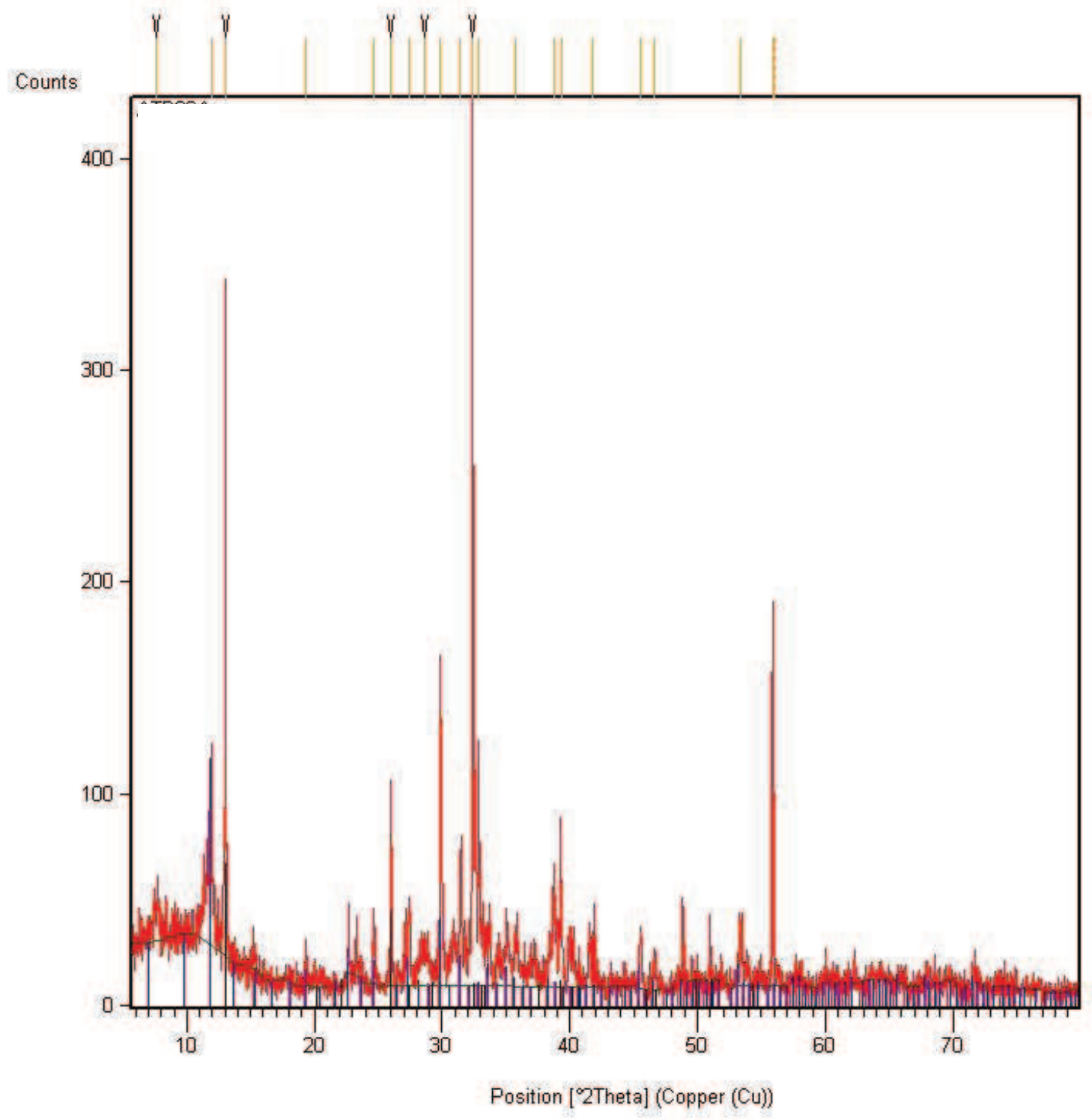

Figure 18: XRD of the crystalline product, $\mathrm{K}_{6} \mathrm{Ga}_{6}\left(\mathrm{GeO}_{4}\right)_{6}\left(\mathrm{H}_{2} \mathrm{O}\right)_{7}$ (pdf 04-009-7324). Small amounts of $\mathrm{K}_{2} \mathrm{Ge}_{8} \mathrm{O}_{17}$ and unreacted $\mathrm{K}_{2} \mathrm{CO}_{3}$ hydrate were also present. 


\subsubsection{Summary}

The solid-state methods described did not synthesise a true inorganic polymer based on the criteria of setting at ambient temperature, X-ray amorphous structure and fully tetrahedral units. Many precursor powders did not set on the addition of water and samples that did set were crystalline. Perhaps it is only possible to incorporate germanium into a geopolymer structure by a postsynthesis substitution mechanism, but such a method could not be used to make a purely gallium-germanium inorganic polymer product.

\begin{tabular}{|l|l|l|}
\hline \multicolumn{1}{|c|}{ Reagents } & \multicolumn{1}{c|}{ Method } & \multicolumn{1}{c|}{ Outcome } \\
\hline $\mathrm{Ga}_{2} \mathrm{O}_{3}+\mathrm{GeO}_{2}$ & Sol-gel & Set, crystalline \\
\hline $\mathrm{KGaO}_{2}+\mathrm{GeO}_{2}$ & Sol-gel & Set, crystalline \\
\hline $\mathrm{KGaO}_{2}+\mathrm{GeO}_{2}$ & Solid-state & Set, crystalline \\
\hline $\mathrm{KGaO}_{2}+\mathrm{K}$ germanate & Sol-gel & Did not set \\
\hline $\mathrm{KGaO}_{2}+\mathrm{K}$ germanate & Solid-state & Did not set \\
\hline $\mathrm{KGaO}_{2}+\mathrm{K}$ germanate melt & Sol-gel & Set, crystalline \\
\hline $\mathrm{KGa}_{5} \mathrm{O}_{8}+\mathrm{K}$ germanate & Solid-state & Set, crystalline \\
\hline
\end{tabular}

Table 2: Summary of the experiments to attempt a synthesis of a gallium-germanium inorganic polymer.

A considerable effort was made to synthesise an inorganic polymer of gallium and germanium oxides (table 2), but despite varying the $\mathrm{GeO}_{2}: \mathrm{Ga}_{2} \mathrm{O}_{3}$ ratio, water content, amount of alkali and processing/setting conditions, the methods tried gave little success. At this point it was decided to focus solely on the incorporation of gallium into a geopolymer structure with silicon, with the possibility of germanium being added in small amounts later. 


\subsection{Synthesis of potassium gallium silicate inorganic polymers}

Without the concerns of germanium, the sol-gel approach, which worked well for silica was returned to. Earlier sol-gel experiments combining alkali silicate with $\mathrm{Ga}_{2} \mathrm{O}_{3}$ showed the product to be partially amorphous, with crystalline phases likely to be unreacted $\mathrm{Ga}_{2} \mathrm{O}_{3}$. It appeared the lack of solubility of the gallium oxide prevented complete reaction or 'geopolymerisation' with the silicate solution.

In contrast $\mathrm{KGaO}_{2}$ is very soluble, shown earlier to form a solution on its own if left exposed to air. A solution of $\mathrm{KGaO}_{2}$ was therefore substituted for $\mathrm{NaAlO}_{2}$ in the original sol-gel type reaction with alkali hydroxide, water and silica fume.

\subsubsection{Dissolving Silica}

The combination of silica fume with an alkali hydroxide solution has been described as the in-situ formation of alkali silicate[29]. However it is important to note that the resulting solution is different from commercial silicate solutions. These are made by a solid-state reaction between silica and alkali carbonate at temperatures around $1300^{\circ} \mathrm{C}$. The product is a water-soluble glass, sometimes referred to as 'water glass'.[20] The chemistry of soluble silicates is complex, and dissolving the silica fume into alkali hydroxide solution more correctly results in a mixture of soluble silicate species and a suspension of colloidal silica.[20] Despite this, such a mixture will be referred to as an alkali silicate solution.

The silica fume is best dissolved directly into a concentrated solution of $\mathrm{KOH}$. Alternatively, the silica can be wetted initially, and then ground $\mathrm{KOH}$ added to the slurry. However the low water content makes this difficult; the wet silica is extremely thick and hard to mix, although after mixing in $\mathrm{KOH}$ the gel relaxes as 
the silica dissolves to form potassium silicate. The former method has proven to be better.

It is important to keep the silicate stirred until the addition of the other reactants for the polymerisation reaction. If the resulting silicate solution is left to stand it begins to thicken, and will eventually set. The resulting solid is soluble, and readily dissolves in warm water, but can no longer be used for the synthesis of an inorganic polymer.

A $\mathrm{KGaO}_{2}$ solution was formed by allowing a weighed mass of dry $\mathrm{KGaO}_{2}$ powder to sit in a porcelain crucible, exposed to ambient air in the laboratory. The powder had absorbed between $43-52 \%$ of its mass in water by the time all the white powder grains had dissolved to give a thick colourless solution.

\subsubsection{Water Content}

Water content was controlled in two ways, firstly by monitoring the mass of water absorbed by the $\mathrm{KGaO}_{2}$. The total mass of the sample and crucible was weighed when the $\mathrm{KGaO}_{2}$ was a dry white powder and then again when it had formed a thick colourless solution. The gain in mass is the mass of water absorbed. Water content was also controlled by measuring the volume of water added to $\mathrm{KOH}$ to make a strongly alkaline solution to dissolve the silica into. This water was added from a $1.00 \mathrm{~mL}$ syringe with $0.05 \mathrm{~mL}$ gradient markings.

\subsubsection{Synthesis}

All reagents were prepared in small porcelain crucibles. The method is outlined schematically below (figure 20). Typically $1.0 \mathrm{~g}$ of silica fume was used for each experiment. The silica was dissolved in a $\mathrm{KOH}$ solution made from 0.19-0.21 g $\mathrm{KOH}$ and $0.1-0.15 \mathrm{~mL}$ of water. The mass of $\mathrm{KGaO}_{2}$ used ranged from $0.50 \mathrm{~g}-$ $1.43 \mathrm{~g}$. The potassium silicate solution was poured into the $\mathrm{KGaO}_{2}$ solution, and the resulting syrup was stirred mechanically with a spatula for a further 5 
minutes, before being poured into a mould which was sealed in an airtight container and left to set at room temperature for 48 hours (figure 19).

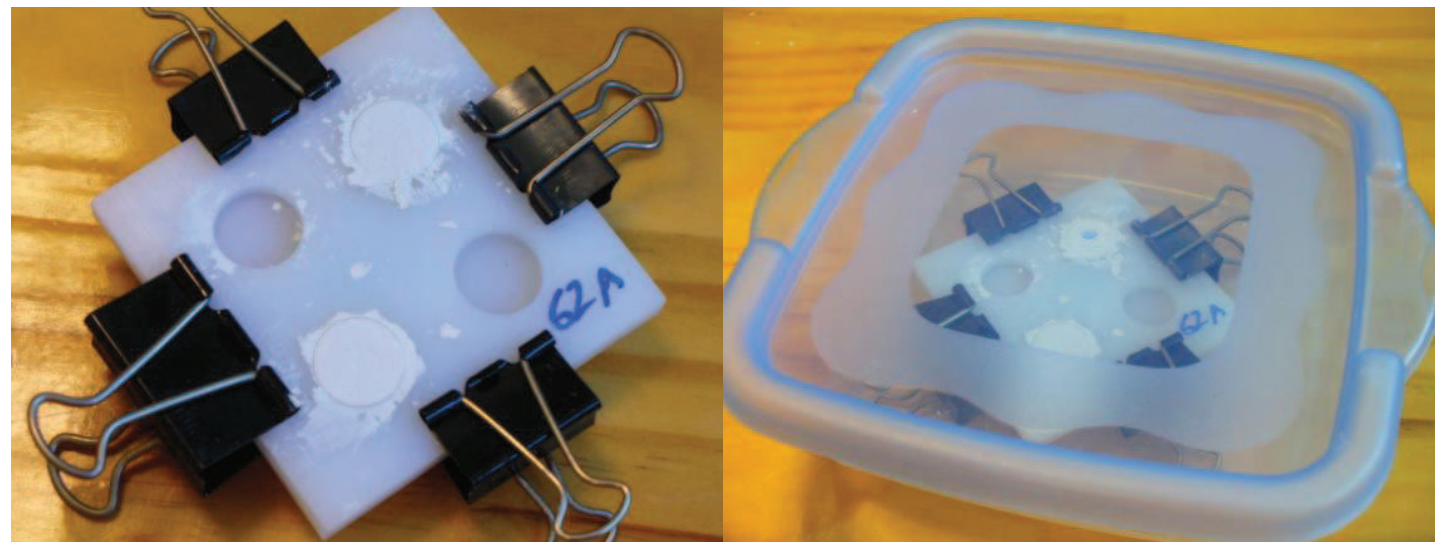

Figure 19: Photos showing set samples in mould (left) and mould inside container (right).

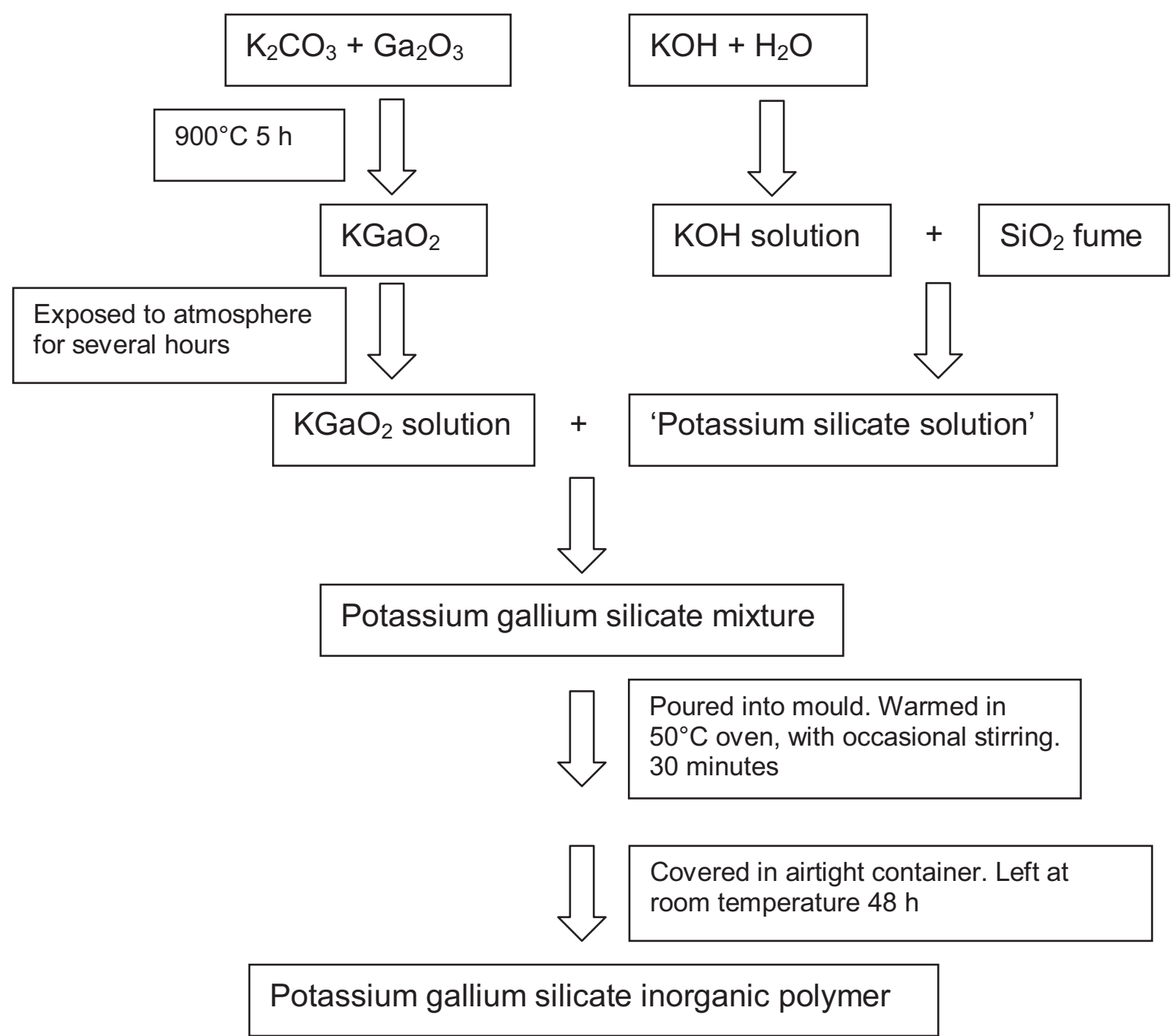

Figure 20: Outline of the method for synthesising a potassium gallium silicate inorganic polymer. 
The mould was made of two sheets of high density polyethylene (HDPE), one with disc-shaped holes the other a flat sheet, clipped together as shown in figure 19. The surface of the flat sheet was greased with a thin film of white petroleum jelly (Vaseline) to prevent samples sticking to the mould and making removal of samples easier. The mould was cleaned thoroughly and was repeatedly reusable. The size of the samples is shown in figure 21.

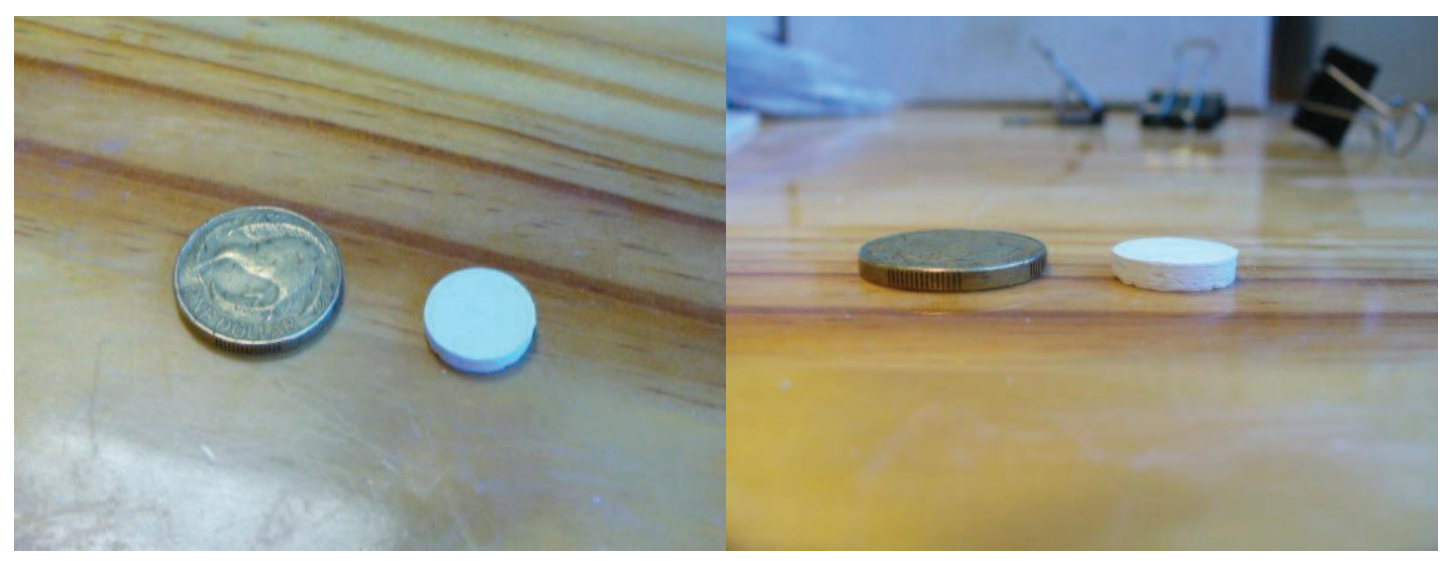

Figure 21: Photos showing the size of a typical set sample relative to a \$NZ 1 dollar coin. 


\subsubsection{XRD characterisation of the products}

The products of these reactions are X-ray amorphous with a broad hump at $30^{\circ} 2 \theta$ (figure 22). This is characteristic of inorganic polymers; however the coordination of gallium and silicon needs to be confirmed by solid-state MAS NMR.

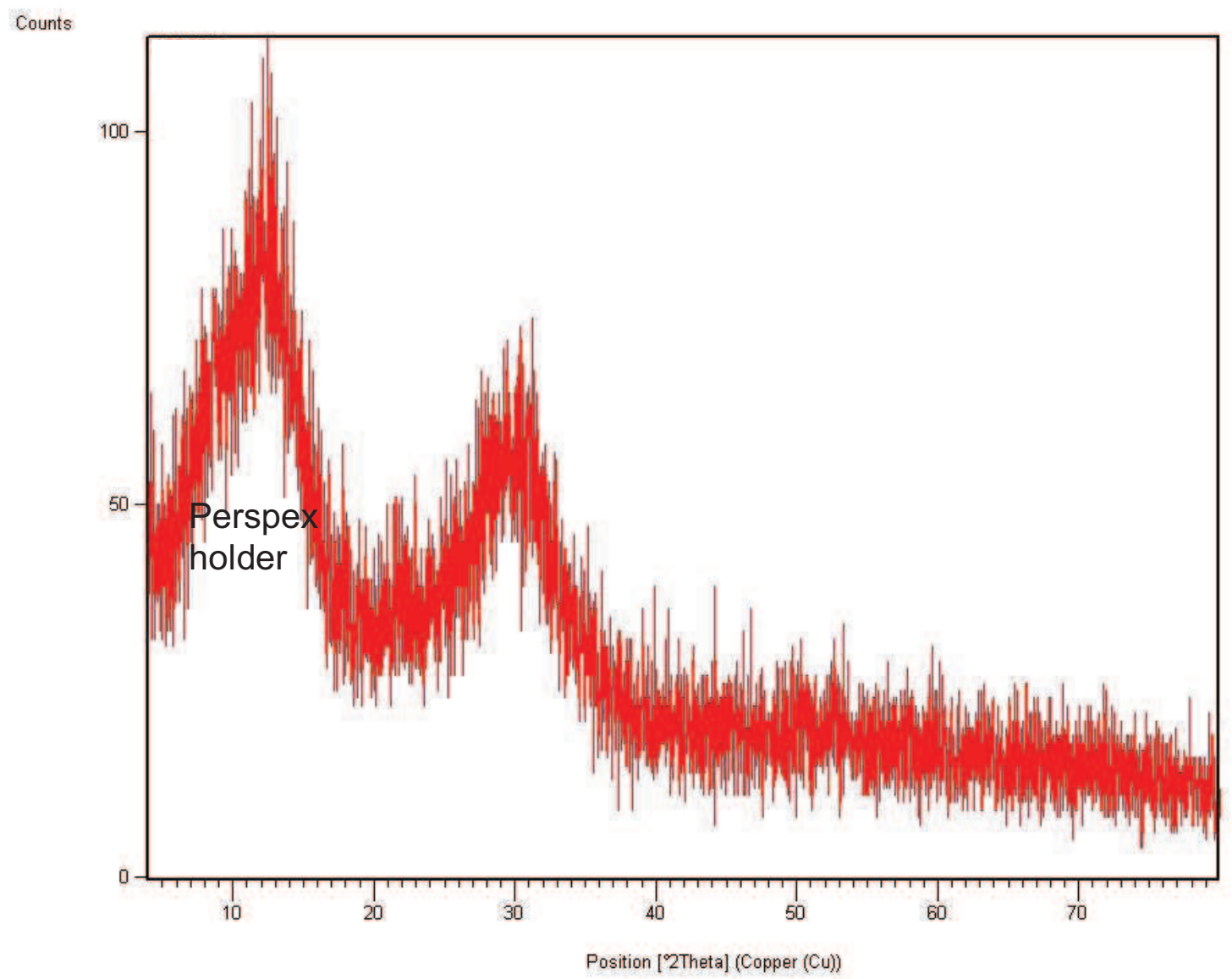

Figure 22: XRD pattern of a typical gallium silicate inorganic polymer. The hump at $10^{\circ} 2 \theta$ is caused by the Perspex sample holder. The hump at $30^{\circ} 2 \theta$ is from the sample. 


\subsubsection{Effect of the $\mathrm{SiO}_{2}: \mathrm{Ga}_{2} \mathrm{O}_{3}$ ratio}

The ratio of $\mathrm{SiO}_{2}: \mathrm{Ga}_{2} \mathrm{O}_{3}$ affects the product. The range of ratios tested was 9.39 -3.28 . The optimum ratio was found to be around 7 . In mass terms this equates to $0.67 \mathrm{~g}$ of $\mathrm{KGaO}_{2}$ with $1 \mathrm{~g}$ of $\mathrm{SiO}_{2}$. Samples made using this ratio set strong and hard, and the product did not crack.

When the ratio $\mathrm{SiO}_{2}: \mathrm{Ga}_{2} \mathrm{O}_{3}$ was $9.39\left(0.5 \mathrm{~g} \mathrm{KGaO}_{2}\right.$ with $\left.1 \mathrm{~g} \mathrm{SiO}_{2}\right)$ there was layer separation in the product, and cracking. When the ratio was lower (4.69) corresponding to $1.0 \mathrm{~g}$ of $\mathrm{KGaO}_{2}$, the product was relatively weaker and cracked severely. The lowest ratio of $3.28\left(1.43 \mathrm{~g} \mathrm{KGaO}_{2}\right)$ did not set. This may have been caused by too much water being introduced from the $\mathrm{KGaO}_{2}$ solution.

This shows that inorganic polymers made by this method have different optimal ratios than conventional aluminosilicate geopolymers prepared from metakaolin clay. However the optimal ratio here of approximately 7 is similar to the geopolymer $\mathrm{SiO}_{2}: \mathrm{Al}_{2} \mathrm{O}_{3}$ ratio of 6-7 suggested by Davidovits in one of his patents.[12] Small variations in the amount of $\mathrm{KOH}$ used between samples did not affect the products.

The optimum ratio of approximately 7 was used for all samples synthesised subsequently.

\subsubsection{Setting conditions}

Unlike conventional geopolymers which set better at approximately $40-60^{\circ} \mathrm{C}$, these gallium silicate inorganic polymers do not set well at such a temperature. When left in moulds to set in the laboratory oven at $50^{\circ} \mathrm{C}$ the products separated into two different layers (figures 23 and 24). This layer separation occurred at this temperature regardless of whether the samples were covered or open.

The top layer was the grey-brown colour of set silicate, the bottom layer was opaque white in appearance. Both layers are X-ray amorphous. The layer 
separation causes the product to be extremely brittle and easily cracked. The two layers can also come apart intact, when a sample is removed from the mould.

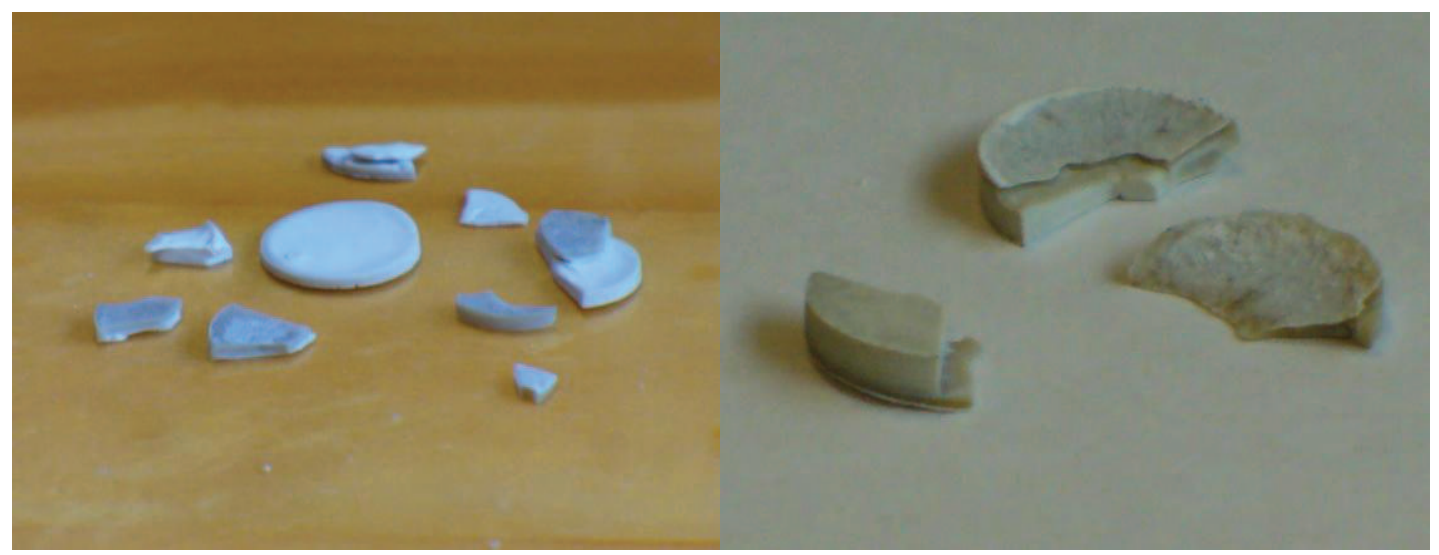

Figure 23: Photos showing layer separation in set gallium silicate inorganic polymer samples.

This layer separation is thought to be caused by the low viscosity of the gallium silicate mixture relative to regular aluminosilicate geopolymer slurry. The low viscosity is even more pronounced at elevated temperatures, where particles of different masses are mobile within the solution mixture. Thus the heavier gallate species migrate to the bottom layer. The lighter silicate species are assumed to remain throughout the sample, in both the bottom and top layers. While the bottom layer probably contains both silicate and gallate species, the ratio of the two are skewed such that the inorganic polymer product does not have good properties, and therefore cracks easily (figure 24).

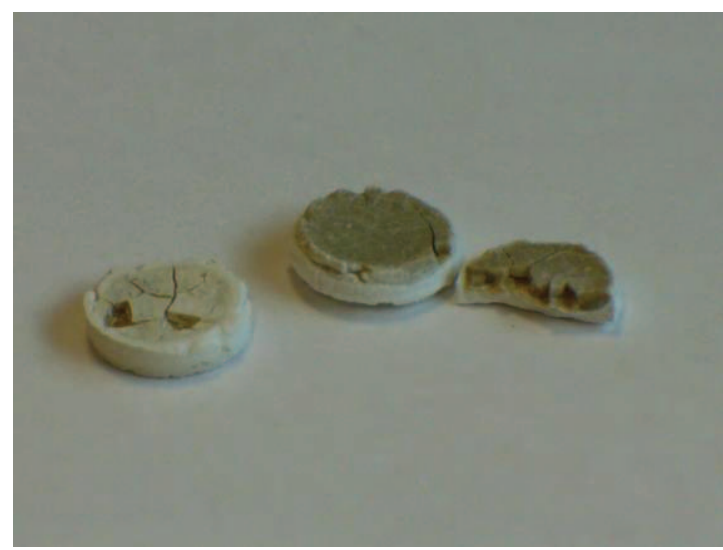

Figure 24: Photo showing layer separation and cracking in set gallium silicate inorganic polymer samples. 
The solution to this layer separation problem turned out to be relatively simple. The samples, once poured into moulds, were left to set at room temperature on the laboratory bench. At this lower temperature the viscosity of the mixture was lower, suggesting that species cannot migrate as easily through the mixture, so were not affected by gravity, and the products were homogeneous. No difference was observed between samples that were sealed in an airtight container and samples that were left exposed.

The setting method was improved further by placing the stirred potassium gallium silicate mixture in and out of the $50^{\circ} \mathrm{C}$ oven at intervals for few minutes duration with stirring between intervals, for approximately five cycles. During this time a thickening of the mixture was observed. After this process the sample was poured into a mould and left to set on the laboratory bench at room temperature in the usual fashion. In this way the reaction gets the benefits of setting at a slightly elevated temperature, such as an increased rate of micro-structural development, but without the product showing signs of layer separation.

\subsubsection{Water Stability}

The set sample discs are insoluble and do not show any signs of weakening or fragmenting when immersed in warm $\left(50^{\circ} \mathrm{C}\right)$ distilled water for 24 hours. This also indicates the strength of the sample is not due to the drying of excess potassium silicate between sol-gel particles.

\subsubsection{Thin films}

Due to the low viscosity of the potassium gallium silicate solution mixture when poured into the mould, occasionally some of the mixture would spread between the two layers of the plastic mould. This thin layer would set like the rest of the bulk of the sample in the mould. When the set sample was removed this thin film of inorganic polymer could also be removed. These thin layers are approximately $0.5 \mathrm{~mm}$ or less in thickness (figure 25). 


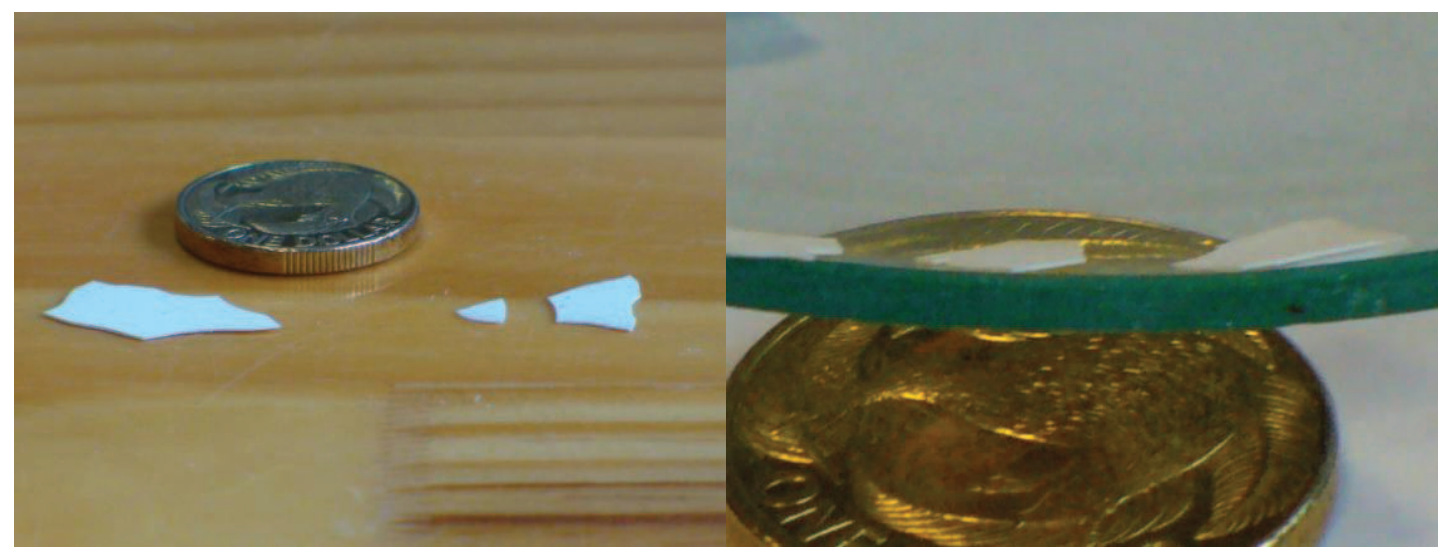

Figure 25: Photos showing examples of gallium silicate inorganic polymer thin films next to a \$NZ 1 dollar coin.

Thin films of this material could potentially have useful applications, depending on the electronic properties of the material, such as ionic conductivity.

\subsubsection{Silica}

The silica fume used contains approximately a $5 \%$ zirconia $\left(\mathrm{ZrO}_{2}\right)$ impurity. Fumed silica (as distinct from silica fume) is a more pure form of silica (99.8\%). Attempts at using fumed silica for the synthesis of gallium silicate IPs were unsuccessful. Fumed silica has a very high surface area resulting in a high water demand. Samples made from this material did not set. As a result, an alkali silicate solution suitable for inorganic polymer synthesis could not be made from fumed silica.

\subsubsection{0 ${ }^{29} \mathrm{Si} \mathrm{NMR}$}

Solid-state silicon MAS NMR is an important tool for characterising the products, and many samples were analysed using this technique. All samples contained unreacted $\mathrm{SiO}_{2}$ indicated by a peak around -109 ppm (figure 26). This is consistent with the spectra reported for aluminosilicate inorganic polymers made using the aluminate-in situ silicate sol-gel method in the literature.[29]

This also confirms that the $\mathrm{SiO}_{2}$ dissolved into $\mathrm{KOH}$ solution does not yield a solution entirely of potassium silicate solution, and is likely to also contain a colloidal suspension of silica. 
The spectra (figure 26) also show a broad peak made up of two resonances at approximately -80.6 and $-86.5 \mathrm{ppm}$, with very slight differences in these values between samples. Typically one of these resonances will be dominant, with the other resonance appearing as a shoulder on the dominant resonance.

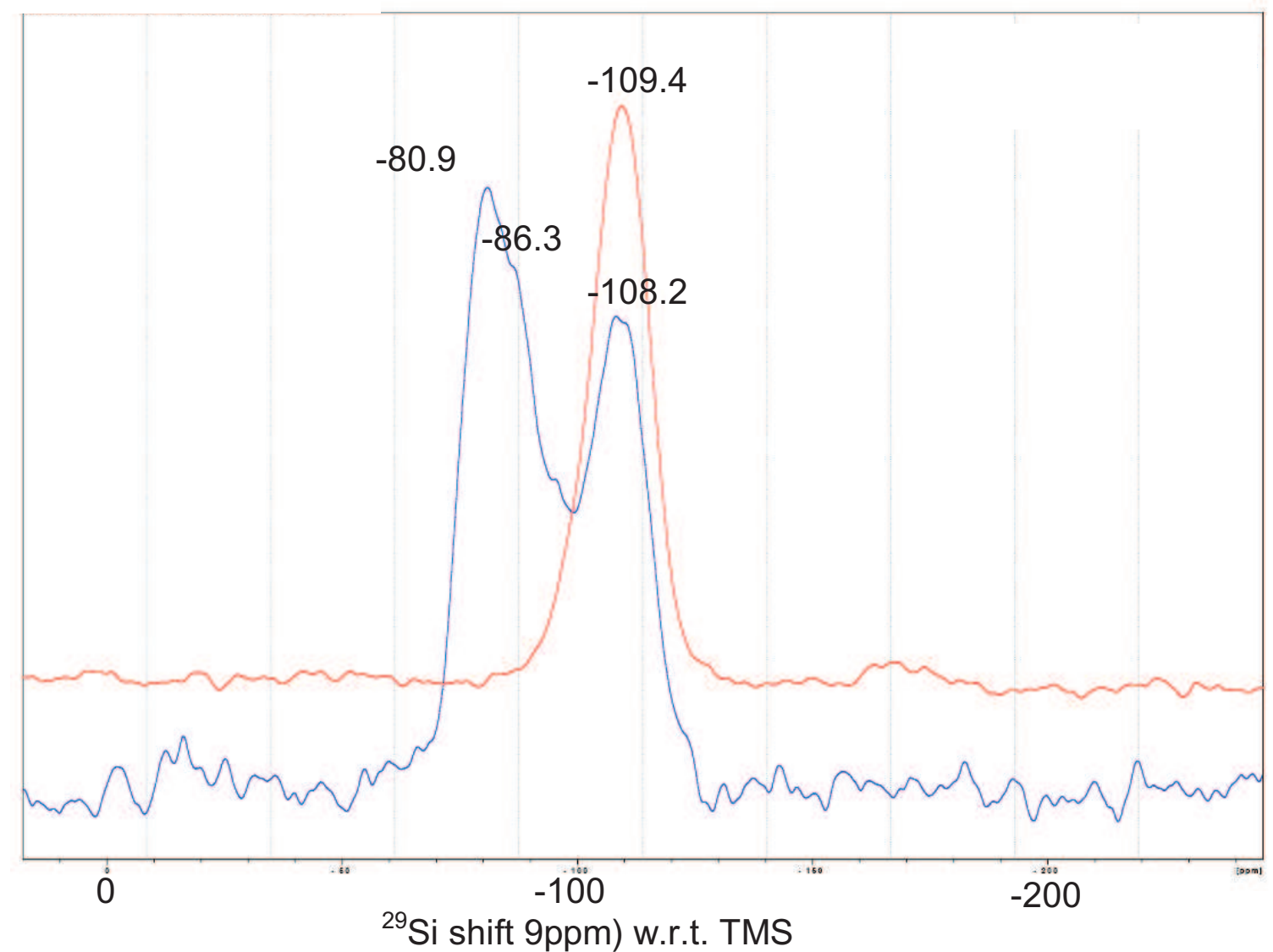

Figure 26: $11.7 \mathrm{~T}^{29} \mathrm{Si}$ MAS NMR of a typical gallium silicate inorganic polymer (blue) with silica fume starting material (red).

Gallium is better able to screen silicon than aluminium and so the presence of gallium causes a shift of silicon resonances slightly towards the positive end of the spectrum compared to aluminium. The resonance at around $-80 \mathrm{ppm}$ is likely to be from $\mathrm{Si}(4 \mathrm{Ga})$ sites, while the other resonance around $-86 \mathrm{ppm}$ could be indicate either $\mathrm{Si}(4 \mathrm{Ga})$ or $\mathrm{Si}(3 \mathrm{Ga})$ sites. The presence of $\mathrm{Si}(4 \mathrm{Ga})$ sites compares well with the $\mathrm{Si}(4 \mathrm{Al})$ sites typical of potassium aluminosilicate inorganic polymers.[31] 
The two peaks, one from the inorganic polymer and the other from $\mathrm{SiO}_{2}$ are joined at the base, and the separation between them varies slightly between samples. Typically the inorganic polymer peak is stronger than the silica peak, although occasionally the two are approximately equal in height (figure 27).

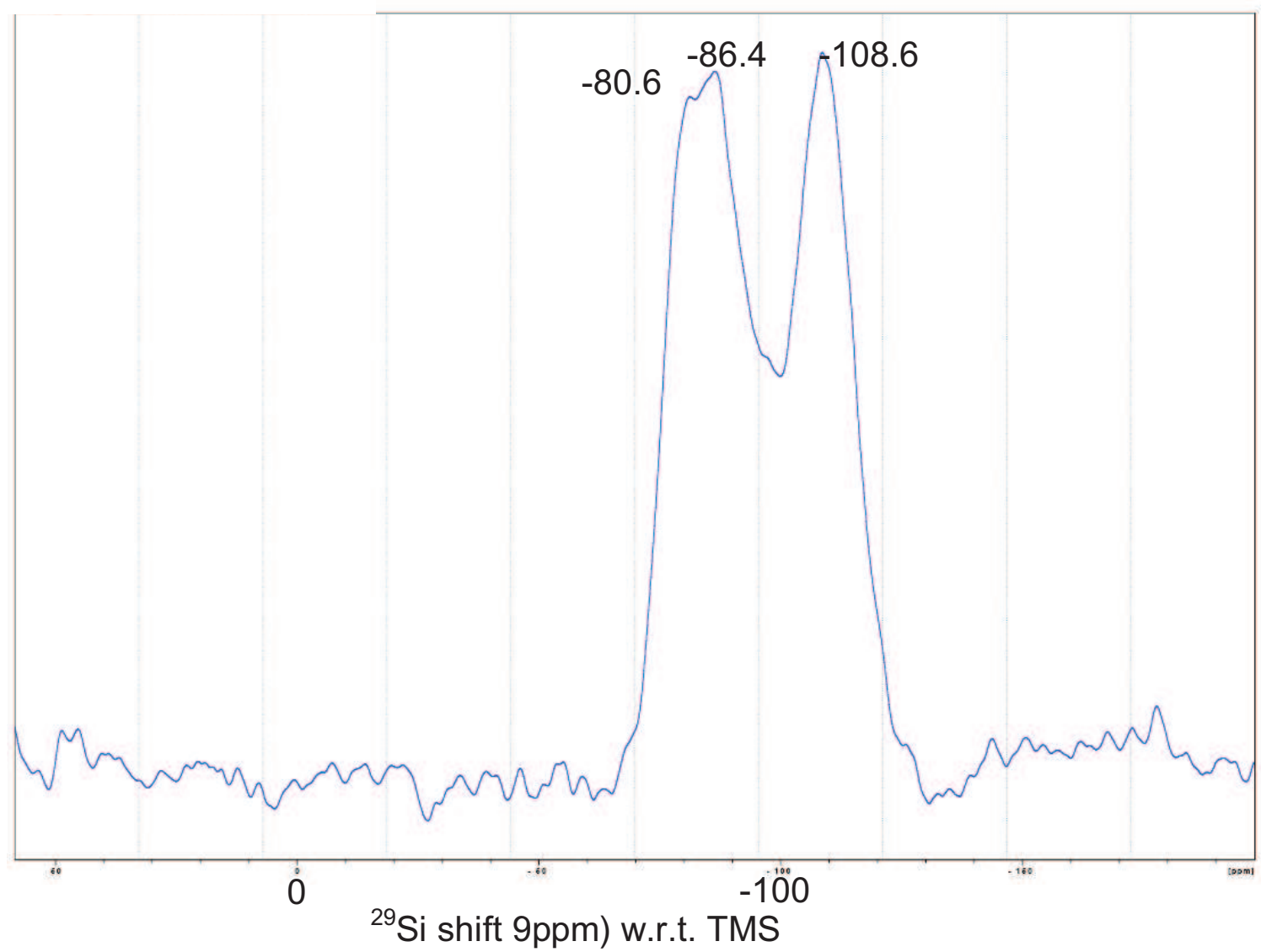

Figure 27: $11.7 \mathrm{~T}^{29} \mathrm{Si}$ MAS NMR of a typical gallium silicate inorganic polymer showing unreacted silica peak approximately equal in intensity to the product peak.

\subsubsection{1 ${ }^{71} \mathrm{Ga}$ NMR}

Solid-state ${ }^{71} \mathrm{Ga}$ NMR was carried out by Hideki Maekawa at Tohoku University, Japan, on a few selected samples. These were:

1) $\mathrm{Ga}-\mathrm{Si}$ inorganic polymer $\mathrm{SiO}_{2}: \mathrm{Ga}_{2} \mathrm{O}_{3}=9.4$

2) $\mathrm{Ga}-\mathrm{Si}$ inorganic polymer $\mathrm{SiO}_{2}: \mathrm{Ga}_{2} \mathrm{O}_{3}=7.0$

3) $\mathrm{Ga}_{2} \mathrm{O}_{3}$

4) $\mathrm{KGaO}_{2}$ 


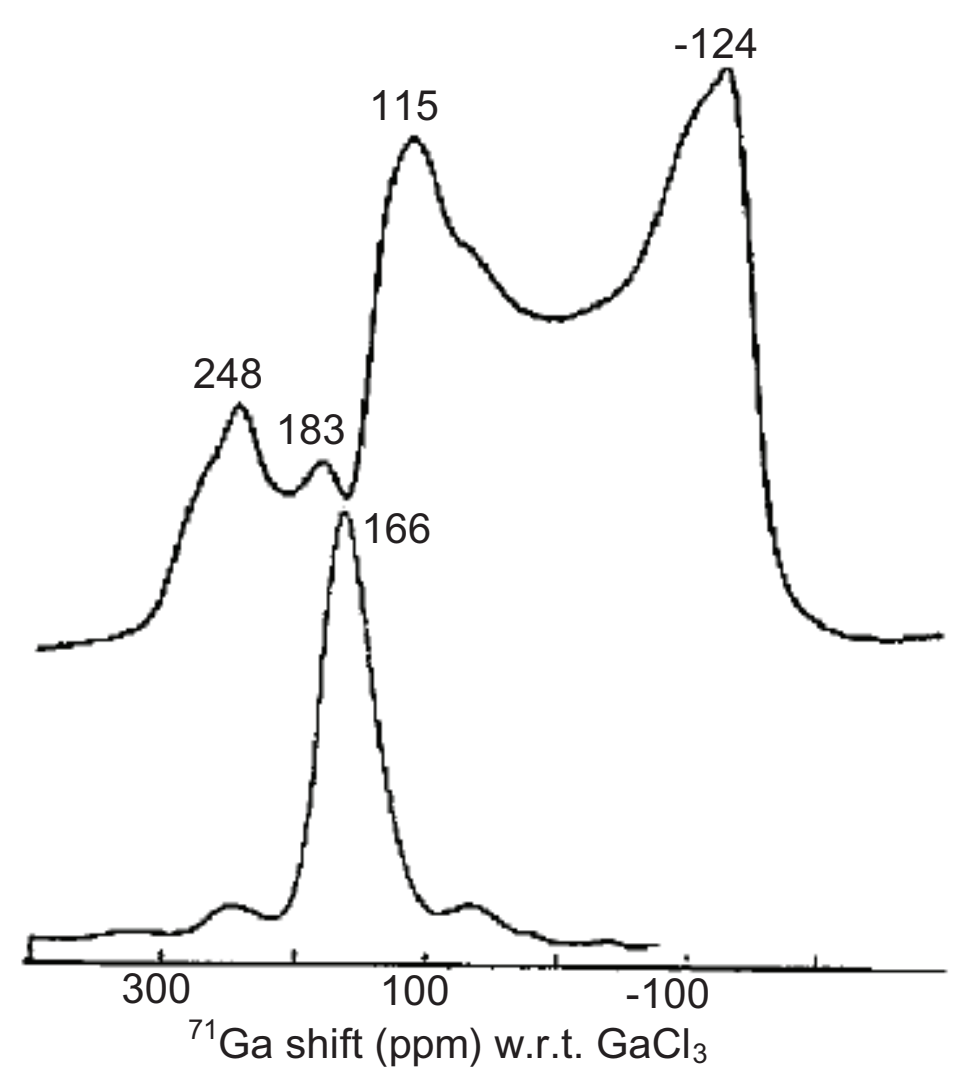

Figure 28: $14.1 \mathrm{~T}^{71} \mathrm{Ga}$ MAS NMR spectra of a gallium silicate inorganic polymer (bottom) and $\mathrm{Ga}_{2} \mathrm{O}_{3}$ (top)

The inorganic polymer samples were shown to contain $\mathrm{Ga}$ in solely 4-fold (tetrahedral) coordination indicated by a broad resonance at approximately 166 ppm (figure 28). This is in contrast with the $\mathrm{Ga}_{2} \mathrm{O}_{3}$ from which the $\mathrm{KGaO}_{2}$ was derived. $\mathrm{Ga}_{2} \mathrm{O}_{3}$ has a broad spectrum with four peaks; two major peaks at -124 and $115 \mathrm{ppm}$, and two smaller peaks at 183 and $248 \mathrm{ppm}$. The peaks at -124 ppm and 115 arise from a quadrupolar lineshape from a single distorted octahedral gallium site and those at 183 and 248 are a quadrupolar line shape from a tetrahedral gallium site within $\mathrm{Ga}_{2} \mathrm{O}_{3}$. A spectrum for $\mathrm{KGaO}_{2}$ could not be obtained as it would not spin, due to being highly hygroscopic.

The $\mathrm{SiO}_{2}: \mathrm{Ga}_{2} \mathrm{O}_{3}$ ratio did not affect the coordination of gallium within the inorganic polymer structure. 


\subsubsection{SEM}

Secondary electron imaging (SEI) shows the presence of spherical silica particles approximately 1-3 microns across (figure 29). The inorganic polymer fragments have no defined or regular shape, which is expected for an amorphous cermic-like material. Small circular pores are visible on the surface of some pieces, and range in size from 0.1-0.4 microns in diameter (figure 30). These may be caused by water evaporation or particle diffusion during curing.

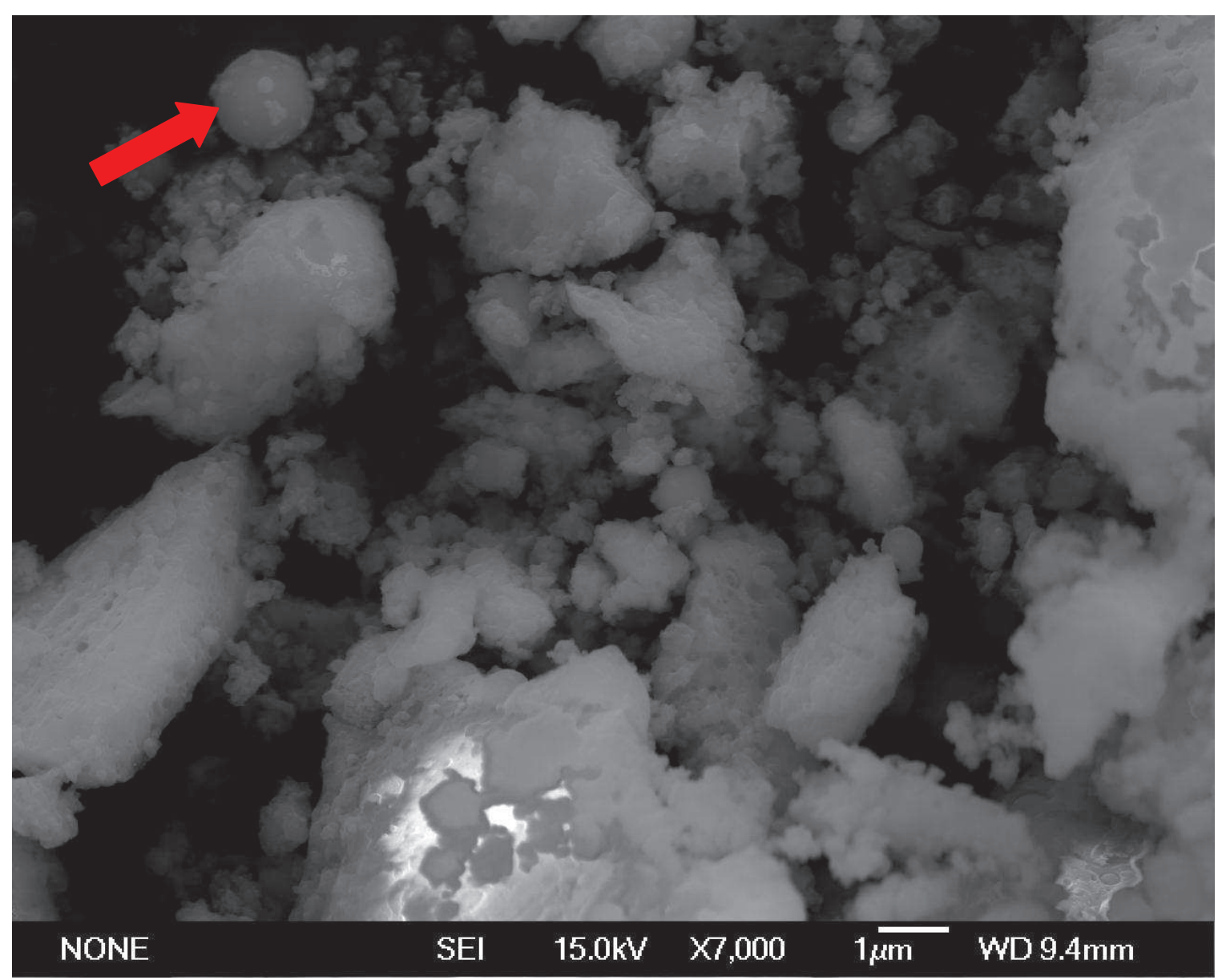

Figure 29: x7000 SEl image of a gallium silicate inorganic polymer. A spherical silica particle can be seen at top left (red arrow). The brighter regions at bottom centre are due to charging on the sample surface. 


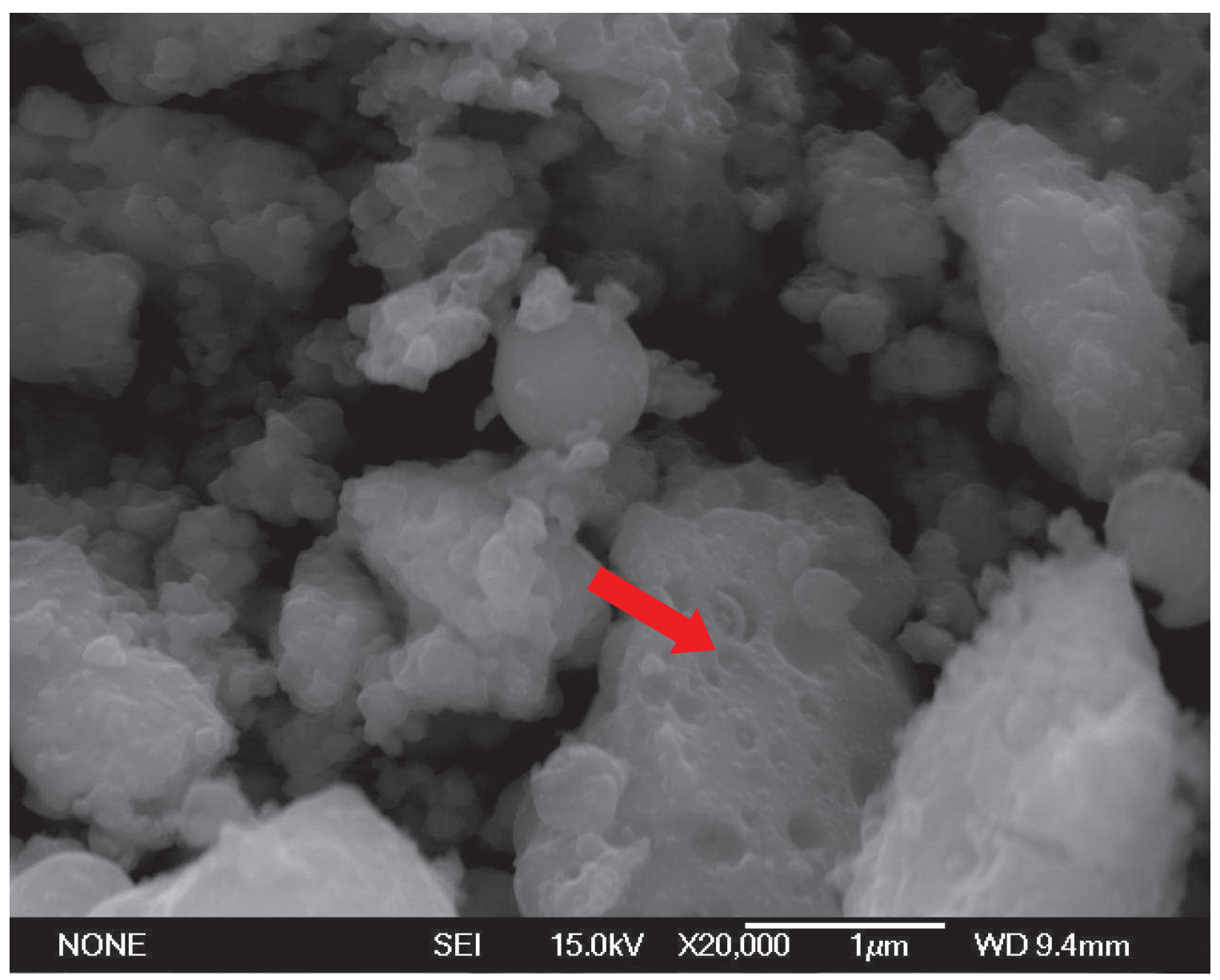

Figure 30: x7000 SEI image of a gallium silicate inorganic polymer showing the circular pores (red arrow) on the surface of a sample fragment.

Backscatter images at 4000x, 7000x, 14000x and 20000x magnification show the sample at a uniform level of brightness, indicating a homogeneous distribution of atomic weight of the component elements.

A gallium silicate inorganic polymer sample was mapped for elemental analysis in backscatter mode at 500x, 7000x, 14000x and 43000x magnification (figures 31-34). 


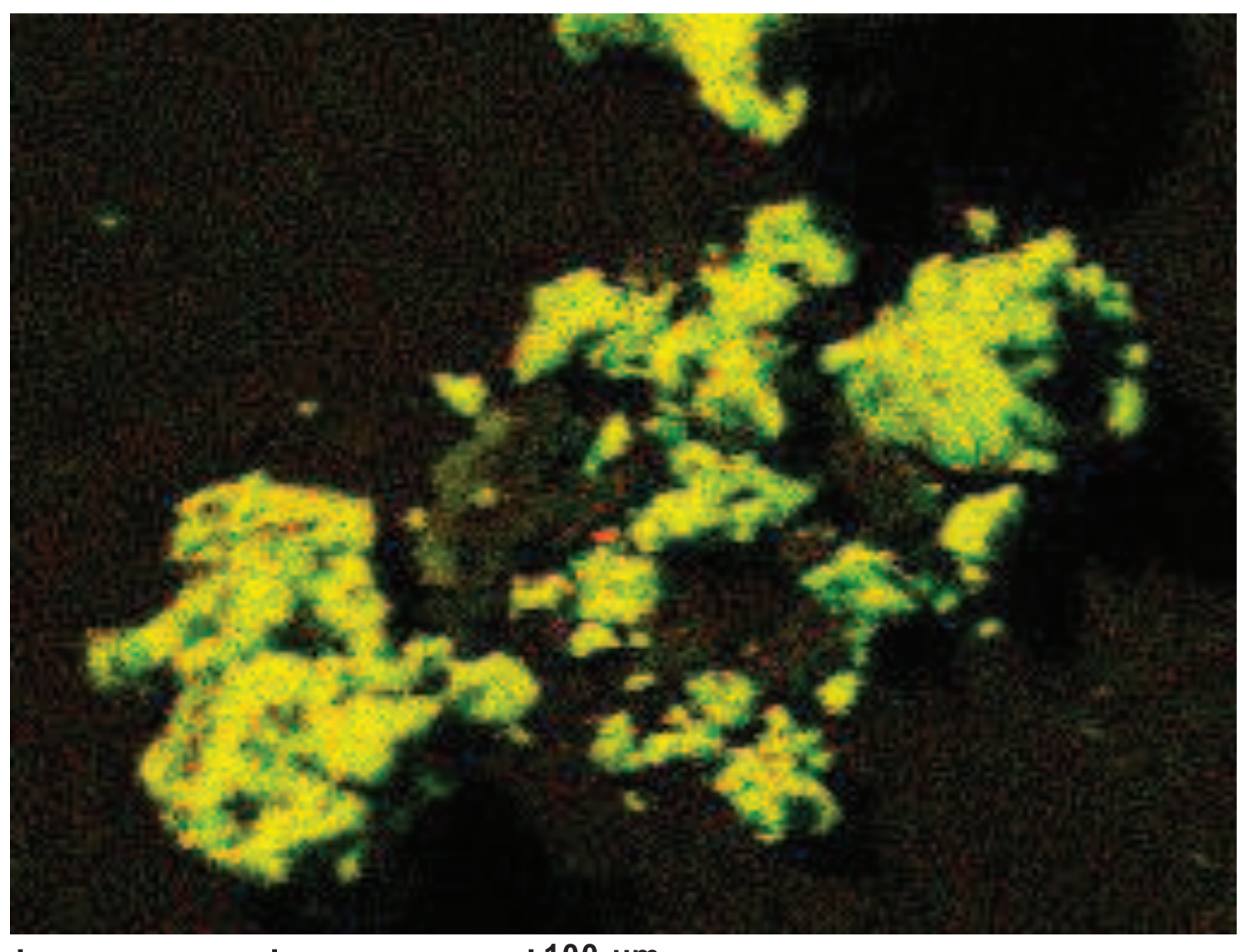

Figure 31: gallium silicate inorganic polymer x500 EDS map overlay of silicon (green) and gallium (red) maps (below). Yellow indicates the green and red are together, and therefore where silicon and gallium are homogeneously distributed. Most of the sample viewed in this image is yellow, with small green areas indicating small silicon rich areas.

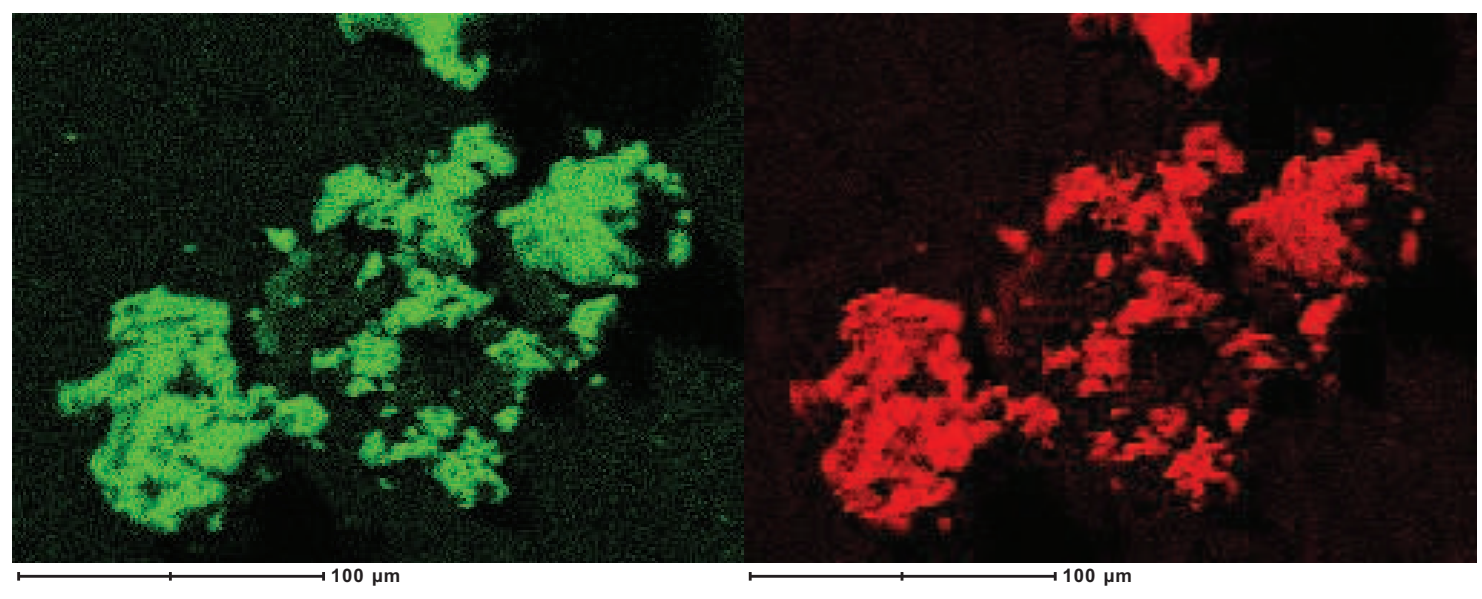

x500 EDS maps of silicon (green, left) and gallium (red, right). 


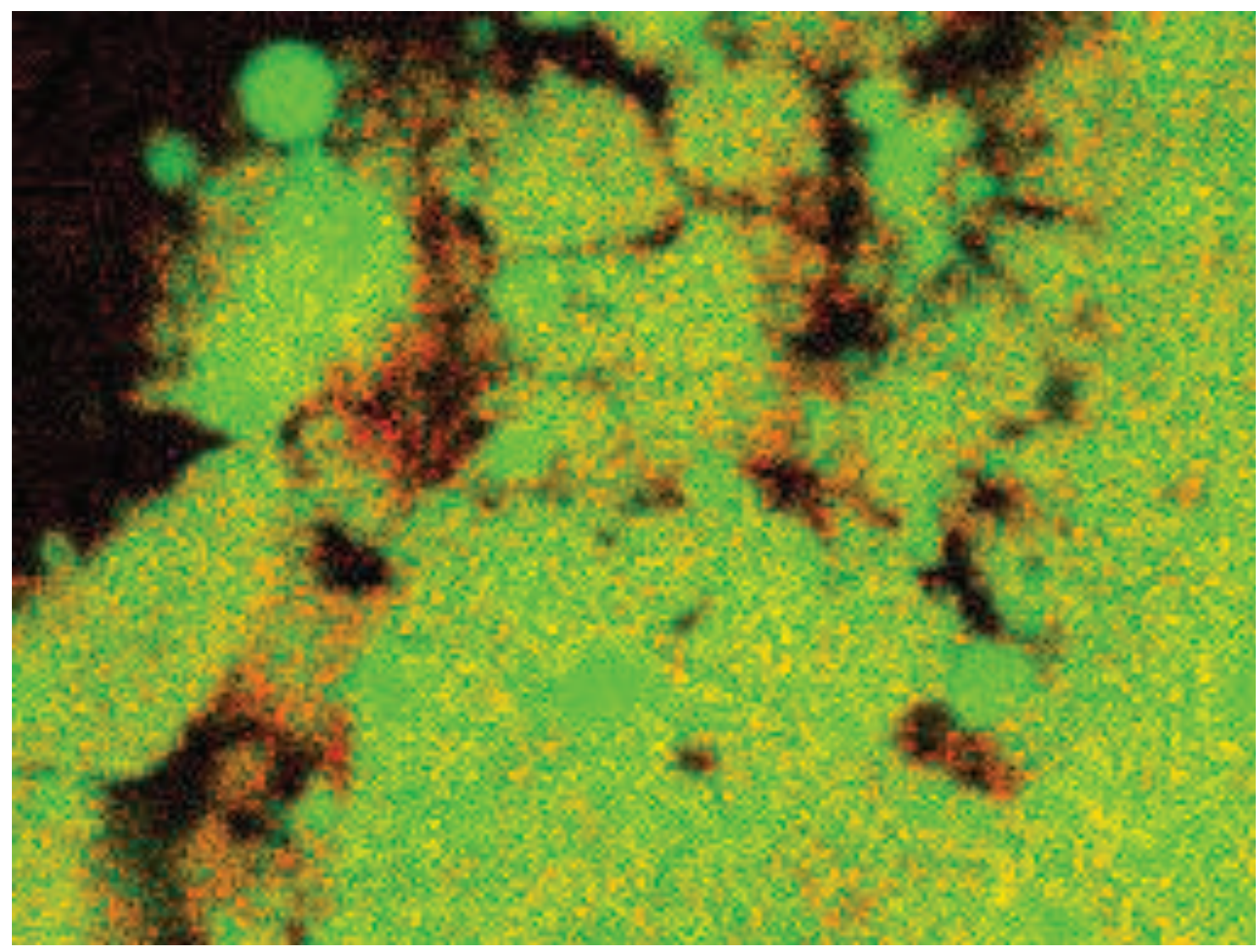

$5.0 \mu \mathrm{m}$

Figure 32: gallium silicate inorganic polymer x7000 EDS map overlay of silicon (green) and gallium (red) maps. Unreacted silica particles can be clearly seen, amongst a homogeneous distribution of silicon and gallium.

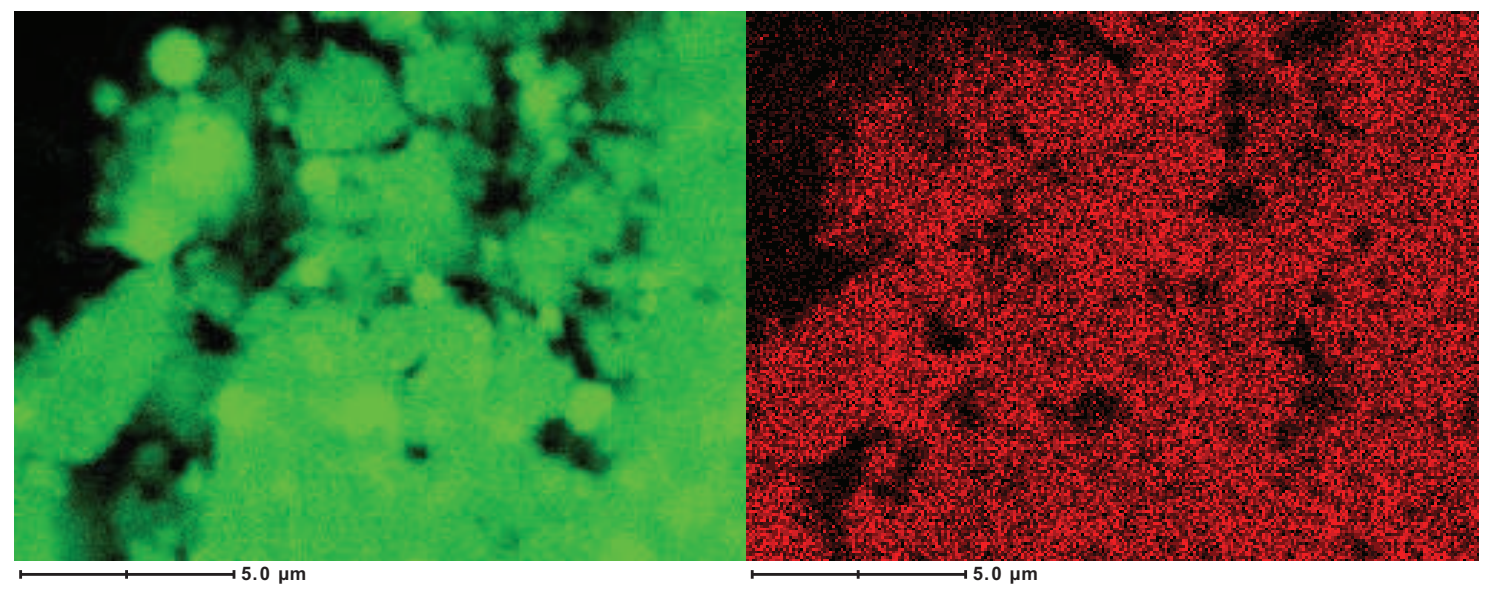

x7000 EDS maps of silicon (green, left) and gallium (red, right). 


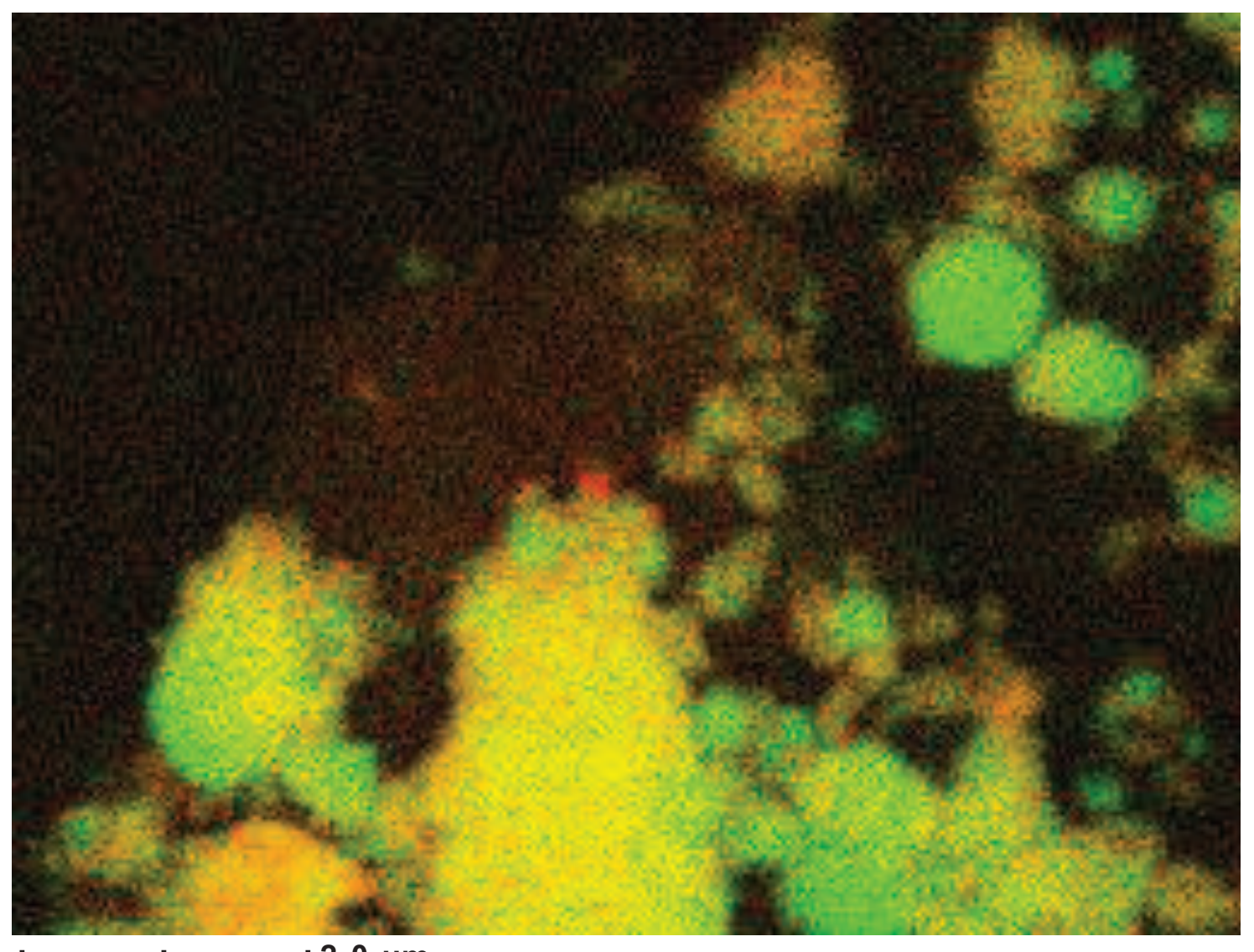

\section{$2.0 \mu \mathrm{m}$}

Figure 33: Gallium silicate inorganic polymer x14000 EDS map overlay of silicon (green) and gallium (red) maps (below).

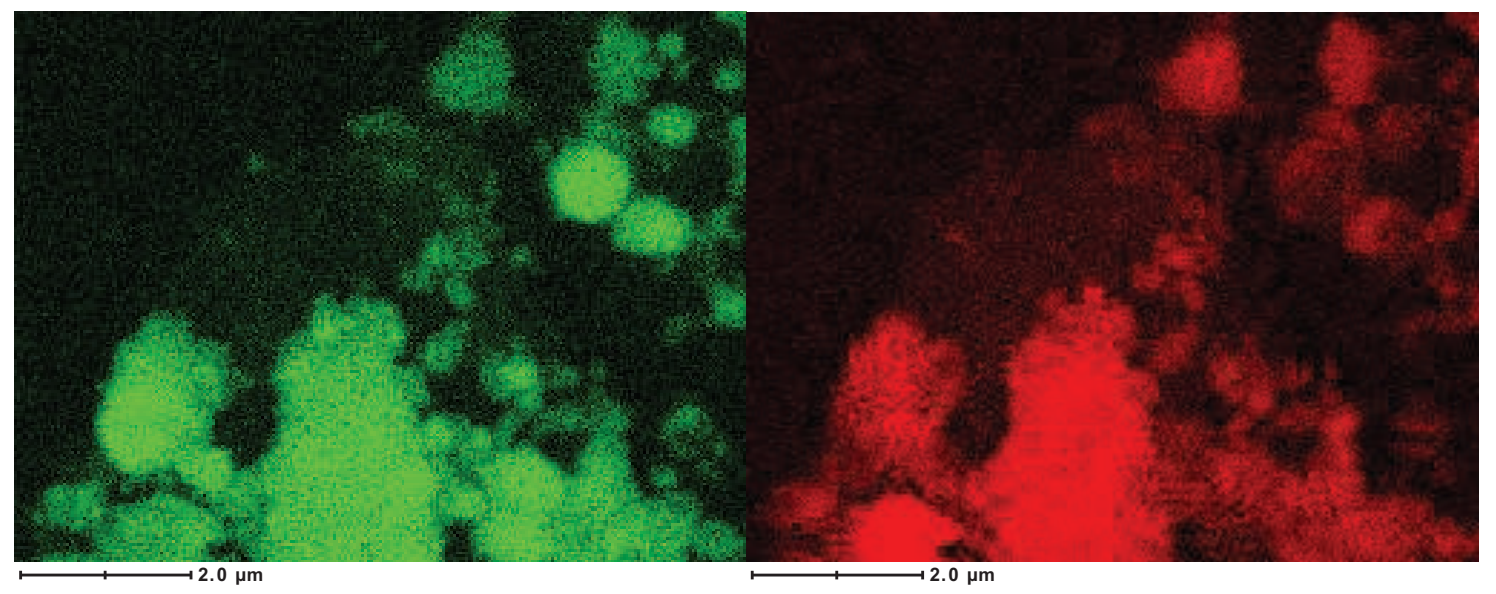

x14000 EDS maps of silicon (green, left) and gallium (red, right). 


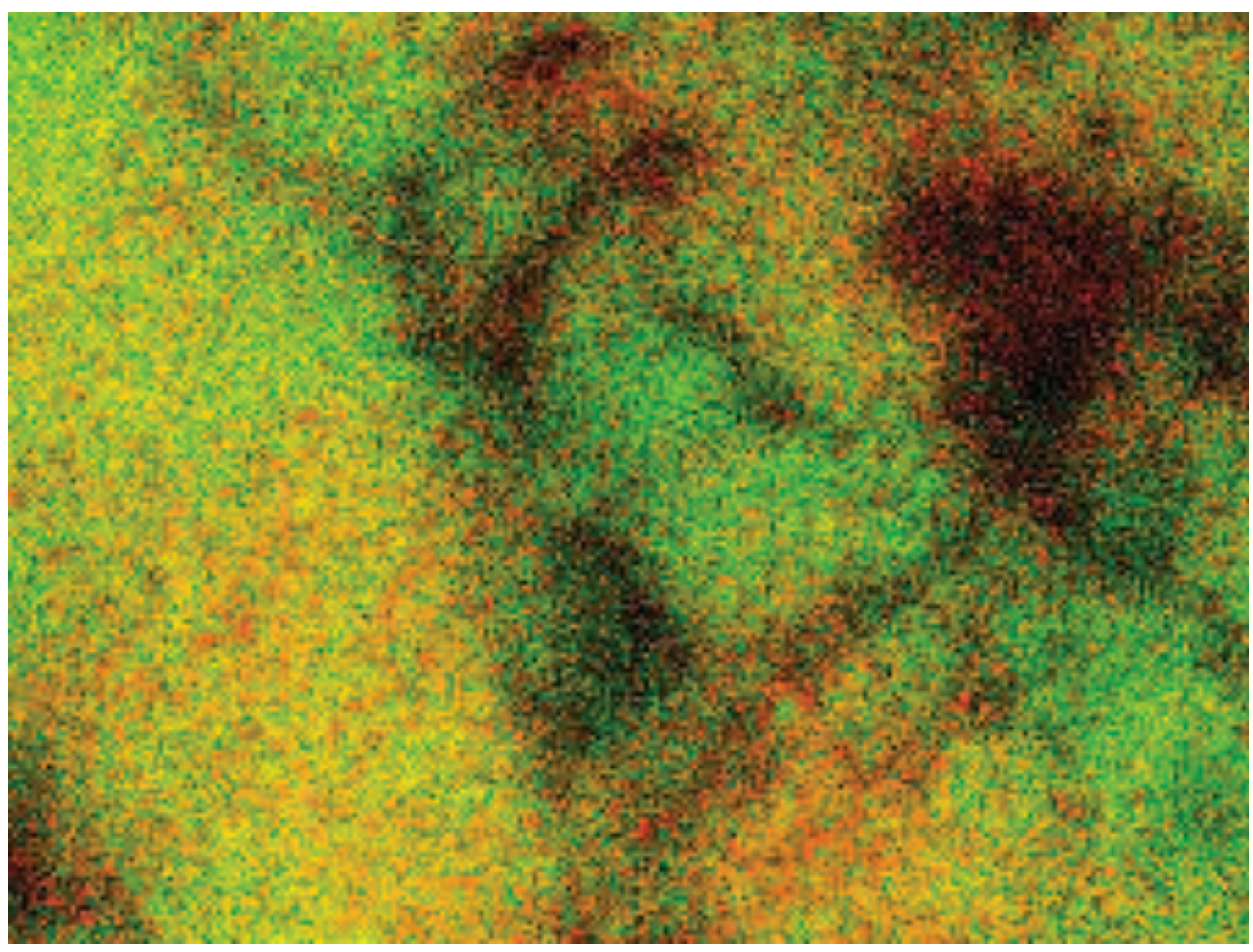

$1.0 \mu \mathrm{m}$

Figure 34: Gallium silicate inorganic polymer x43000 EDS map overlay of silicon (green) and gallium (red) maps (below).

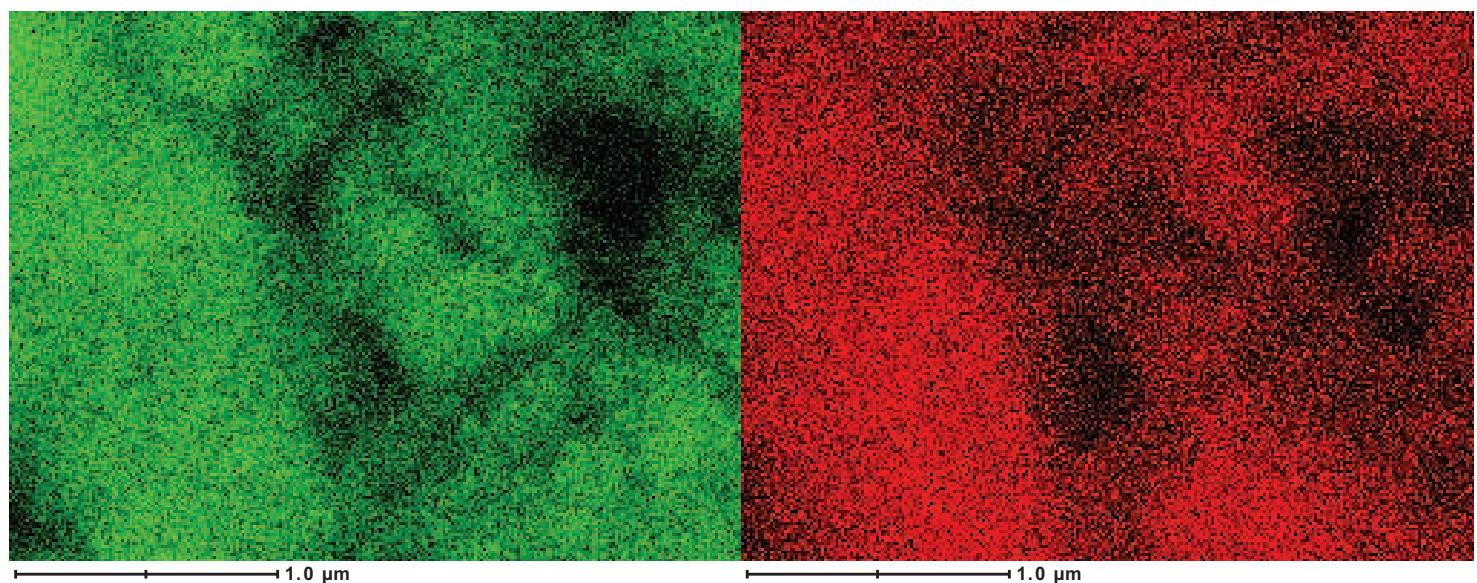

x43000 EDS maps of silicon (green, left) and gallium (red, right).

EDS mapping (figures 31-34) shows gallium, silicon, potassium and oxygen are all associated together at each of the magnification levels, indicating the sample is mostly chemically homogeneous. However the overlay of the gallium and 
silicon maps show some areas where silicon is dominant, but mostly a yellow colour results from overlap of gallium and silicon (either red or green). This is consistent with Si NMR evidence showing unreacted silica particles.

\subsubsection{Structure Conclusion}

The product of the combined solid-state-sol-gel synthesis method for a gallium silicate inorganic polymer is non-crystalline, contains silicon in an inorganic polymer environment, and tetrahedral gallium. These results of XRD, and solidstate silicon and gallium NMR confirm the product of this reaction is a potassium gallium silicate inorganic polymer. Therefore gallium has replaced aluminium in a geopolymer-type material, an objective of the project.

\subsubsection{Addition of small amounts of potassium germanium oxide}

Although attempts at entirely replacing silicon with germanium in the structure failed, it may be possible to incorporate small amounts of germanium into this product during this synthesis.

Potassium germanium oxide synthesised earlier by solid-state reaction was added to a solution of potassium silicate. The ratio of $\mathrm{SiO}_{2}: \mathrm{GeO}_{2}$ ranged from 7.5 - 17.1. For all ratios a thickening was observed as the potassium germanate was added to the potassium silicate solution. This mixed silicate-germanate solution was combined with a solution of potassium gallate to give the ratio $\left(\mathrm{SiO}_{2}+\mathrm{GeO}_{2}\right): \mathrm{Ga}_{2} \mathrm{O}_{3}=7$.

All samples set in an air-tight container at room temperature after 24 hours. The lower ratio samples (those containing more germanate) set with a speckled appearance, with light spots in a pale grey matrix, possibly representing two polymer phases. These samples seemed more brittle when ground, but were not cracked on removal from mould. XRD showed the products were amorphous except for the samples containing the greatest amount of germanate. These showed a small amount of crystalline phase on top of the amorphous hump. The 
crystalline peaks could not be identified with any compound in the powder database, but are likely to arise from unreacted potassium germanate. It may be possible that a crystalline phase is present in all samples but cannot be observed due to its relatively low concentration, or possibly it is too fine grained. The XRD diffraction patterns of samples with higher $\mathrm{SiO}_{2}: \mathrm{GeO}_{2}$ ratios (17.1) are amorphous, and germanium may be incorporated into the amorphous inorganic polymer structure.

Solid-state ${ }^{29} \mathrm{Si}$ MAS NMR of the amorphous sample showed the silicon to be in similar environments to the potassium gallium silicate inorganic polymers (figure 35). Two broad peaks at -84.1 and -107.8 ppm are observed; the former from the inorganic polymer, the later from unreacted $\mathrm{SiO}_{2}$ in the product. The inorganic polymer peak has two shoulders at -81 and -96 ppm.

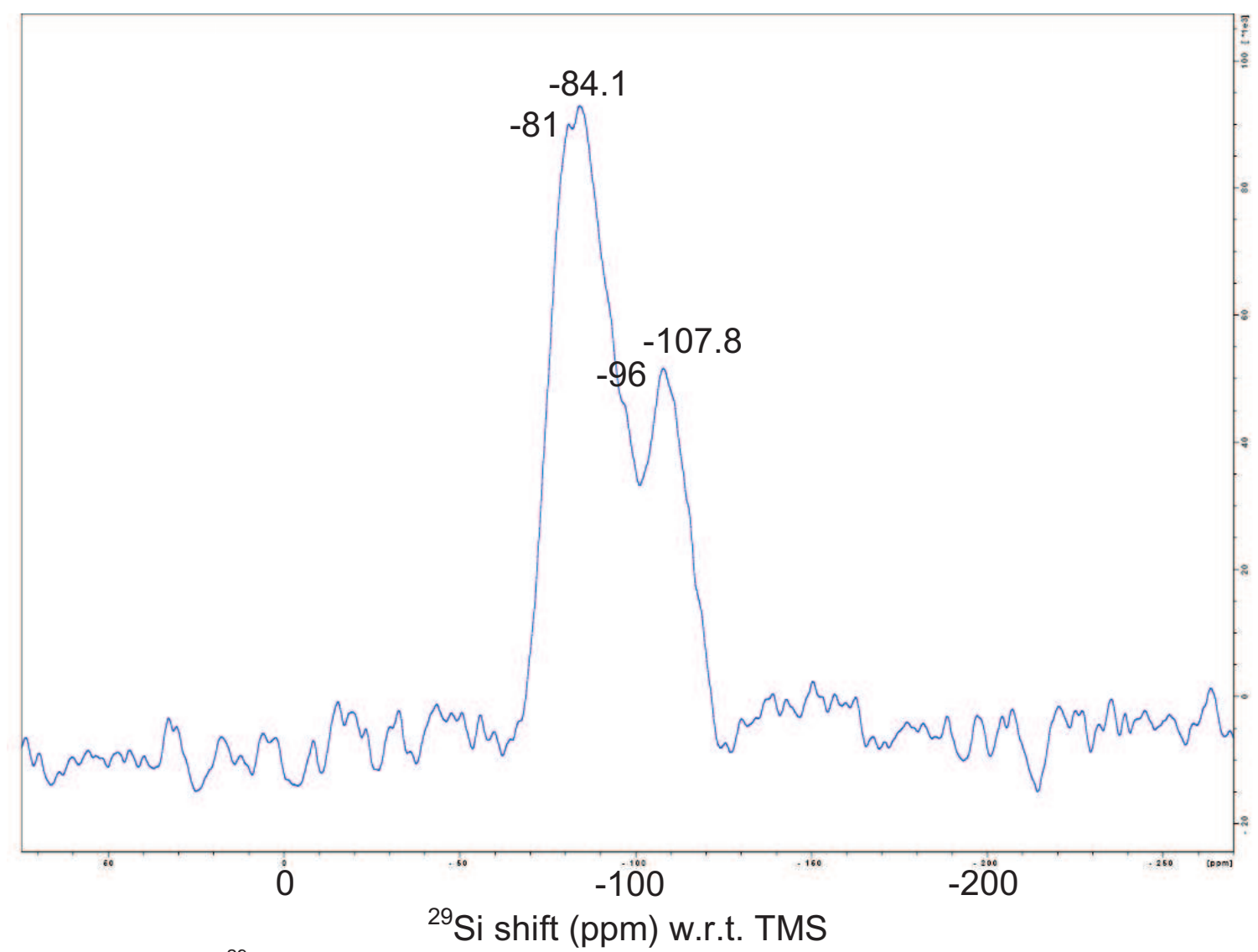

Figure 35: $11.7 \mathrm{~T}^{29} \mathrm{Si}$ MAS NMR spectrum of a gallium silicate inorganic polymer with potassium germanate added. 
Another sample with a lower $\mathrm{SiO}_{2}: \mathrm{GeO}_{2}$ ratio shows broader peaks with values slightly shifted to -87.8 and $-107.9 \mathrm{ppm}$.

\section{Gallium NMR}

Solid-state ${ }^{71} \mathrm{Ga}$ MAS NMR of a gallosilicate inorganic polymer incorporating potassium germanate with a $\mathrm{SiO}_{2}: \mathrm{GeO}_{2}$ ratio of 17.1 shows a broad resonance at approximately $170 \mathrm{ppm}$, indicating no change to the gallium coordination, compared to a gallium silicate inorganic polymer with no germanate added (figure 36).

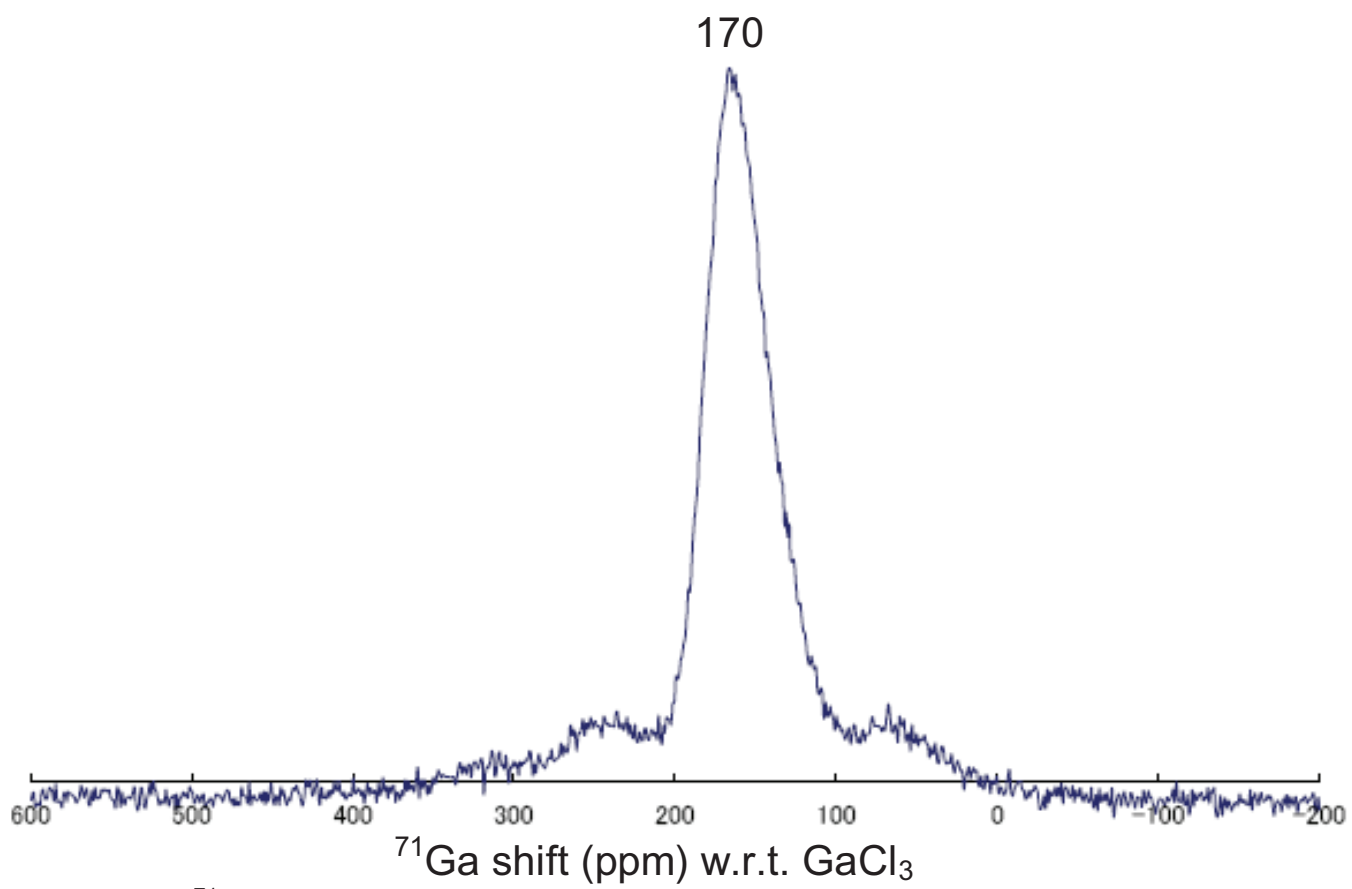

Figure 38: $14.1 \mathrm{~T}^{71} \mathrm{Ga}$ MAS NMR spectrum of a gallium silicate inorganic polymer with potassium germanate added.

Germanium could not be detected in these samples in the EDS detector of the SEM because its concentration is too low. Whether the germanium has been incorporated into the amorphous structure of the inorganic polymer remains inconclusive. 


\subsubsection{Summary}

Gallium silicate inorganic polymers were successfully synthesised. The products set hard, were X-ray amorphous, contained tetrahedral gallium and $\mathrm{Si}(4 \mathrm{Ga})$ and $\mathrm{Si}(3 \mathrm{Ga})$ sites. The product also contained unreacted spherical silica particles detected by ${ }^{29}$ Si MAS NMR and observed using SEM. Silica with a smaller particle size (fumed silica) could not be used to synthesise a gallium silicate inorganic polymer. The optimum ratio of $\mathrm{SiO}_{2}: \mathrm{Ga}_{2} \mathrm{O}_{3}$ to synthesise good products was determined to be 7 . The setting conditions can influence the properties of the product. Setting is best achieved by initially warming the sample in a $50^{\circ} \mathrm{C}$ oven for about 30 minutes with intermittent mixing, then at room temperature in a sealed air-tight container for 48 hours. The low viscosity of the gallium silicate mixture before setting allows thin films of set inorganic polymer to be made. 


\subsection{Synthesis of gallium aluminosilicate inorganic polymers}

Aluminium was also incorporated into the gallium silicate inorganic polymers. This gave the advantage of being able to use ${ }^{27} \mathrm{Al}$ MAS NMR to characterise the products. Unlike ${ }^{71} \mathrm{Ga}$ MAS NMR, ${ }^{27} \mathrm{Al}$ MAS NMR is readily available, and all samples could be tested shortly after synthesis.

The synthesis was tested initially using sodium aluminate, $\mathrm{NaAlO}_{2}$, as the aluminium source. A solution of $\mathrm{NaAlO}_{2}$ was combined with a solution of $\mathrm{KGaO}_{2}$ in a 50:50 molar ratio, and the two were mixed with a potassium silicate solution in a similar process to the gallium silicate inorganic polymer synthesis, using the optimal ratios mentioned earlier. The product set hard and XRD indicated the product was amorphous.

\subsubsection{Synthesis of $\mathrm{KAIO}_{2}$}

Potassium aluminate, $\mathrm{KAIO}_{2}$, was synthesized to allow a gallium aluminosilicate inorganic polymer to be made with potassium as the sole charge-balancing cation. This keeps the resulting system as simple as possible.

$\mathrm{KAIO}_{2}$ was prepared by solid-state reaction of a mixture of gibbsite (aluminium trihydroxide), and potassium carbonate, with a molar composition of $\mathrm{K}_{2} \mathrm{O}: \mathrm{Al}(\mathrm{OH})_{3}$ $=1: 2$. The two powders were ground together under hexane, and then the solvent was allowed to evaporate. The mixture was calcined at $900^{\circ} \mathrm{C}$ for 17 hours. The product was shown by XRD analysis to be $\mathrm{KAIO}_{2}$ (figure 37), and was only very mildly hygroscopic, very much less so than $\mathrm{KGaO}_{2}$. Solid-state ${ }^{27} \mathrm{Al}$ MAS NMR of the product showed a sharp strong peak at $75.2 \mathrm{ppm}$ and a weak broader peak at $62.3 \mathrm{ppm}$ indicating two tetrahedral coordination sites in the product (figure 38 ). There was also a very weak and very broad hump at -5.8 
ppm, which indicated octahedrally coordinated aluminium from unreacted aluminium hydroxide.

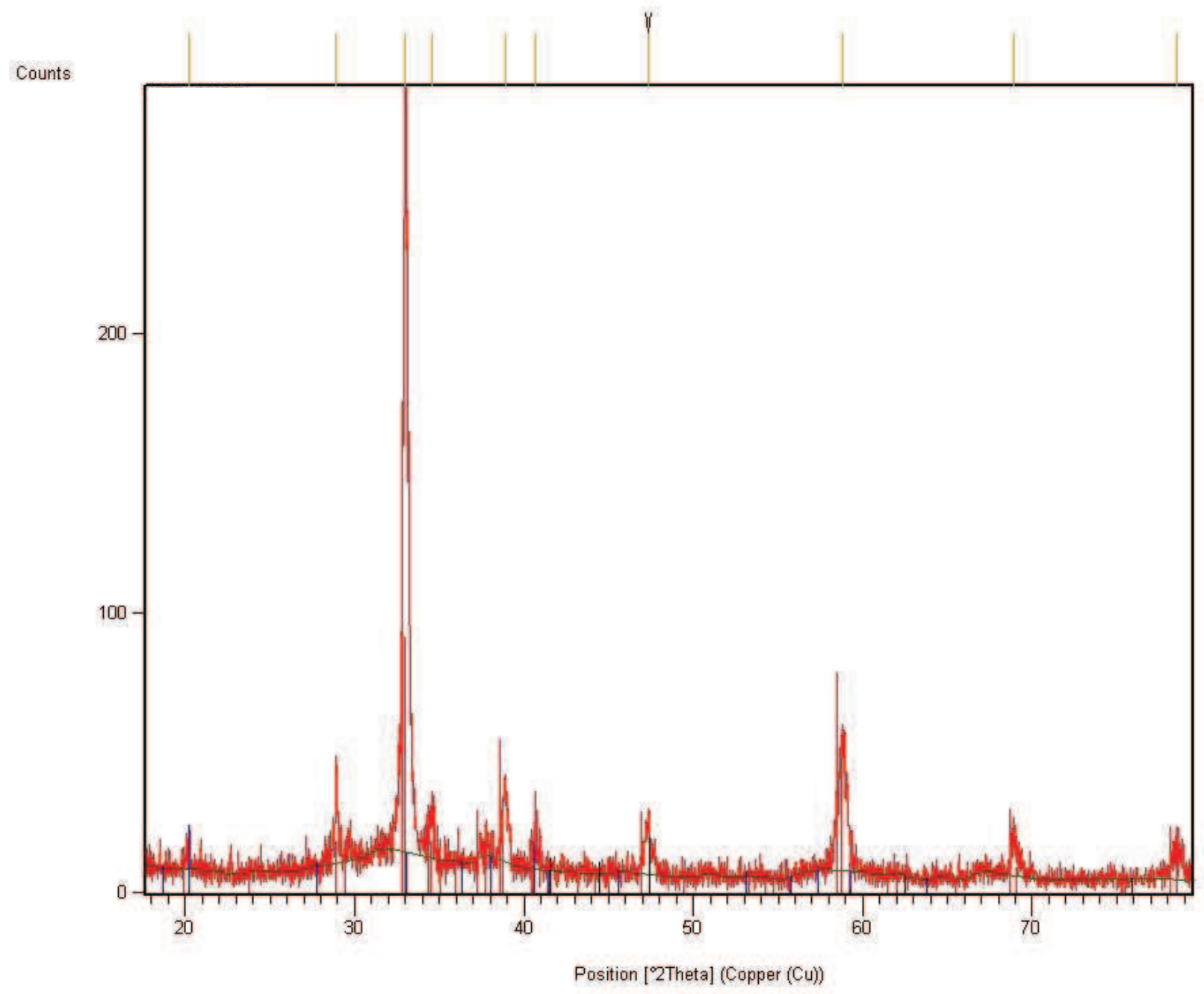

Figure 37: XRD of synthesised $\mathrm{KAIO}_{2}$ (pdf 00-053-0809). 


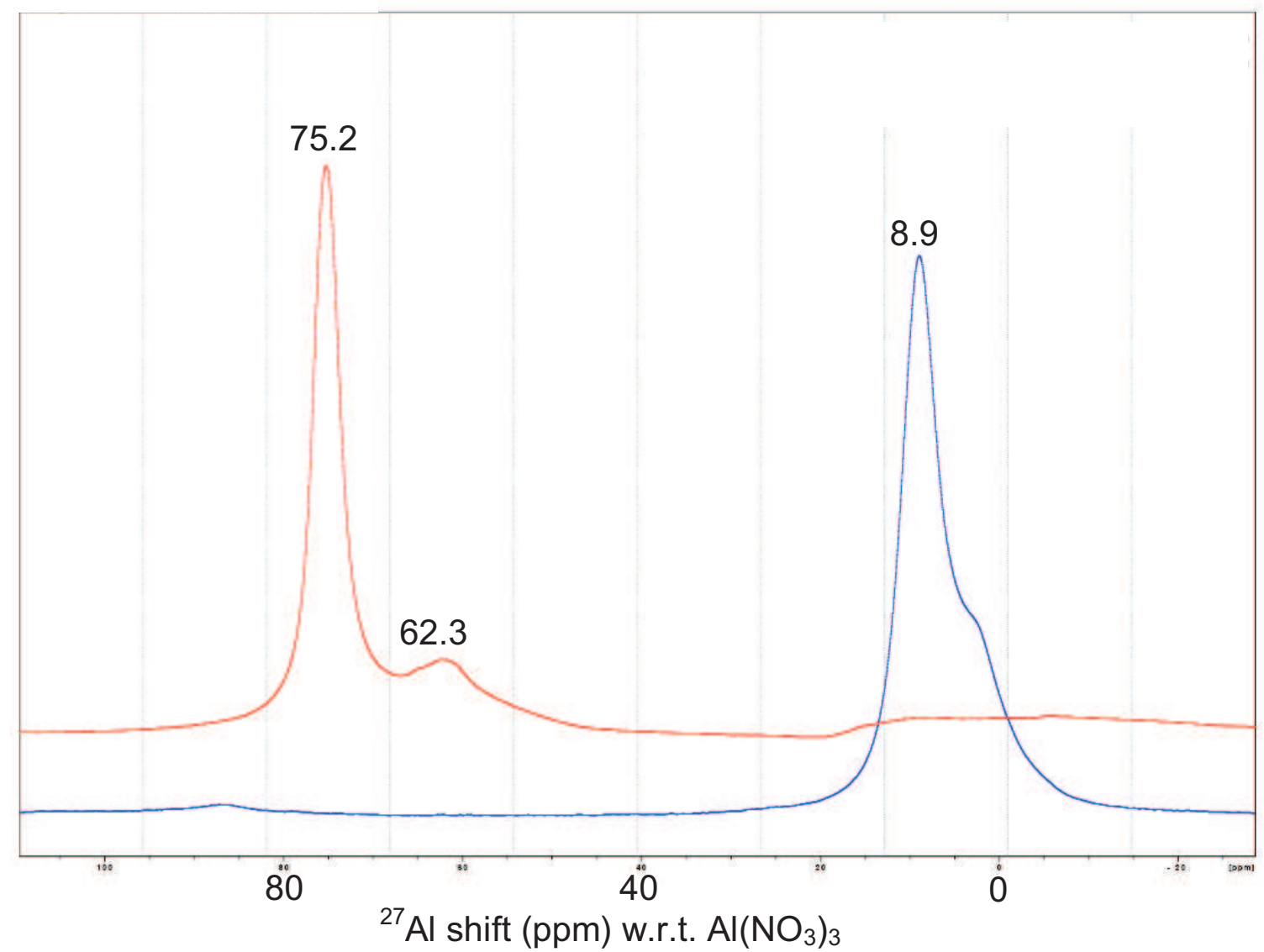

Figure 38: $11.7 \mathrm{~T}^{27} \mathrm{Al}$ MAS NMR spectra of $\mathrm{Al}(\mathrm{OH})_{3}$ starting material (blue) and synthesised $\mathrm{KAIO}_{2}$ product (red).

\subsubsection{Synthesis of gallium aluminosilicate inorganic polymers}

A series of samples were prepared with different molar ratios of $\mathrm{KGaO}_{2}: \mathrm{KAIO}_{2}$.

The ratios were:

90:10

$75: 25$

$50: 50$

$25: 75$

10:90

The optimal molar ratio with the potassium silicate solution was always chosen such that $\mathrm{SiO}_{2}:\left(\mathrm{Ga}_{2} \mathrm{O}_{3}+\mathrm{Al}_{2} \mathrm{O}_{3}\right)=7.0$. The amount of potassium was also unchanged. 
The synthesis method is similar to making gallium silicate inorganic polymers (figure 39).

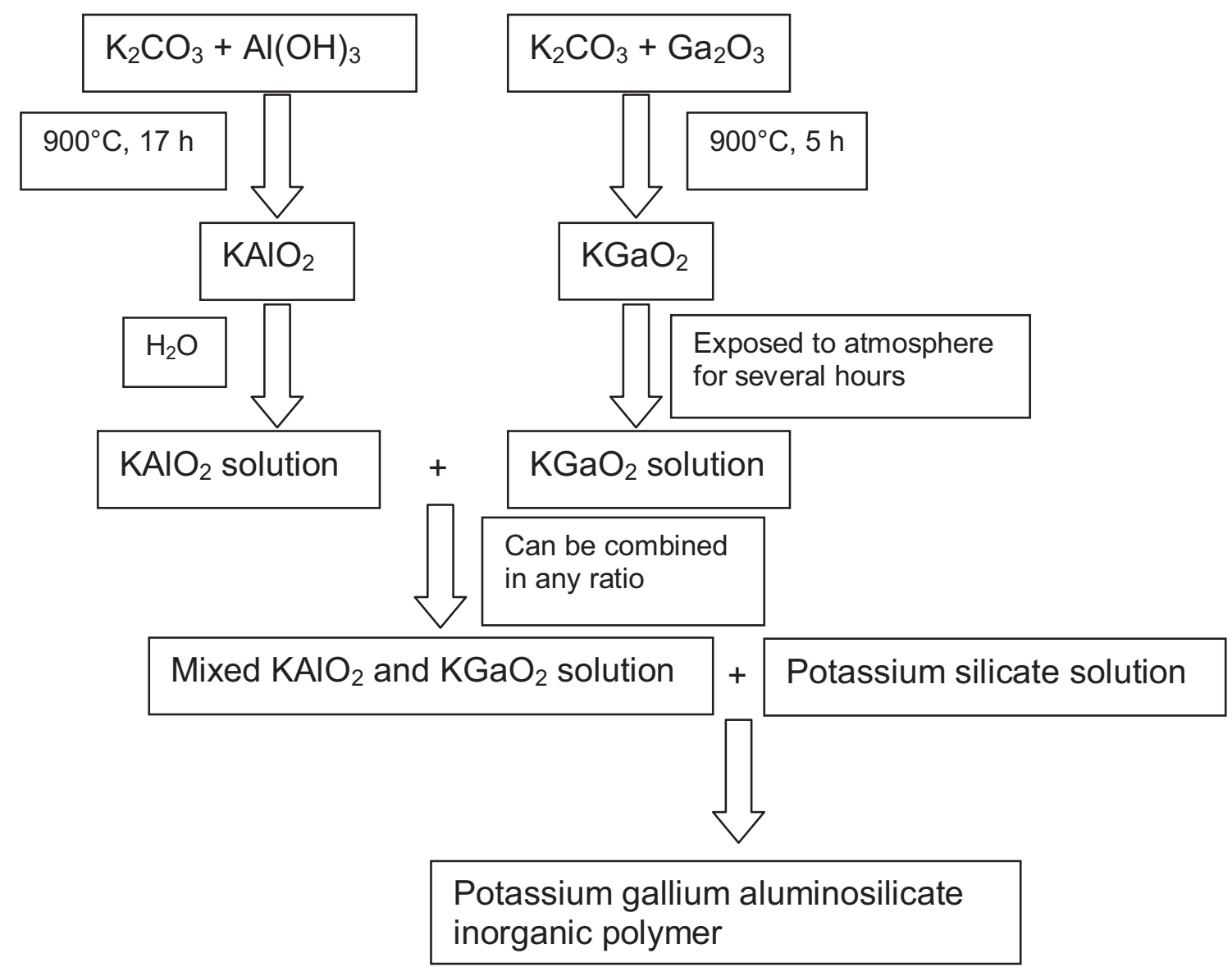

Figure 39: Outline of method for making the gallate-aluminate mixture. This mixture was combined with the potassium silicate solution in the same way as for the synthesis of gallium silicate inorganic polymers (outlined in diagram in section 3.3.15). Samples were set at room temperature in an airtight container for 48 hours.

$\mathrm{KGaO}_{2}$ and $\mathrm{KAIO}_{2}$ were wetted and mixed easily without reacting. When this mixture was combined with the potassium silicate solution the viscosity of the resulting paste was dependant on the proportion of aluminate in the mixture. Increasing the amount of aluminate added caused the viscosity of the resulting mixture to increase. When only $\mathrm{KGaO}_{2}$ or a $90: 10$ ratio of $\mathrm{KGaO}_{2}: \mathrm{KAIO}_{2}$ was used the mixture when combined with silicate was a syrup with relatively low viscosity, whereas when only $\mathrm{KAIO}_{2}$ or $10: 90$ ratio of $\mathrm{KGaO}_{2}: \mathrm{KAIO}_{2}$ was used, 
the resulting mixture was a very thick paste. The other ratios varied between these two extremes, following the same trend.

The increased thickness of the paste when aluminate was added meant that the samples could be set at $50^{\circ} \mathrm{C}$ without layer separation in the product.

\section{Rate of reaction Al v Ga}

The increased viscosity of the mixture as the proportion of aluminate is increased could be related to the relative rates of the geopolymerisation reaction in this system. It appears that the aluminate species react faster than the gallate species with the silicate solution. More aluminate creates a thick paste on addition, whereas more gallate creates a fluid syrup. As a result the aluminium containing samples appear to set faster than the gallium samples. This may affect the resulting compressive strengths of the cured samples. In metakaolin geopolymer systems compressive strength is reduced if samples set too quickly, known as 'flash setting'.[25] While compressive strength measurements were not made for any of the samples synthesised, it could be inferred that samples which took longer to set may have a greater compressive strength. However the effects of incorporation of gallium into inorganic polymer structures on compressive strength are not known, and the sample dimensions were too small for accurate testing of this.

\section{Texture Difference}

Inorganic polymers containing gallium only set with a shiny surface 'glaze'. In contrast when aluminium is incorporated, the surface of set samples is matte, without any sort of glaze. This may relate to the relative viscosities of pure gallium silicate and mixed gallium-aluminium silicate mixtures prior to setting although the glaze is not a layer separation effect. 


\section{Colour Difference}

On grinding, a colour difference was observed between pure gallium silicate inorganic polymers and gallium aluminosilicate inorganic polymers. When aluminium was introduced the colour tended towards a very pale brown, rather than the white pale-grey of the samples without any aluminium. This difference was most obvious in samples that contained a large portion of aluminium, such as $50: 50 \mathrm{Ga}: A l$ samples. This colour variation was only observed when the set monoliths were ground to powder for XRD analysis. All samples were white when set regardless of the amount of aluminium introduced.

\subsubsection{XRD}

The ratio of gallium to aluminium was varied from being predominantly gallium to predominantly aluminium, and all products made by this process set hard and were X-ray amorphous. The XRD patterns of some of the mixed galliumaluminium products were slightly different from the gallium-only samples. A secondary smaller hump appeared around $20^{\circ} 2 \theta$ (figure 40 ) when the ratio of aluminate to gallate is $50: 50$ or greater. The cause of this hump is uncertain. It may be caused by the relative solubilities of the aluminate and the gallate, the former being less soluble. However the products appear to be homogeneous, so the secondary hump is unlikely to be caused by a separate phase.
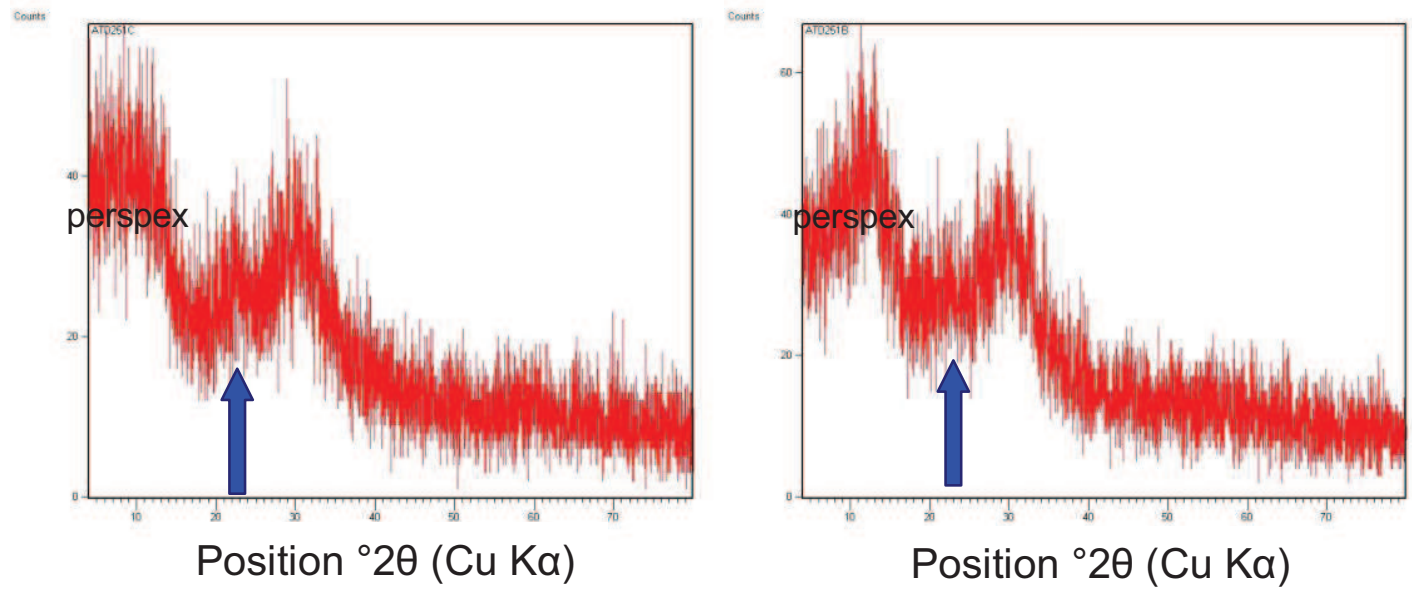

Figure 40: XRD of gallium aluminosilicate inorganic polymers with Ga:Al ratios of 10:90 (left) and 50:50 (right) showing secondary hump (blue arrows). 


\subsubsection{Al NMR}

Solid-state ${ }^{27} \mathrm{Al}$ MAS NMR spectra show that all samples contain aluminium in predominantly tetrahedral coordination, characteristic of an inorganic polymer (figure 41). This is indicated by the broad peak around $58-62 \mathrm{ppm}$. A very weak broad octahedral peak is also observed in most samples between $0-10$ ppm.

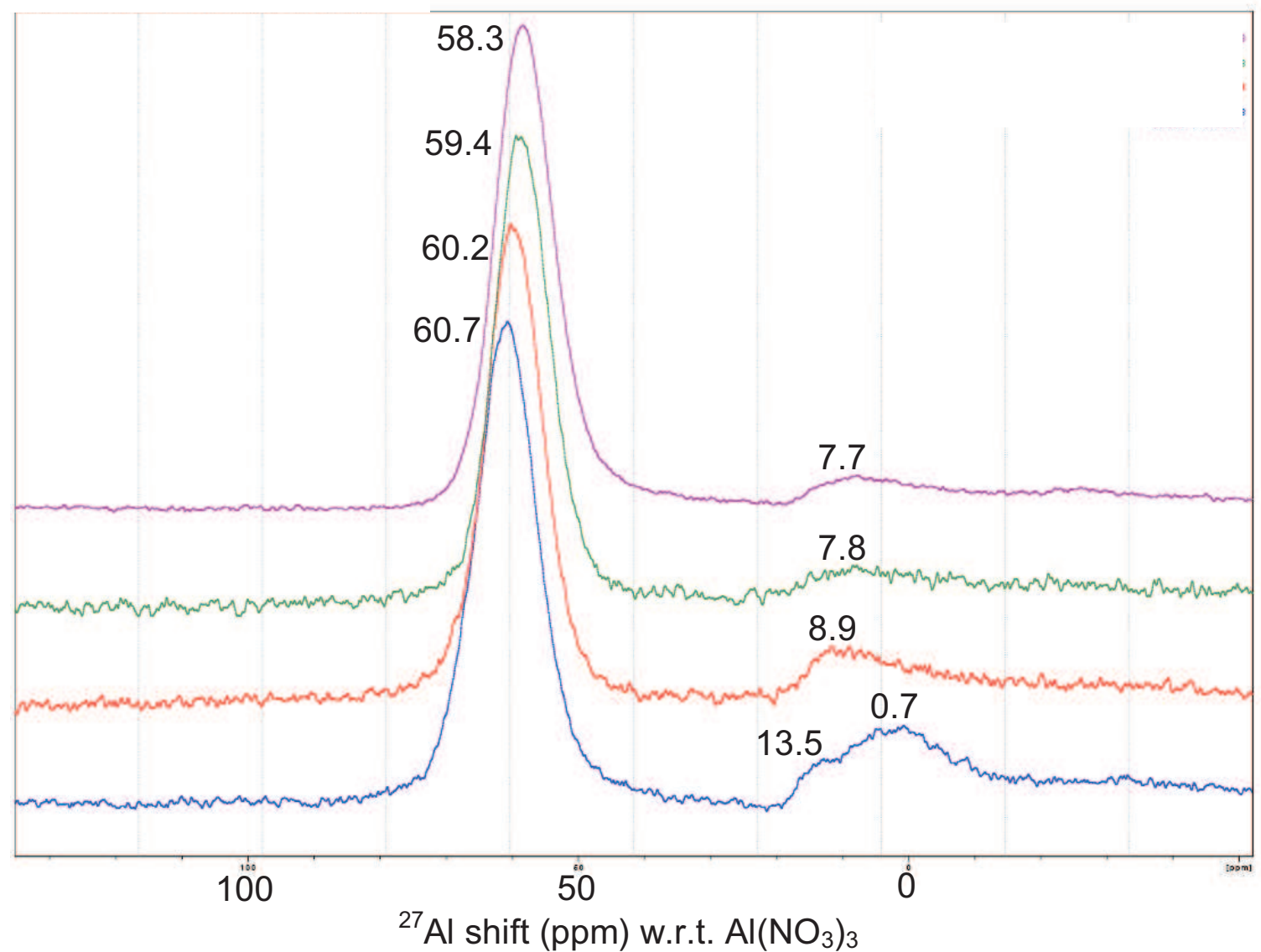

Figure 41: $11.7 \mathrm{~T}^{27} \mathrm{Al}$ MAS NMR spectra of gallium aluminosilicate inorganic polymers with a variety of Ga:Al ratios: 50:50 (blue), 90:10 (red), 75:25 (green), 25:75 (purple).

\subsubsection{Si NMR}

Solid-state ${ }^{29}$ Si MAS NMR spectra for these aluminium containing samples are slightly different to those for the gallium silicate inorganic polymers (figure 42). They still show a resonance at approximately $-109 \mathrm{ppm}$ from unreacted silica particles, but the peaks from silicon in the polymer matrix are more complex. 
The spectra show resonances at approximately -95 and -89 ppm, which are typical of an aluminosilicate inorganic polymer, and also retain the gallium silicate resonances ranging from approximately -80 to $-87 \mathrm{ppm}$. As in the gallium silicate products, the resonance at lower ppm is slightly stronger than the other.

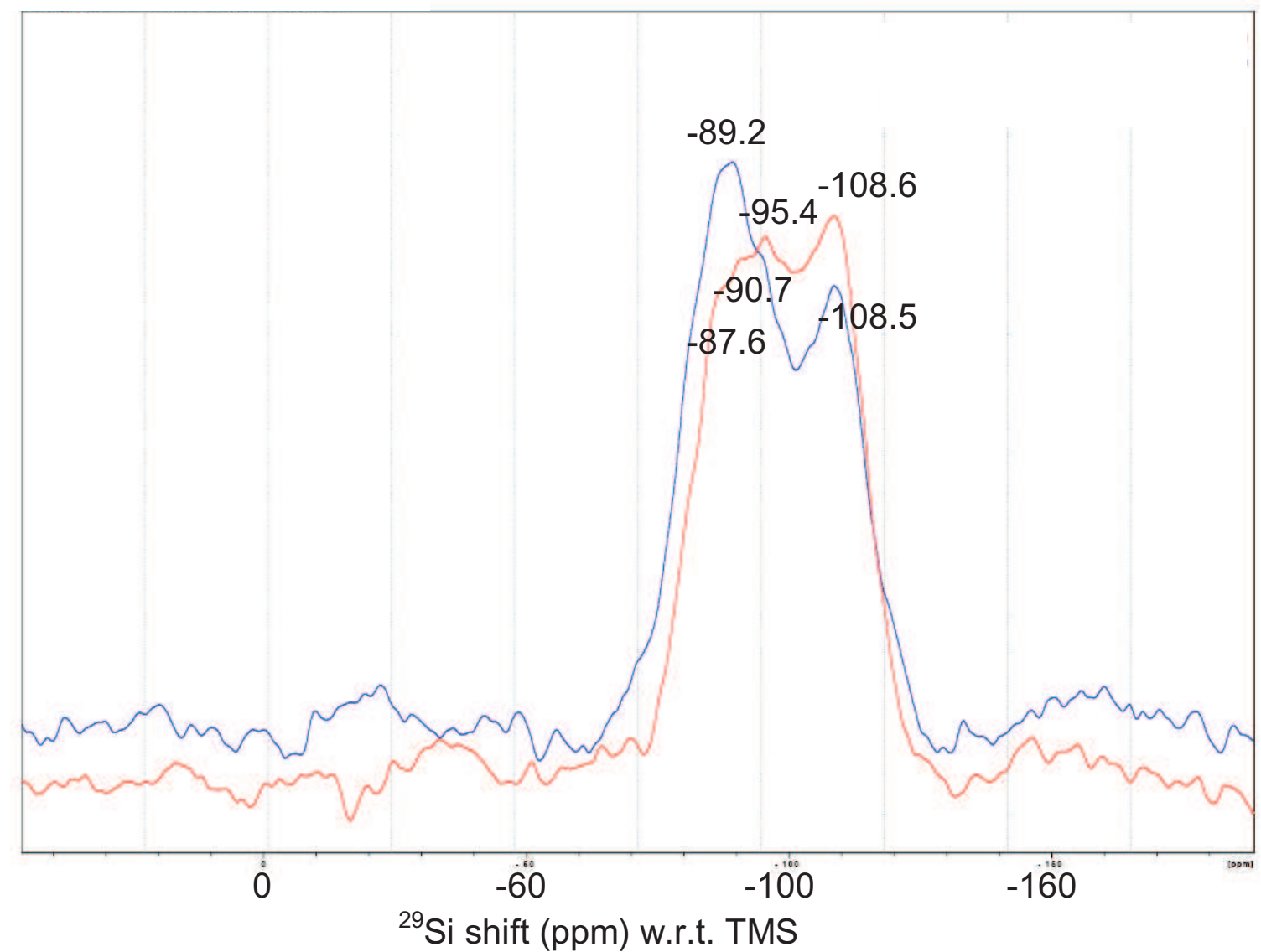

Figure 42: $11.7 \mathrm{~T}^{29} \mathrm{Si}$ MAS NMR spectra comparing gallium aluminosilicate inorganic polymers with Ga:Al of 75:25 (blue) and 25:75 (red).

The resonance at about $-95 \mathrm{ppm}$ is likely to be from $\mathrm{Si}(2 \mathrm{Al})$ sites, and resonances around -89 could be either $\mathrm{Si}(4 \mathrm{Al})$ or $\mathrm{Si}(3 \mathrm{Al})$ sites, but most likely $\mathrm{Si}(3 \mathrm{Al})$. The relative strengths of the different resonances correlate with the ratio of gallium to aluminium in the sample. Samples with more aluminium have stronger $\mathrm{Si}-\mathrm{Al}$ resonances which dominate the inorganic polymer peak, leaving the Si-Ga resonances as weaker shoulders. The opposite is observed if the samples have more gallium than aluminium, and 50:50 Ga:Al samples have all peaks present at approximately the same intensity. 
The presence of so many silicon resonances close together has the effect of broadening the overall peak to such an extent that its separation from the free silica peak is significantly reduced, and in some cases is one very broad hump with smaller sharp peaks and shoulders on the top and sides.

\subsubsection{Gallium NMR}

Solid-state ${ }^{71} \mathrm{Ga}$ MAS NMR of a gallium aluminosilicate inorganic polymer with a gallium to aluminium ratio of 75:25 shows a single broad resonance at $165 \mathrm{ppm}$, indicating the gallium is in a solely tetrahedral environment (figure 43). The incorporation of aluminium does not appear to affect the nature of the gallium sites within the inorganic polymer.

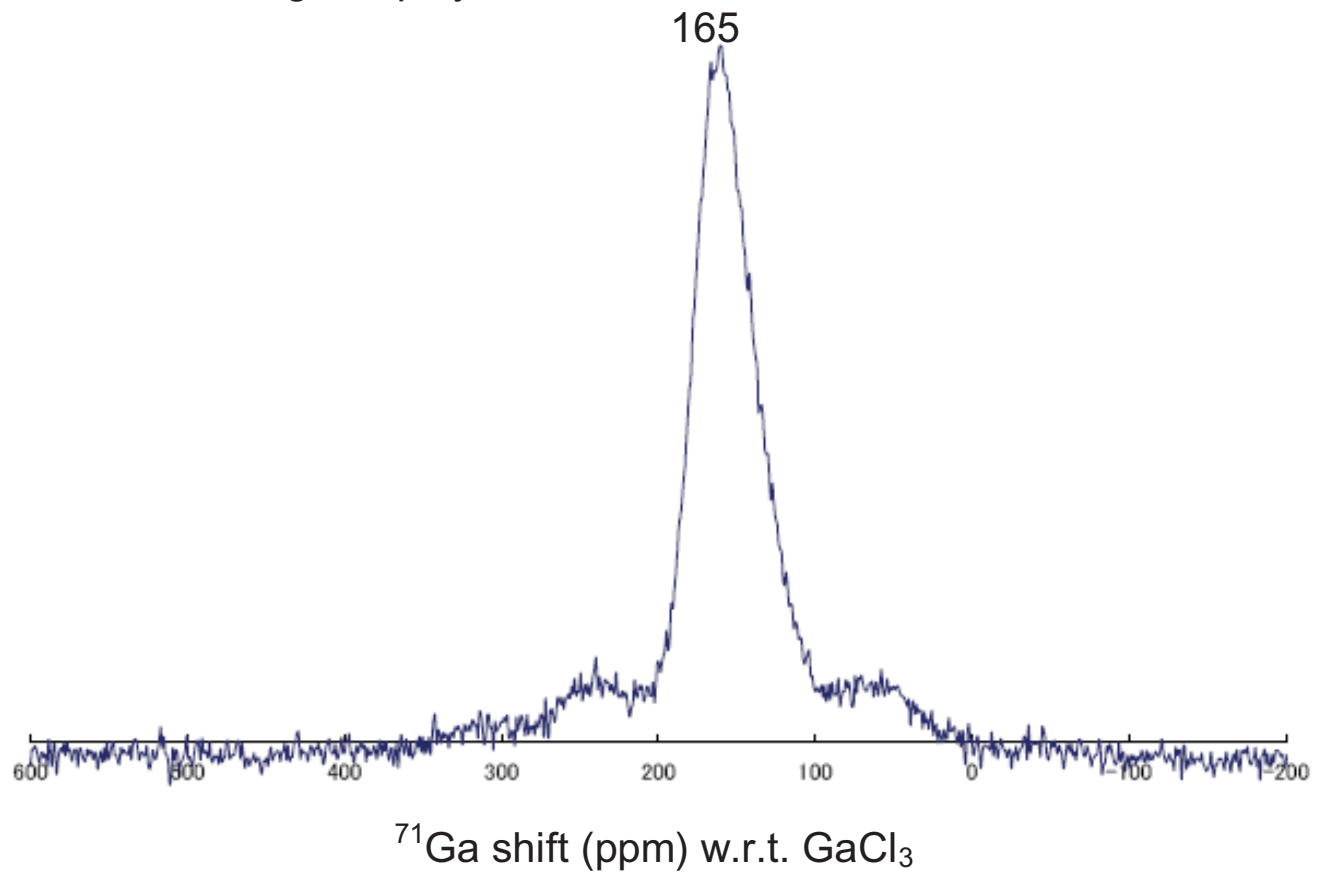

Figure 43: 14.1 $\mathrm{T}^{71} \mathrm{Ga}$ MAS NMR of a gallium aluminosilicate inorganic polymer. 


\subsubsection{Potassium NMR}

Two potassium gallium aluminosilicate inorganic polymers were studied using solid-state ${ }^{39} \mathrm{~K}$ MAS NMR (figure 44). The ratio of gallium and aluminium differed between the samples, being 75:25 for one and 25:75 for the other.

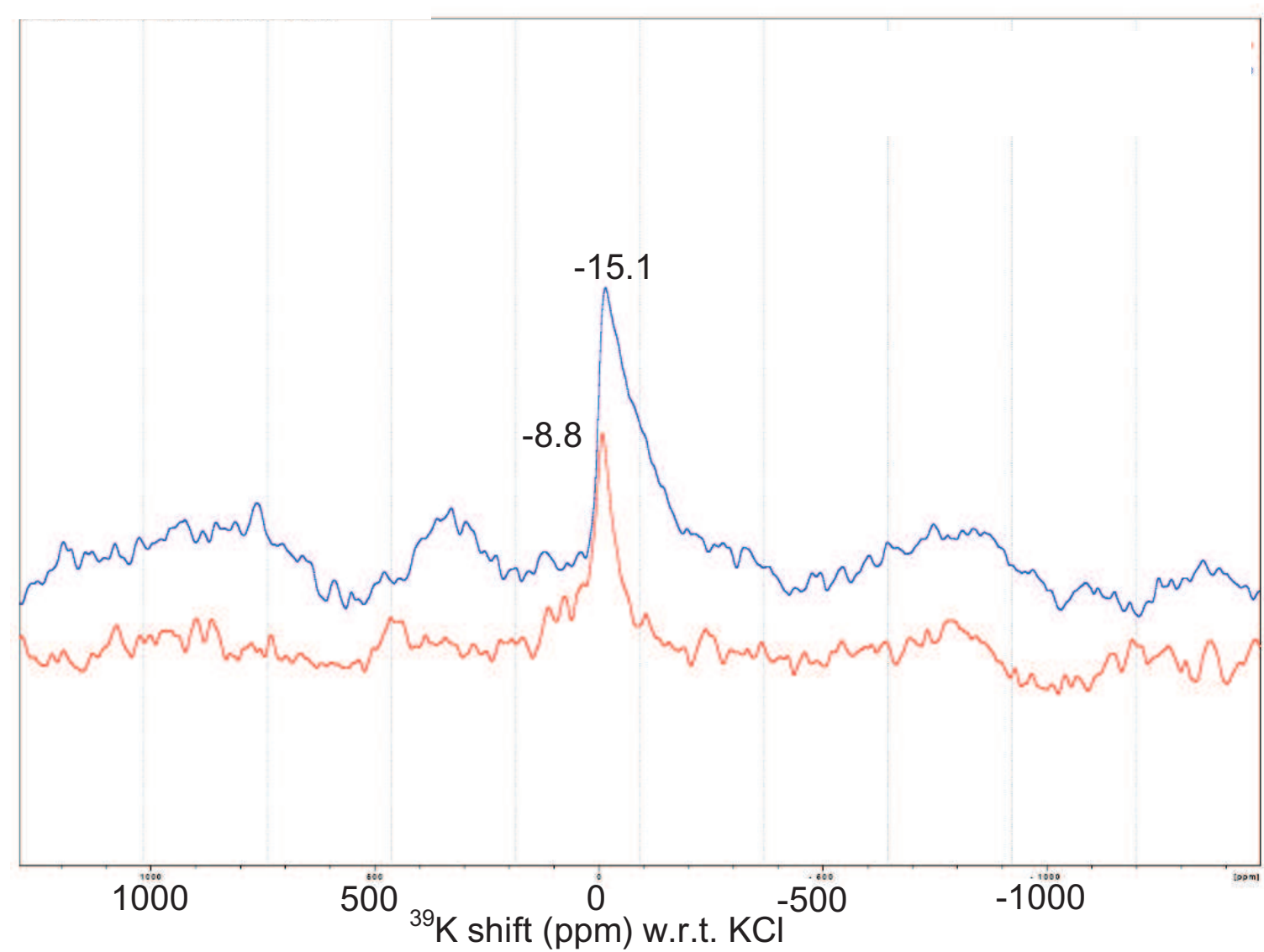

Figure 44: $11.7 \mathrm{~T}^{39} \mathrm{~K}$ NMR spectra showing gallium aluminosilicate inorganic polymers with $\mathrm{Ga}: \mathrm{Al}$ 75:25 (blue) and 25:75 (red).

The 75:25 (higher gallium) sample (blue) showed a single potassium resonance at -15.1 ppm. The 25:75 (higher aluminium) sample (red) also had a single resonance, but shifted to $-8.8 \mathrm{ppm}$, and narrower. It is uncertain whether the $\mathrm{Ga}: \mathrm{Al}$ ratio is causing the position of the resonance to be different between these samples. Only one resonance in each sample indicates a uniform potassium site distributed through the matrix, and the position suggests the potassium is hydrated in both samples. 
A typical potassium geopolymer made from aluminosilicate clay has a potassium resonance at $-47.1 \mathrm{ppm}$.[61] The difference between this and the potassium signal in the inorganic polymers synthesised here may be caused by the different $\mathrm{SiO}_{2}$ ratios.

Potassium NMR experiments are time consuming and more complicated compared to aluminium and silicon, and no other samples were studied using this technique. 


\subsubsection{SEM}

Secondary electron imaging shows the mixed gallium aluminosilicate inorganic polymers look the same as the gallium silicate inorganic polymers shown earlier. Spherical silica particles ranging in size from about 1-3 microns are clearly visible, and are surrounded by the inorganic polymer, which does not have significant structural detail, but shows an array of crushed fragment sizes and shapes (figure 45).

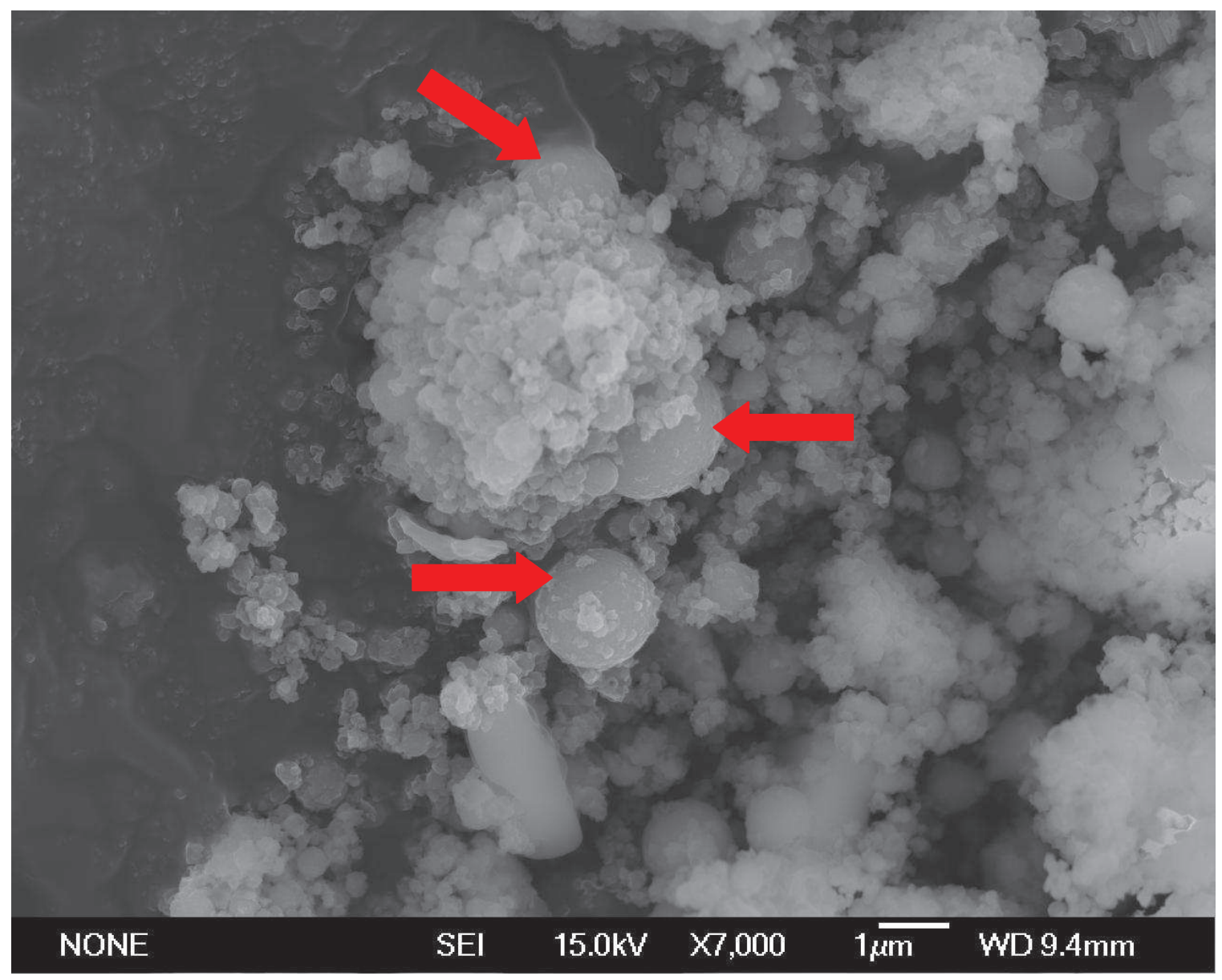

Figure 45: x7000 SEl image of a gallium aluminosilicate inorganic polymer. Spherical silica particles are indicated with red arrows.

Backscatter imaging does not provide much additional information or detail than secondary electron imaging, but does show the brighter inorganic polymer sitting on a darker silica sphere (figure 46), indicating the inorganic polymer has a 
higher average atomic weight than silica, consistent with the incorporation of gallium.

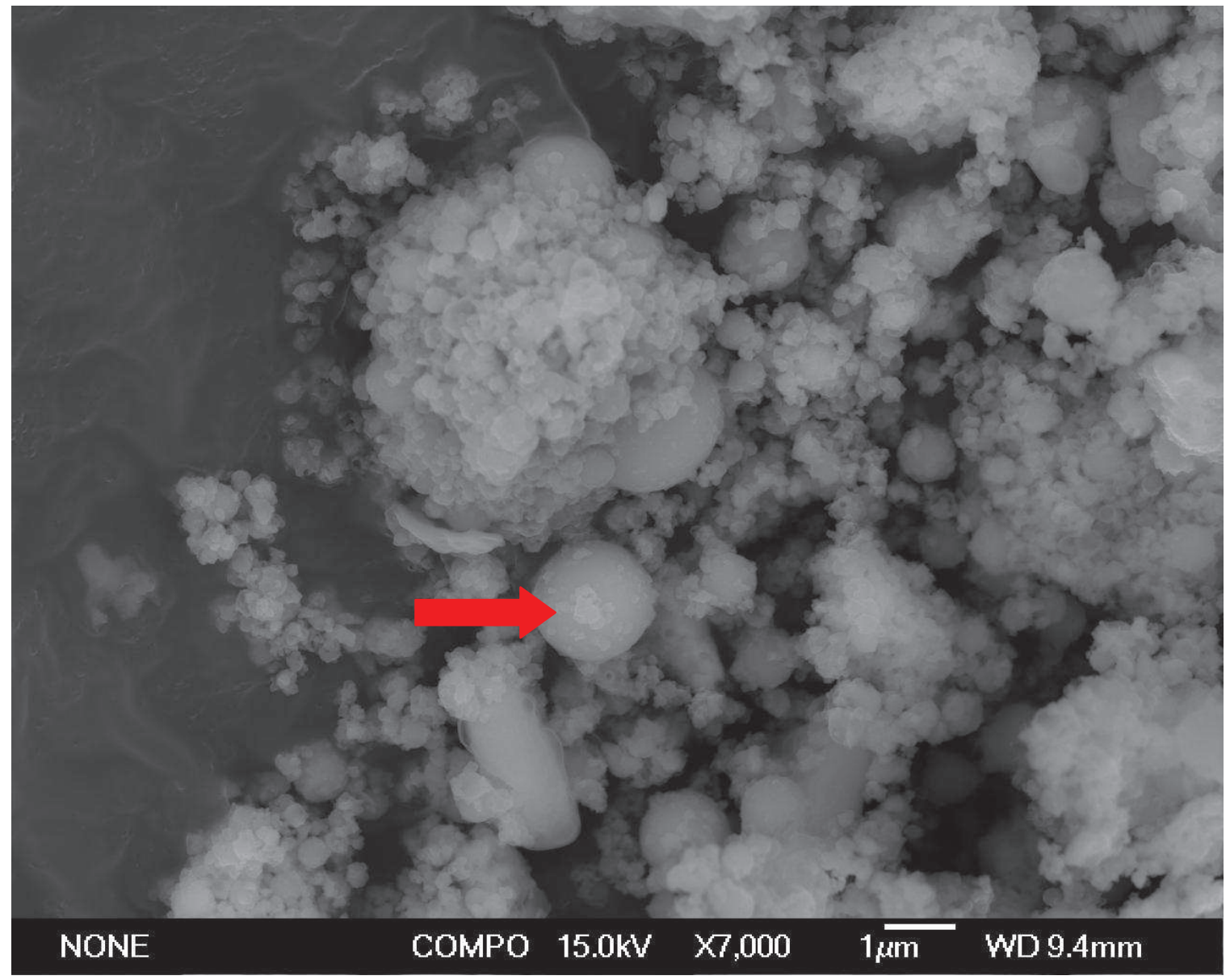

Figure 46: $x 7000$ Backscatter image of the same view as the SEI image above. The red arrow shows the brighter inorganic polymer material sitting on the darker silica particle. 
EDS mapping in backscatter mode shows an even distribution of gallium aluminium and silicon throughout the inorganic polymer (figure 47). It shows the spheres are of silica, and also shows a small number of unreacted aluminate particles, indicated by areas where aluminium is present but silicon and gallium are absent.

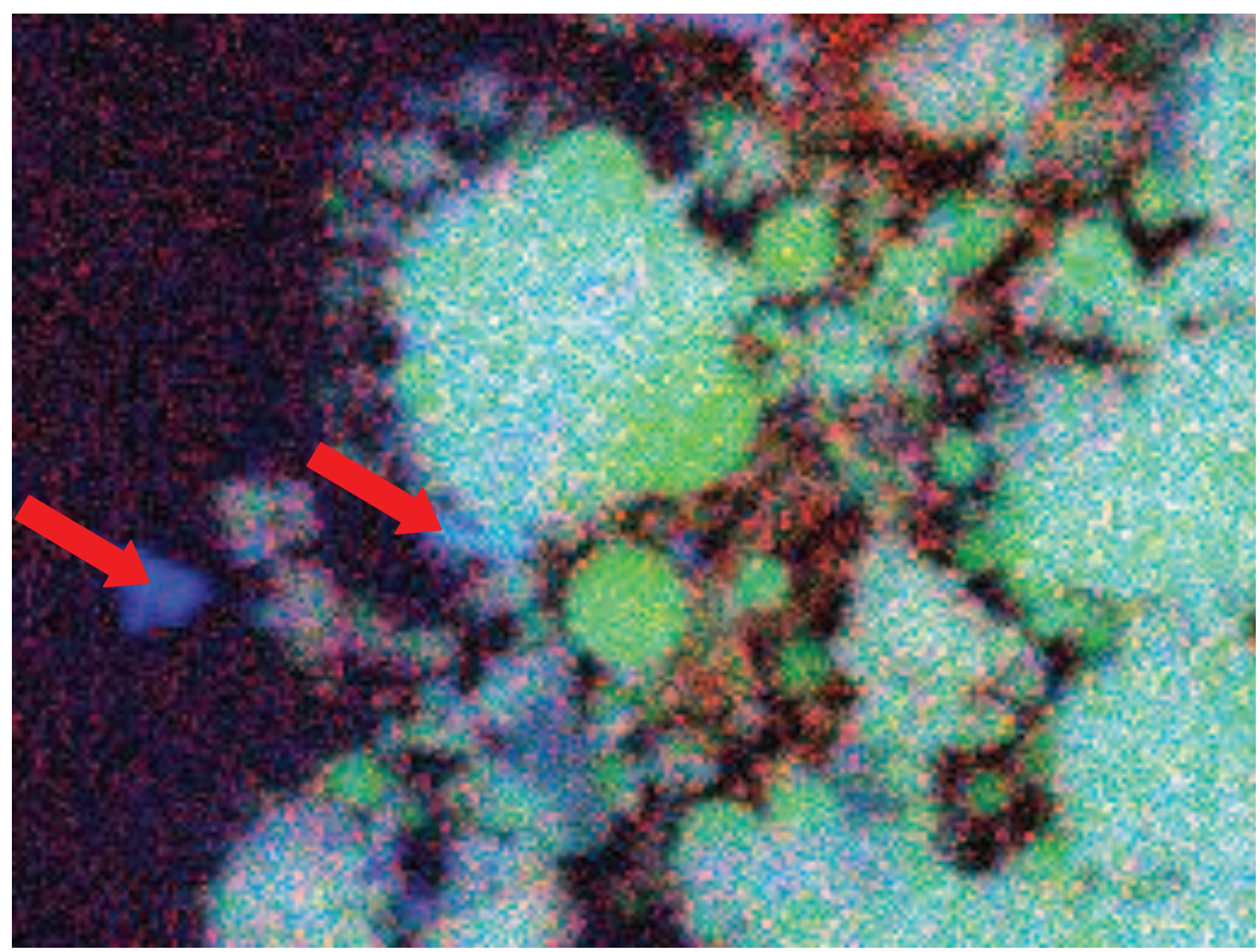

\section{$5.0 \mu \mathrm{m}$}

Figure 47: x7000 EDS map overlay of silicon, gallium and aluminium maps (below). The red arrows show unreacted aluminate particles. The green circles are spherical silica particles.
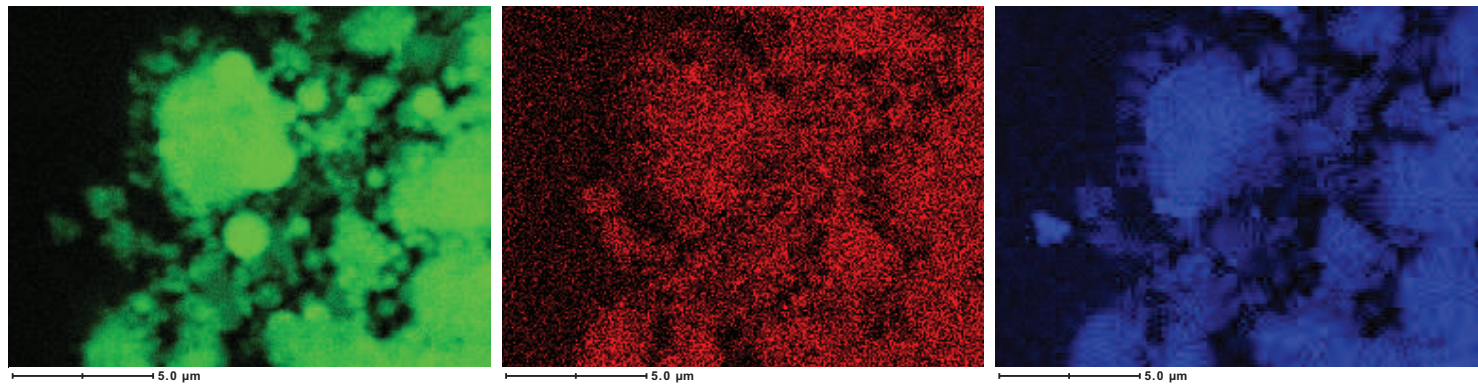

x7000 EDS maps of silicon (green, left), gallium (red, centre) and aluminium (blue, right). 


\subsubsection{Summary}

Gallium aluminosilicate inorganic polymers can be synthesised with any Ga:Al ratio. The aluminium is in predominantly tetrahedral coordination. The presence of aluminium is observed in ${ }^{29} \mathrm{Si} \mathrm{MAS} \mathrm{NMR} \mathrm{with} \mathrm{more} \mathrm{negative} \mathrm{shifts} \mathrm{compared}$ to gallium silicates, and a broader silicate peak made up of several resonances. SEM shows gallium aluminosilicate inorganic polymers have a similar structure to gallium silicate inorganic polymers, with unreacted spherical silica particles randomly dispersed through a chemically homogeneous inorganic polymer matrix. 


\subsection{Sol-gel reaction of aluminate and germanium dioxide}

A series of sol-gel reactions, separate from the earlier described sol-gel reactions involving silica, were carried out using germanium dioxide. The target compounds of these syntheses were aluminogermanate inorganic polymers.

\subsubsection{Synthesis}

$\mathrm{NaAlO}_{2}$ was dissolved in a solution of $\mathrm{KOH}$, and added to wetted $\mathrm{GeO}_{2}$.

On combining, the viscosity of the resulting mixture increased rapidly to a very thick paste, and extra water was added to aid mixing. The paste was pressed into a mould and left to set at $20^{\circ} \mathrm{C}$ in an airtight container for 24 hours.

The molar ratios were:

$\mathrm{GeO}_{2}: \mathrm{Al}_{2} \mathrm{O}_{3}=3.14$

$\mathrm{H}_{2} \mathrm{O}: \mathrm{M}_{2} \mathrm{O}=8.8$

$\mathrm{H}_{2} \mathrm{O}: \mathrm{GeO}_{2}=4.65$

The product set and was subsequently dried in an oven at $50^{\circ} \mathrm{C}$ for several hours, and then ground for XRD analysis.

\subsubsection{Characterisation}

XRD shows the product is amorphous, whereas the starting materials $\mathrm{GeO}_{2}$ and $\mathrm{NaAlO}_{2}$ are both crystalline. In one of several repeats of this experiment a minor peak was found in the XRD diffraction pattern, arising from a small amount of unreacted $\mathrm{GeO}_{2}$ (figure 48).

${ }^{27} \mathrm{Al}$ MAS NMR shows both tetrahedral (64.8-66.6 ppm) and octahedral (7.6-8.4 ppm) aluminium sites are present, and both peaks are approximately equal in size, but vary in relative height between different samples (figure 49). 
This experiment was repeated without the addition of $\mathrm{KOH}$. Instead, wetted $\mathrm{GeO}_{2}$ was mixed into a solution of $\mathrm{NaAlO}_{2}$. XRD analysis showed that not all the $\mathrm{GeO}_{2}$ reacted, but the aluminate had (figure 48). The ${ }^{27} \mathrm{Al}$ MAS NMR spectrum was similar to that of the original experiment, but the octahedral peak was stronger and the tetrahedral peak was shifted slightly to $70.5 \mathrm{ppm}$. It appears that extra $\mathrm{KOH}$ must be added to this system for complete reaction and for an amorphous product to form. 

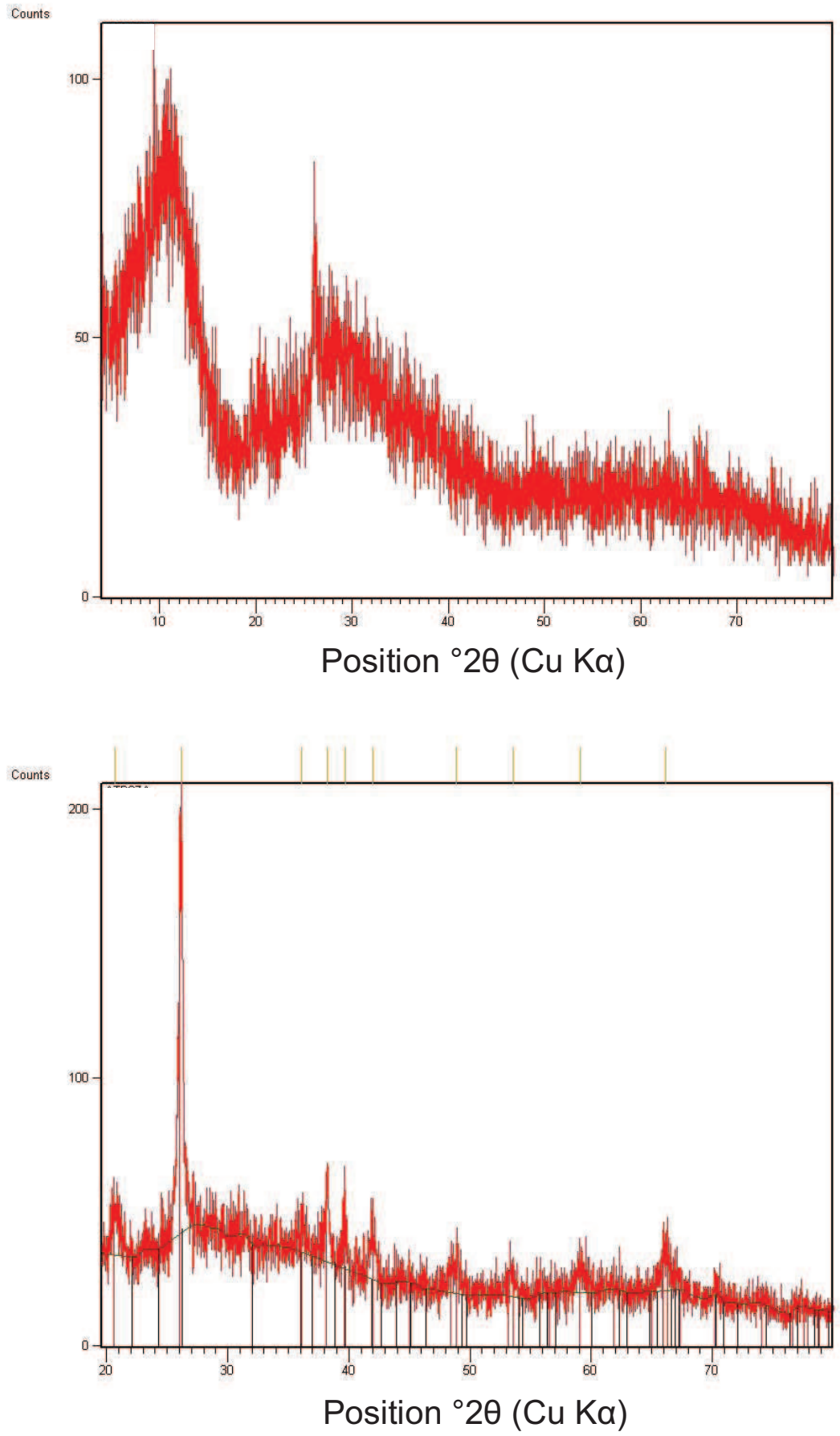

Figure 48: XRD diffraction patterns showing the amorphous product when $\mathrm{KOH}$ is added to the $\mathrm{NaAlO}_{2}$ and $\mathrm{GeO}_{2}$ mixture (top) and product with unreacted $\mathrm{GeO}_{2}$ (pdf 00-004-0497) when $\mathrm{KOH}$ is not added (bottom). The small peak in the top picture is some unreacted $\mathrm{GeO}_{2}$. 


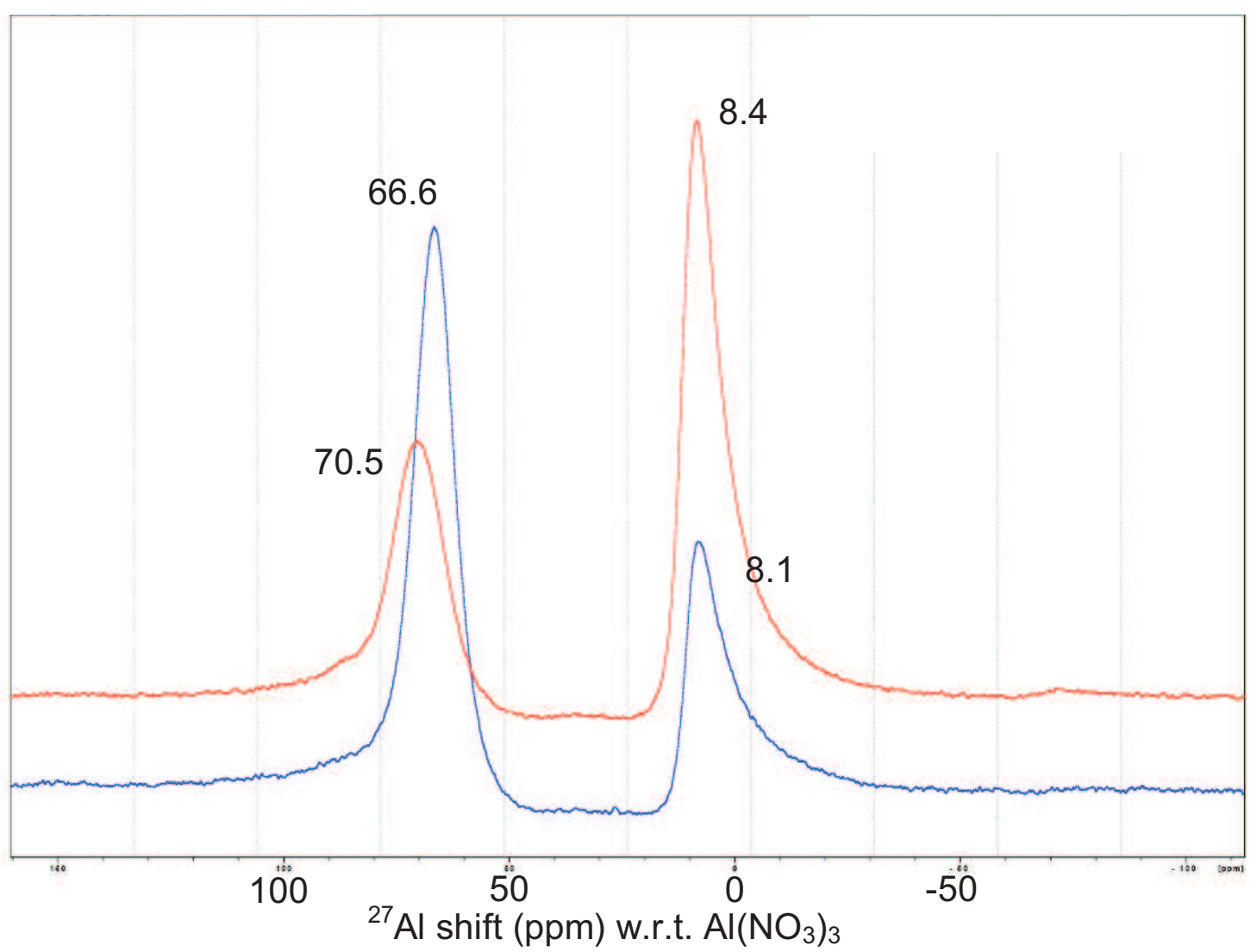

Figure 49: $11.7 \mathrm{~T}^{27} \mathrm{Al}$ MAS NMR spectra of products of the sol-gel $\mathrm{NaAlO}_{2}$ and $\mathrm{GeO}_{2}$ reaction with added $\mathrm{KOH}$ (blue) and sample without $\mathrm{KOH}$ added (red).

While the product of this reaction is an amorphous insoluble white solid, it is weak and brittle, and is probably not analogous in structure to an aluminosilicate geopolymer. Further experiments would be required to study this reaction and products further; however the inability to do ${ }^{73} \mathrm{Ge}$ NMR is a barrier to structural determination.

\subsection{3 $\mathrm{KAIO}_{2}$ vs $\mathrm{NaAlO}_{2}$}

When $\mathrm{KAIO}_{2}$ replaced $\mathrm{NaAlO}_{2}$ in a similar experiment, the observed behaviour of the reactants during processing was the same as with $\mathrm{NaAlO}_{2}$, but when left to set in the oven at $50^{\circ} \mathrm{C}$ the sample disc had shrunk after 24 hours (figure 50). This may have been caused by evaporation of water from the sample during setting. This sample shrinkage was not observed in any other syntheses. 


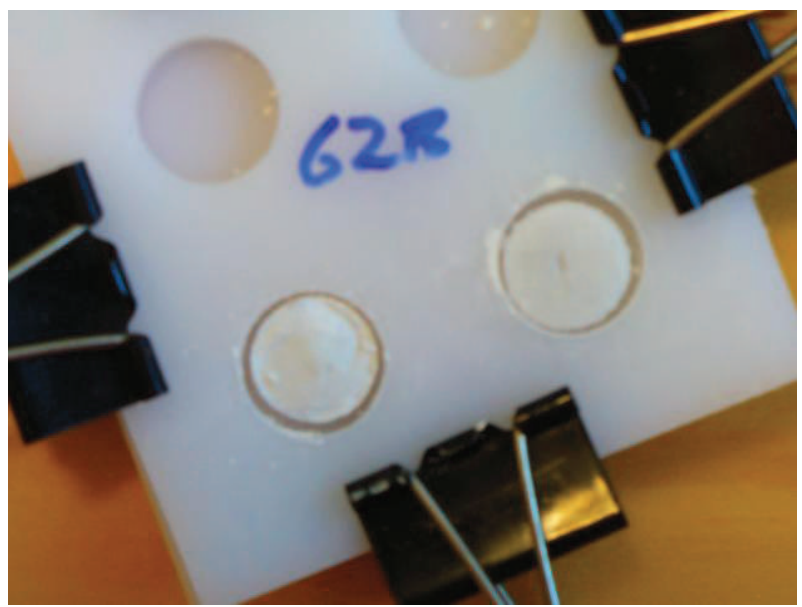

Figure 50: Photo showing sample shrinkage after setting in $50^{\circ} \mathrm{C}$ oven.

XRD showed the product to contain two crystalline phases (figure 51), with a good match to a potassium aluminium germanium oxide hydrate, $\mathrm{K}(\mathrm{Al} \mathrm{Ge}$ $\left.\mathrm{O}_{4}\right)\left(\mathrm{H}_{2} \mathrm{O}\right.$ ) (pdf 01-070-3740), and a potassium germanium oxide hydrate, $\mathrm{K}_{3} \mathrm{HGe}_{2} \mathrm{O}_{6}\left(\mathrm{H}_{2} \mathrm{O}\right)$ (pdf 00-029-1001). 


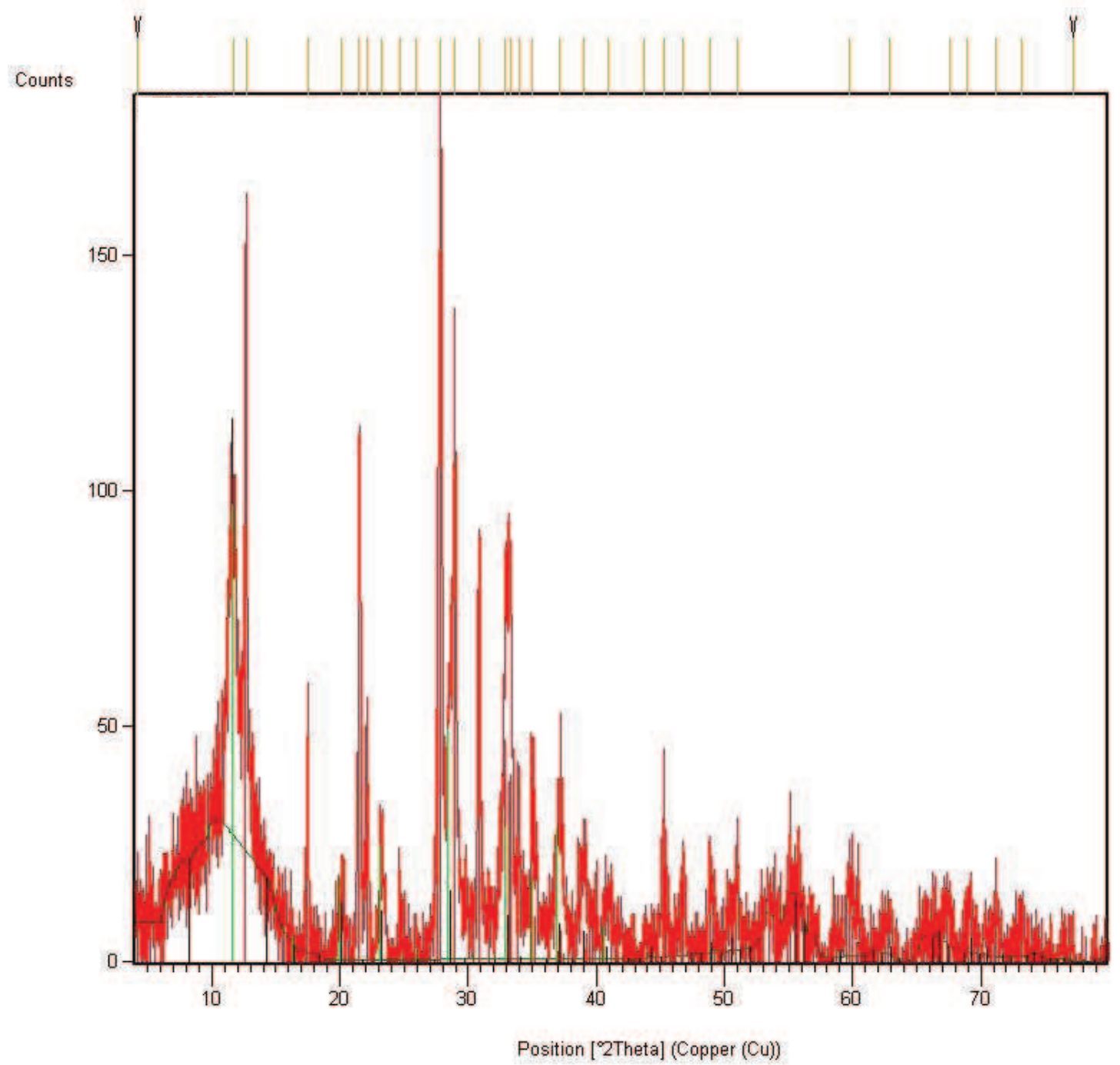

Figure 51: XRD of the crystalline products of the reaction of $\mathrm{KAIO}_{2}$ and $\mathrm{GeO}_{2}$. The crystalline products are $\mathrm{K}\left(\mathrm{Al} \mathrm{Ge} \mathrm{O}_{4}\right)\left(\mathrm{H}_{2} \mathrm{O}\right)$ (pdf 01-070-3740), and $\mathrm{K}_{3} \mathrm{HGe}_{2} \mathrm{O}_{6}\left(\mathrm{H}_{2} \mathrm{O}\right)$ (pdf 00-029-1001).

$\mathrm{KAIO}_{2}$ and $\mathrm{GeO}_{2}$ were not observed in the product. Because the product was crystalline and the shrinkage was anomalous, it was not further investigated. Solid-state ${ }^{27} \mathrm{Al}$ MAS NMR showed a different result for this product compared to the sodium aluminate reaction (figure 52). A strong sharp resonance at $66.7 \mathrm{ppm}$ indicates the aluminium is almost exclusively tetrahedral with good ordering of sites, consistent with the crystalline nature of the product, and that the $\mathrm{KAIO}_{2}$ 
(peak at $75.2 \mathrm{ppm}$ ) has completely disappeared. A very small broad octahedral resonance at $7.8 \mathrm{ppm}$ is also observed.

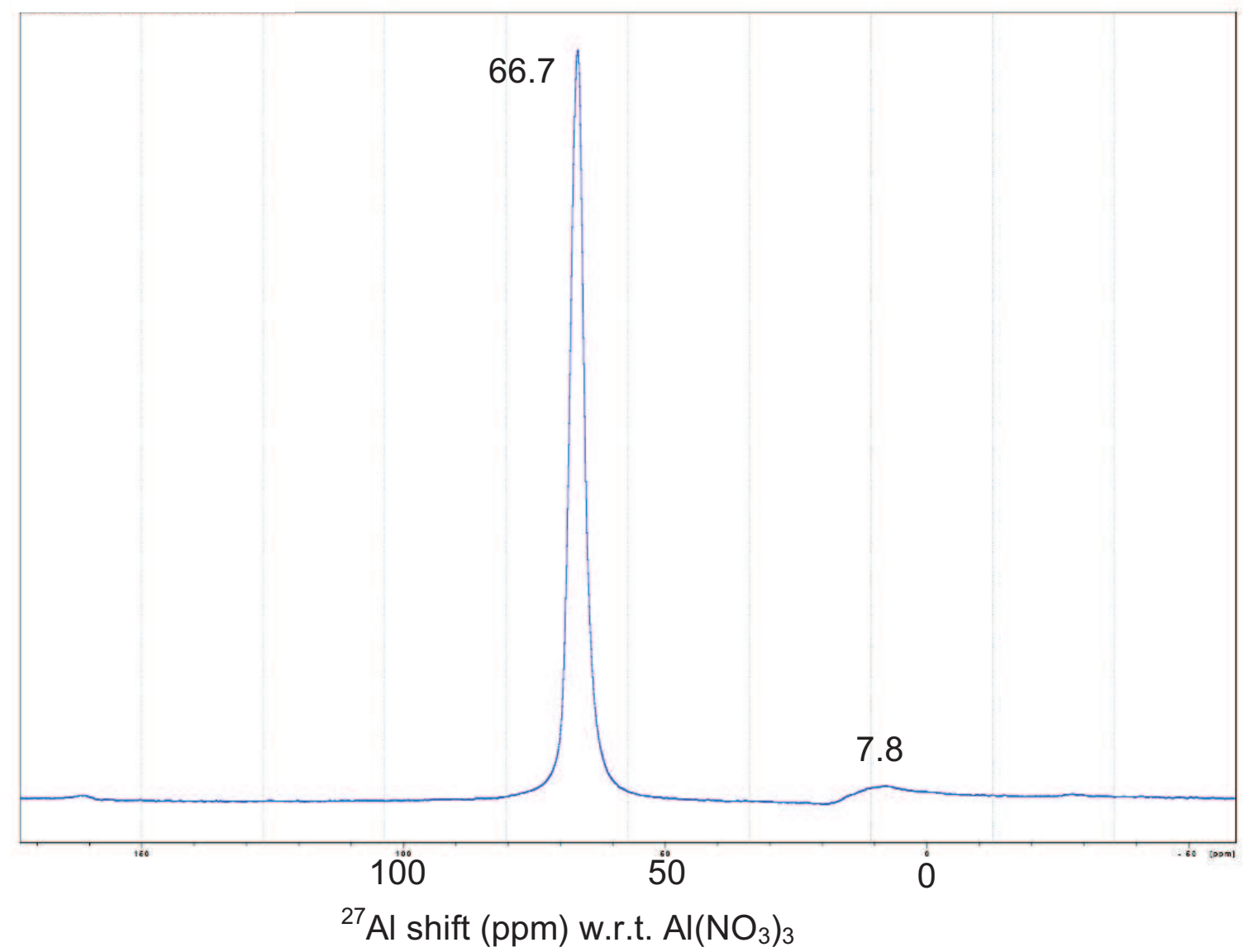

Figure 52: $11.7 \mathrm{~T}^{27} \mathrm{Al}$ MAS NMR spectrum of the sample made using $\mathrm{KAIO}_{2}$. The aluminium coordination is very different to that of the samples made using $\mathrm{NaAlO}_{2}$ (Figure 49)

\subsubsection{Summary}

It appears from these sets of reactions that an amorphous solid product is produced when $\mathrm{GeO}_{2}$ is reacted with $\mathrm{NaAlO}_{2}$, but not when reacted with either $\mathrm{KAIO}_{2}$ or $\mathrm{KGaO}_{2}$. However this product contains both tetrahedral and octahedral aluminium coordination sites, and is therefore different in structure to an aluminosilicate geopolymer. It is possible that a sodium gallium oxide species could be used in this reaction to yield an amorphous product. The potential synthesis of a soluble sodium gallate species was not investigated as part of this research project. 


\section{Effect of heat on potassium gallium silicate and potassium gallium aluminosilicate inorganic polymers}

The thermal behaviour of the inorganic polymers synthesised was investigated. The products of heat treatment may have potentially interesting high-technology properties.

\subsection{Sequential firings of gallium silicate inorganic polymers}

A potassium gallium silicate sample was fired sequentially at increasing temperatures, and analysed by XRD at each firing step to observe any crystallisation transitions. The firing temperatures were 500,600, 700, 800 and $900^{\circ} \mathrm{C}$, each for 18 hours duration. Both a sample fragment and powdered sample were fired. XRD showed that the amorphous inorganic polymer crystallised into $\mathrm{KGaSi}_{2} \mathrm{O}_{6}$ after the $800^{\circ} \mathrm{C}$ firing (figure 53). No changes were observed in the sample after firing at $900^{\circ} \mathrm{C}$. 

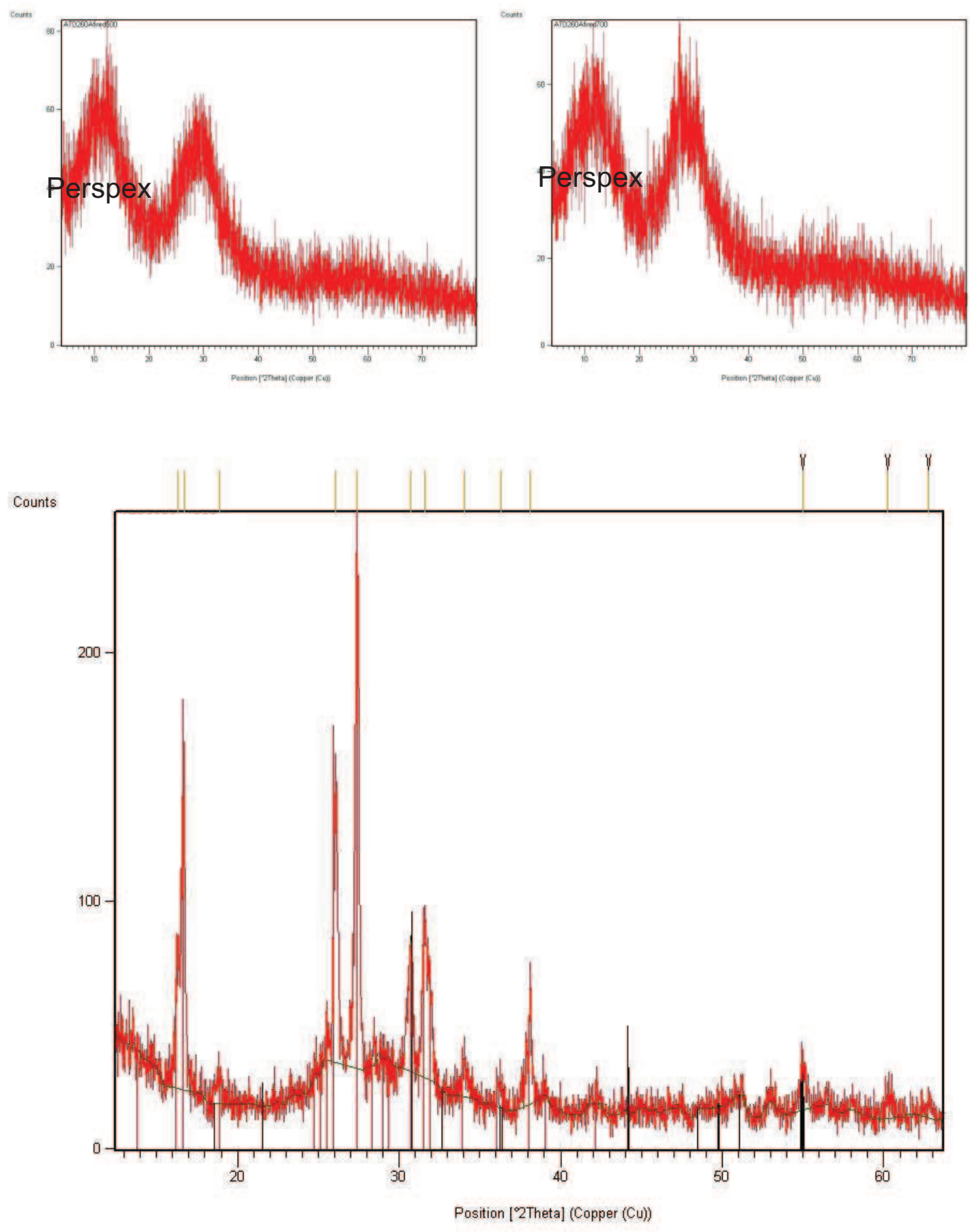

Figure 53: XRD of a gallium silicate inorganic polymer fired at 500 (top left), 700 (top right) and $800^{\circ} \mathrm{C}$ (bottom left). After the $800^{\circ} \mathrm{C}$ firing the inorganic polymer has crystallised to $\mathrm{KGaSi}_{2} \mathrm{O}_{6}$ (pdf 00-037-0349). 
Several different samples were fired in a furnace to $1000^{\circ} \mathrm{C}$ to see whether they would melt at this temperature. A small chip of each sample was placed in separate vitreous silica crucibles. The samples fired were:

potassium gallium silicate inorganic polymer

potassium aluminosilicate inorganic polymer

potassium gallium aluminosilicate inorganic polymer (50:50 Ga:Al)

potassium gallium (germanium) silicate inorganic polymer (17:1 Si:Ge)

None of the samples melted at this temperature, indicating that they could be analysed with DSC-TGA up to $1000^{\circ} \mathrm{C}$.

\subsection{DSC-TGA}

Each of the samples were run individually in the DSC-TGA from room temperature up to $1000^{\circ} \mathrm{C}$ with a heating rate of $10^{\circ} \mathrm{C} /$ minute, in air with an airflow of $50 \mathrm{~mL} /$ minute. The thermograms are all approximately similar, showing endotherms at approximately 75 and $160^{\circ} \mathrm{C}$, due to water loss (figure 54). The 50:50 sample differs from the others by having a strong endotherm at $300^{\circ} \mathrm{C}$ (figure 55). This is not present in the other samples. Water loss from inorganic polymers typically occurs in stages as some water is bound more strongly.

Following the endotherms is a very broad curve consistent with the baseline drift determined in a blank run. This gradual apparent progressive 'weight loss' is unlikely due to condensation of hydroxyl units, as no progressive shifts were observed in the NMR spectra.

At approximately $950^{\circ} \mathrm{C}$ a broad exotherm is observed in all samples. This is due to a structural rearrangement, probably a transition from the amorphous polymer to a crystalline material. $950^{\circ} \mathrm{C}$ is the kineti is higher than the thermodynamic crystallisation te inorganic polymers $\left(800^{\circ} \mathrm{C}\right)$ observed from sequential sample firing in the furnace. 
DSC-TGA

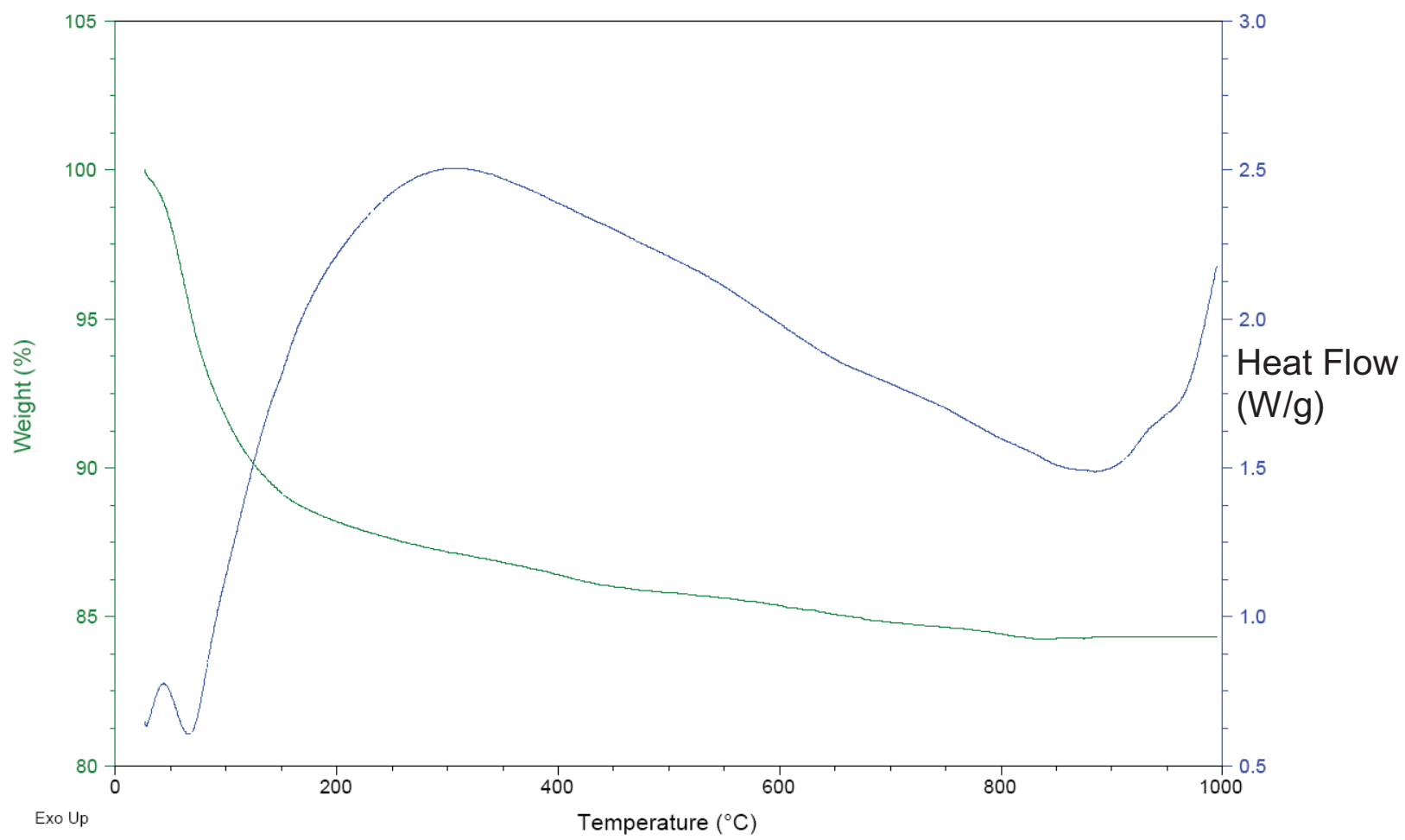

Figure 54: Thermogram of a gallium silicate inorganic polymer heated to $1000^{\circ} \mathrm{C}$. 


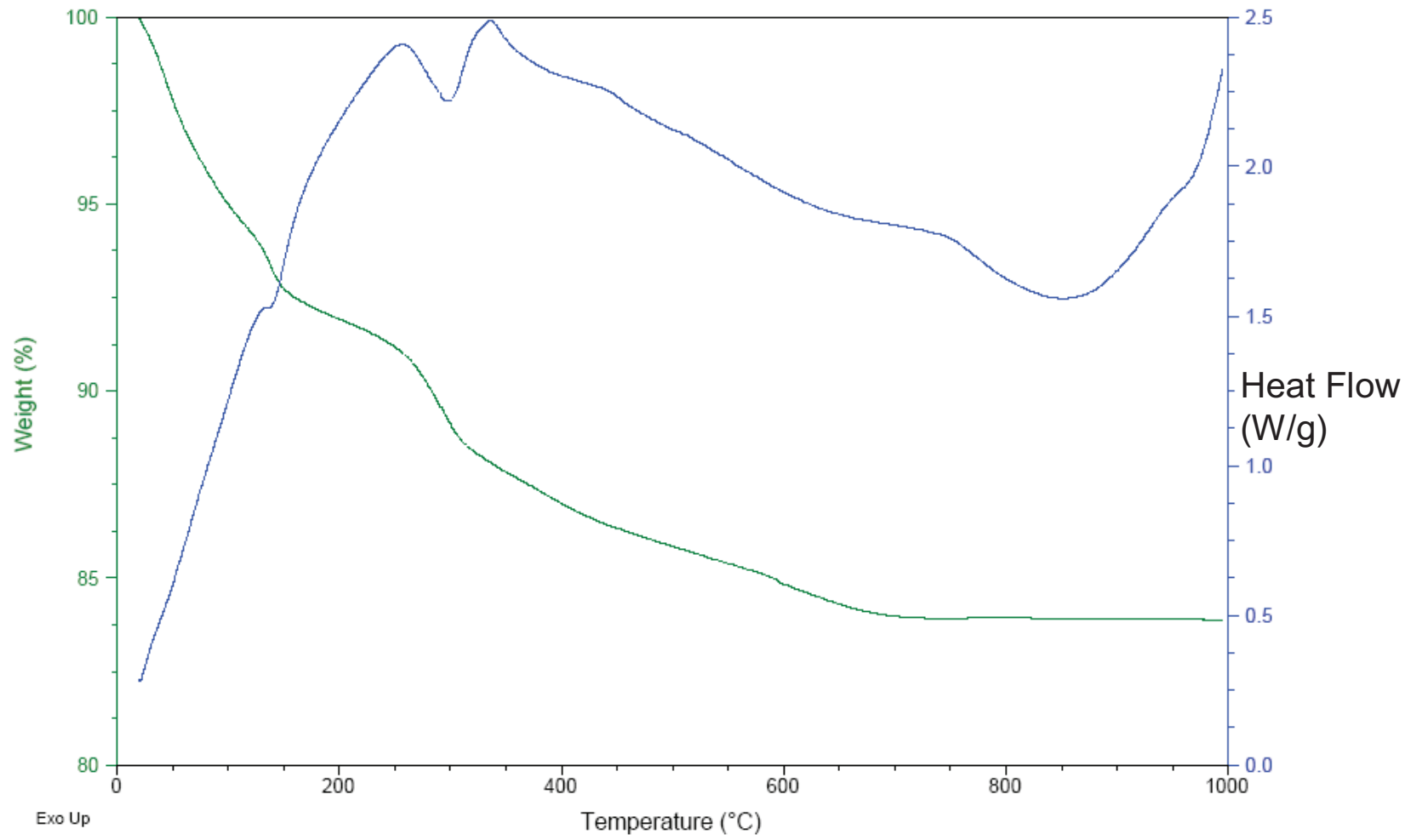

Figure 55: Thermogram of a 50:50 gallium aluminosilicate inorganic polymer heated to $1000^{\circ} \mathrm{C}$.

The thermograms show the samples continue losing mass up to around $700^{\circ} \mathrm{C}$. Mass loss is initially rapid then plateaus after the water-loss endotherms. The total mass decrease is very likely to be solely due to the loss of water.

Regular potassium aluminosilicate inorganic polymers remain amorphous up to around $1100^{\circ} \mathrm{C}$ then crystallise to leucite and possibly mullite.[31] Sodium aluminosilicate inorganic polymers can melt above $1100^{\circ} \mathrm{C}$.[63] However these thermal properties are dependant on the $\mathrm{SiO}_{2}: \mathrm{Al}_{2} \mathrm{O}_{3}$ ratio of the inorganic polymer.[31]

The incorporation of gallium into aluminosilicate materials can increase the crystallisation temperature.[2] Three samples, a potassium gallium silicate inorganic polymer, a potassium aluminosilicate inorganic polymer and a 50:50 potassium gallium aluminosilicate inorganic polymer were made and then fired to $1200^{\circ} \mathrm{C}$ for 20 hours. 
A piece of each sample was placed in the furnace on a vitreous silica dish. The gallium-only sample retained its shape, and was opaque white. The aluminiumonly sample melted and slumped, losing its shape, and spreading over the silica dish. It was shiny and opaque glassy white-colourless. The 50:50 sample also melted and was visually similar to the aluminium-only sample. All three samples were fused to the silica dish and had to be prised off. The gallium only sample was more easily removed intact, whereas the melted samples had to be chiselled off in pieces. The parts of each sample that were fused to the silica were removed and discarded, in case of diffusion and contamination. The samples were ground to powder and analysed by XRD.

Both the melted 50:50 sample and melted aluminium-only sample were amorphous (figure 56). This was the expected result for a melt. A few small peaks were observed in some samples on top of the amorphous phase, which were probably from $\mathrm{KAISiO}_{4}$ or $\mathrm{KAISi}_{2} \mathrm{O}_{6}$. In contrast the gallium-only sample had crystallised. The product was crystalline potassium gallium silicate, $\mathrm{KGaSi}_{2} \mathrm{O}_{6}$ (figure 57).

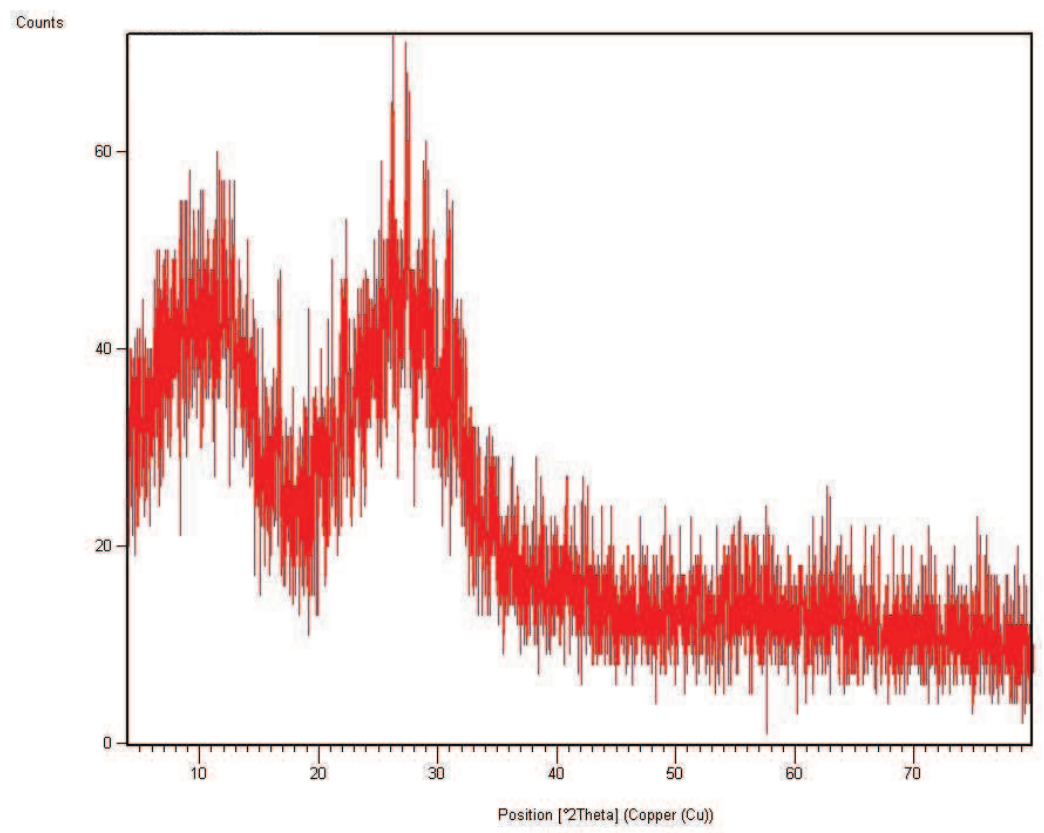

Figure 56: XRD of an aluminosilicate inorganic polymer fired to $1200^{\circ} \mathrm{C}$. The sample melted. 


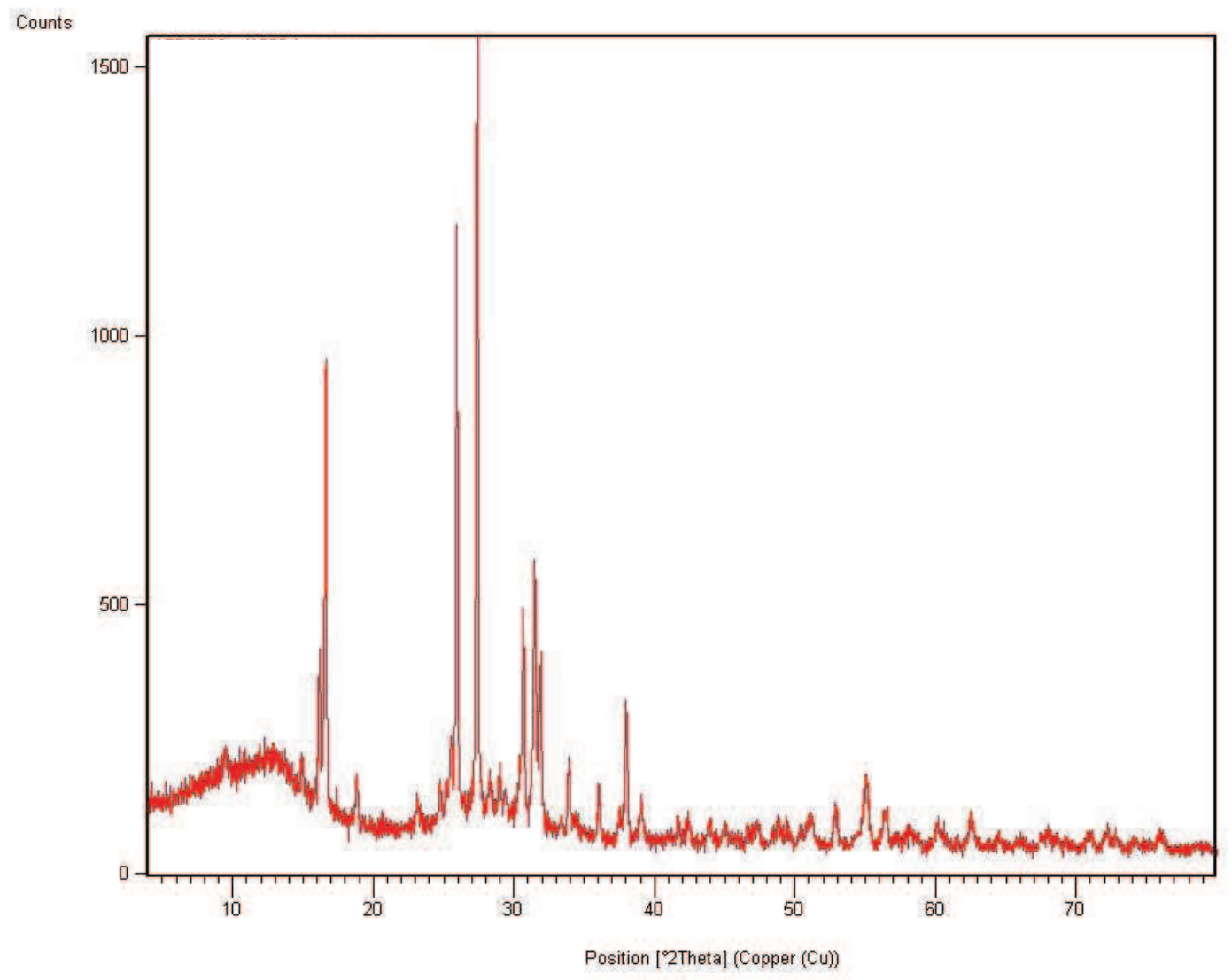

Figure 57: XRD of a gallium silicate inorganic polymer fired to $1200^{\circ} \mathrm{C}$. The product is crystalline $\mathrm{KGaSi}_{2} \mathrm{O}_{6}$ (pdf file number 00-037-0349). 
A gallium silicate inorganic polymer sample was analysed by DSC-TGA up to $1200^{\circ} \mathrm{C}$ (figure 58). This did not show any other thermal changes within the sample than the lower temperature runs up to $1000^{\circ} \mathrm{C}$.

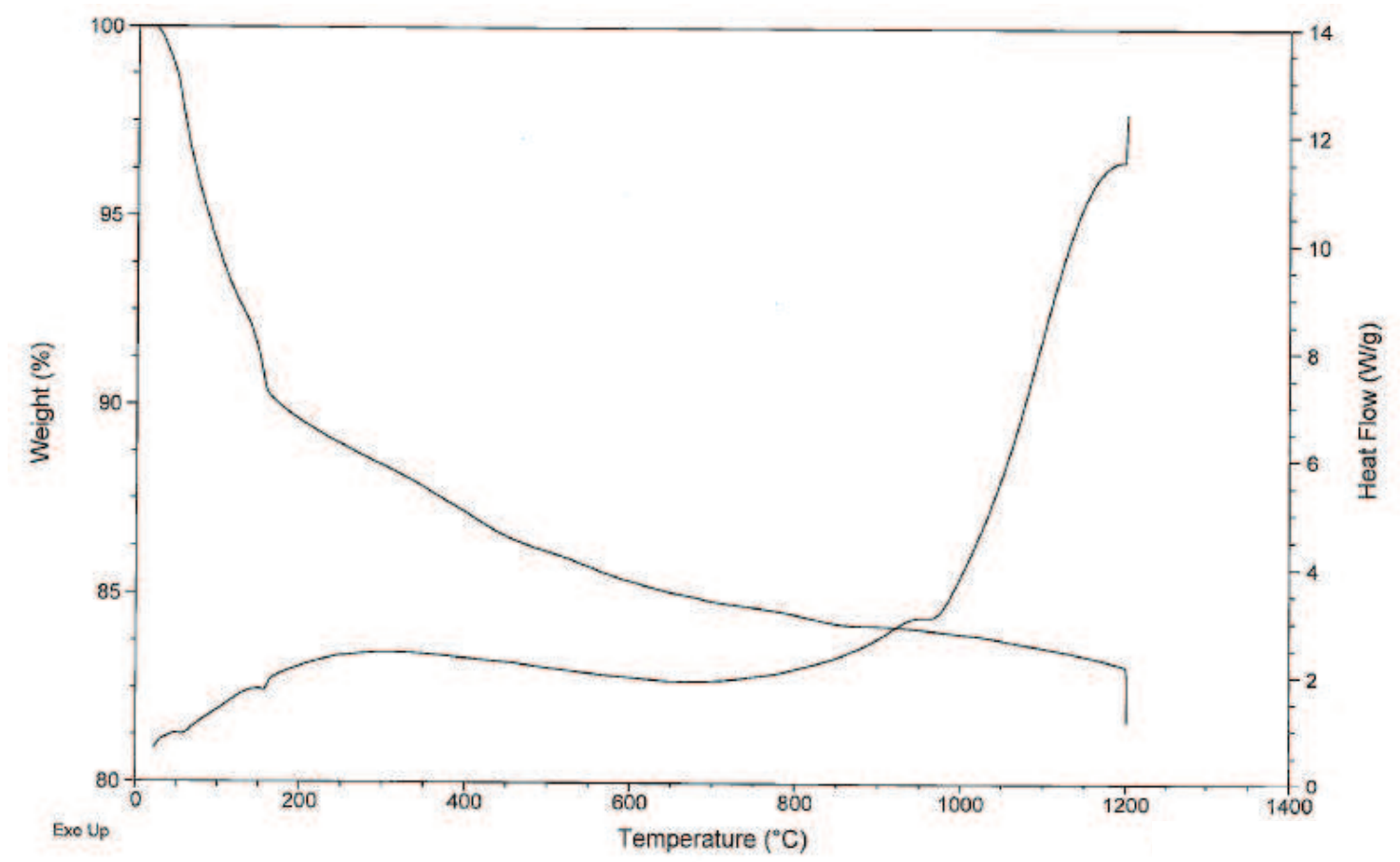

Figure 58: Thermogram of a gallium silicate inorganic polymer heated to $1200^{\circ} \mathrm{C}$.

It was also noted that the secondary hump in the XRD of the unfired aluminosilicate inorganic polymer had disappeared in the XRD of the fired product (figure 56), further confirming a change in structure from inorganic polymer to melt.

This demonstrates a marked difference in the thermal behaviour of an inorganic polymer when gallium replaces aluminium. However, when there is a 50:50 blend of gallium and aluminium this effect is not apparent and the sample behaves as a sample containing aluminium only. The melting of the aluminium component of such a mixed sample causes the remaining gallium component to melt instead of crystallising. This melting is more likely to be caused by the difference in composition, rather than a structural difference. Gallium silicate systems typically have a slightly higher temperature liquid phase than the analogous aluminium 
silicate systems[74]. As a result no structural differences were inferred from this effect, and the structure of the gallium silicate inorganic polymer remains likely to have the same amorphous structure as the aluminosilicate inorganic polymers.

XRD of an aluminium-only sample fired at $1000^{\circ} \mathrm{C}$ showed the beginnings of crystallisation, but the sample was still mostly amorphous. The sample had not melted at this point, and was amorphous because it was still an inorganic polymer at this temperature. A completely crystalline product was not observed by $\mathrm{XRD}$ as the firing temperature was increased up to the sample melting temperature of 1100 to $1200^{\circ} \mathrm{C}$.

A 50:50 gallium and aluminium sample was fired at $900^{\circ} \mathrm{C}$ for 20 hours. XRD shows the product contains both crystalline and amorphous phases (see figure 59). The crystalline phase could be either $\mathrm{KGaSi}_{2} \mathrm{O}_{6}$ or $\mathrm{KAISiO}_{4}$ or $\mathrm{KAISi}_{2} \mathrm{O}_{6}$ or a combination of these, which all have similar peaks listed in the XRD database. There could be a mixture of each component in both phases, but as gallium silicate inorganic polymer had been shown to crystallise to $\mathrm{KGaSi}_{2} \mathrm{O}_{6}$ at around $800^{\circ} \mathrm{C}$, whereas the equivalent aluminosilicate inorganic polymer was still mostly amorphous at around $1000^{\circ} \mathrm{C}$, it is likely that the crystalline phase here is from the gallium, and the amorphous phase from the aluminium. 


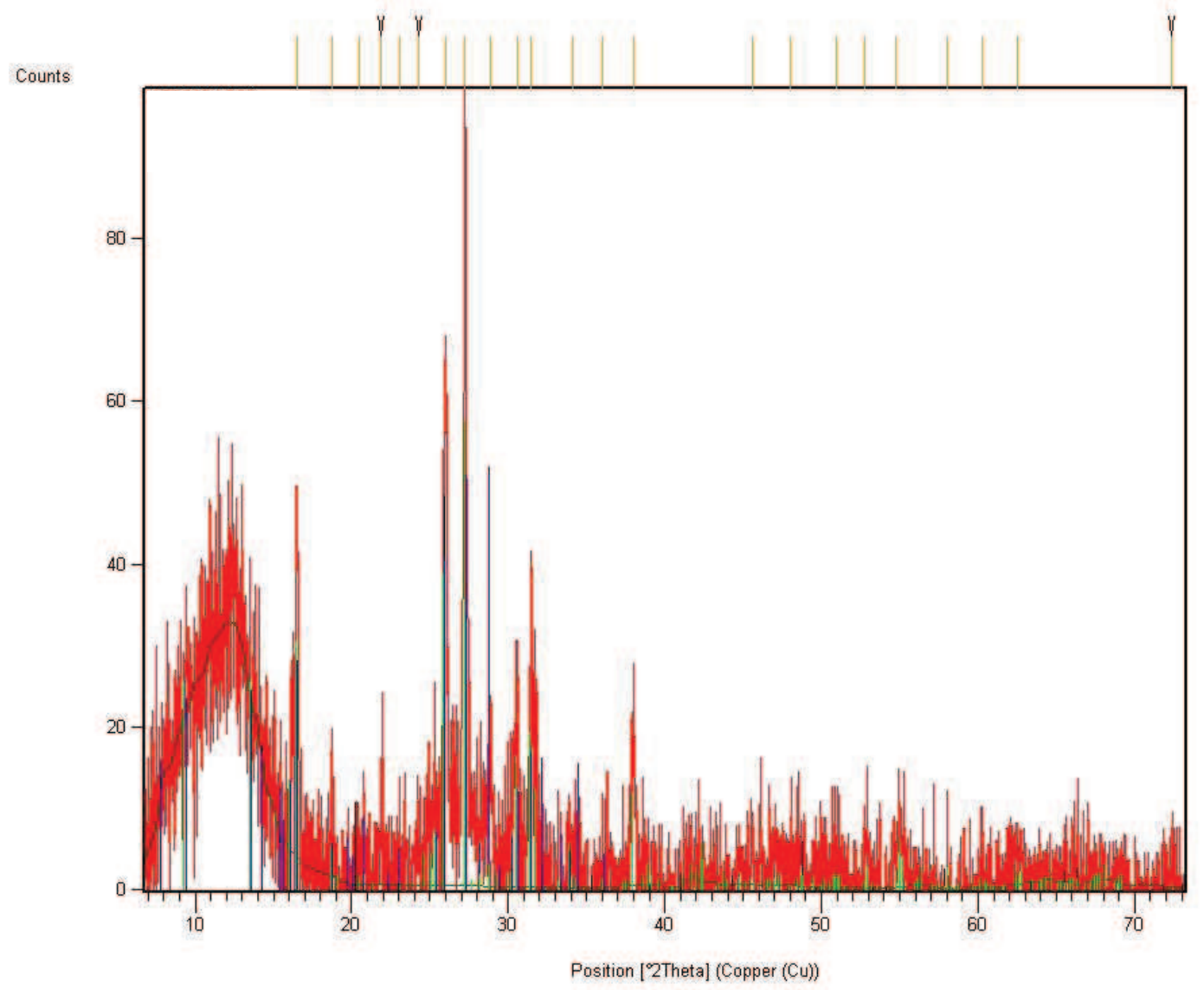

Figure 59: XRD of a 50:50 gallium aluminosilicate inorganic polymer fired at $900^{\circ} \mathrm{C}$ showing crystalline and amorphous phases. The database indicates the crystalline phase could be $\mathrm{KGaSi}_{2} \mathrm{O}_{6}$ or $\mathrm{KAISiO}_{4}$ or $\mathrm{KAISi}_{2} \mathrm{O}_{6}$. 


\subsection{Silicon NMR}

Solid-state ${ }^{29} \mathrm{Si}$ MAS NMR of a gallium silicate inorganic polymer sample fired at $900^{\circ} \mathrm{C}$ shows a broad resonance at $-94.4 \mathrm{ppm}$, with shoulder peaks at -83.2 and $-89.5 \mathrm{ppm}$ (figure 60). The peak at around $-109 \mathrm{ppm}$ in the unfired sample from unreacted silica has disappeared, indicating that the silica has reacted with the inorganic polymer.

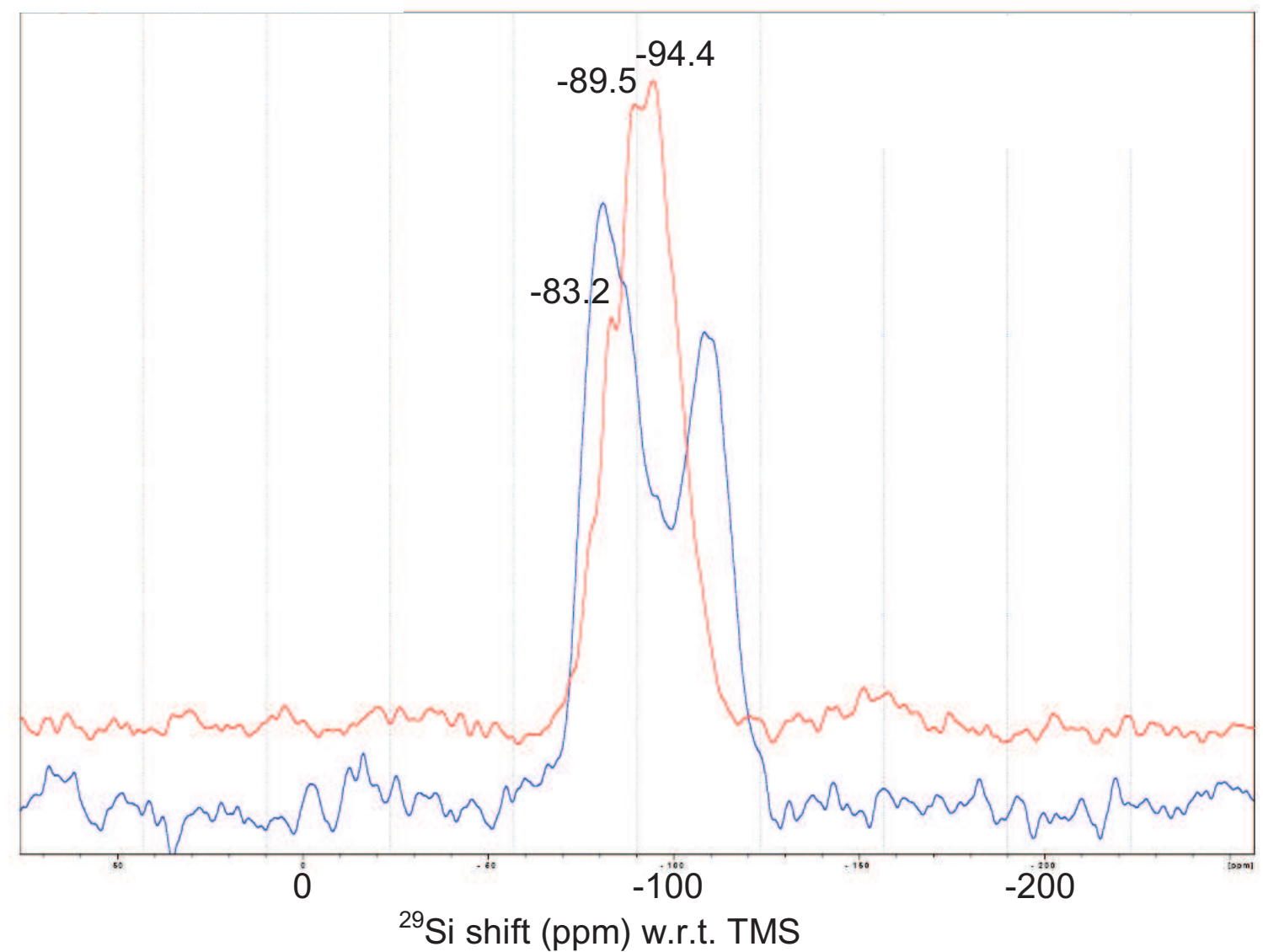

Figure 60: 11.7 $\mathrm{T}^{29} \mathrm{Si}$ MAS NMR spectra showing a gallium silicate inorganic polymer unfired (blue) and fired $900^{\circ} \mathrm{C}$ (red). 
An aluminosilicate inorganic polymer sample fired at $1000^{\circ} \mathrm{C}$ shows a broad resonance at -99.7 ppm, with no other resonances (figure 61).

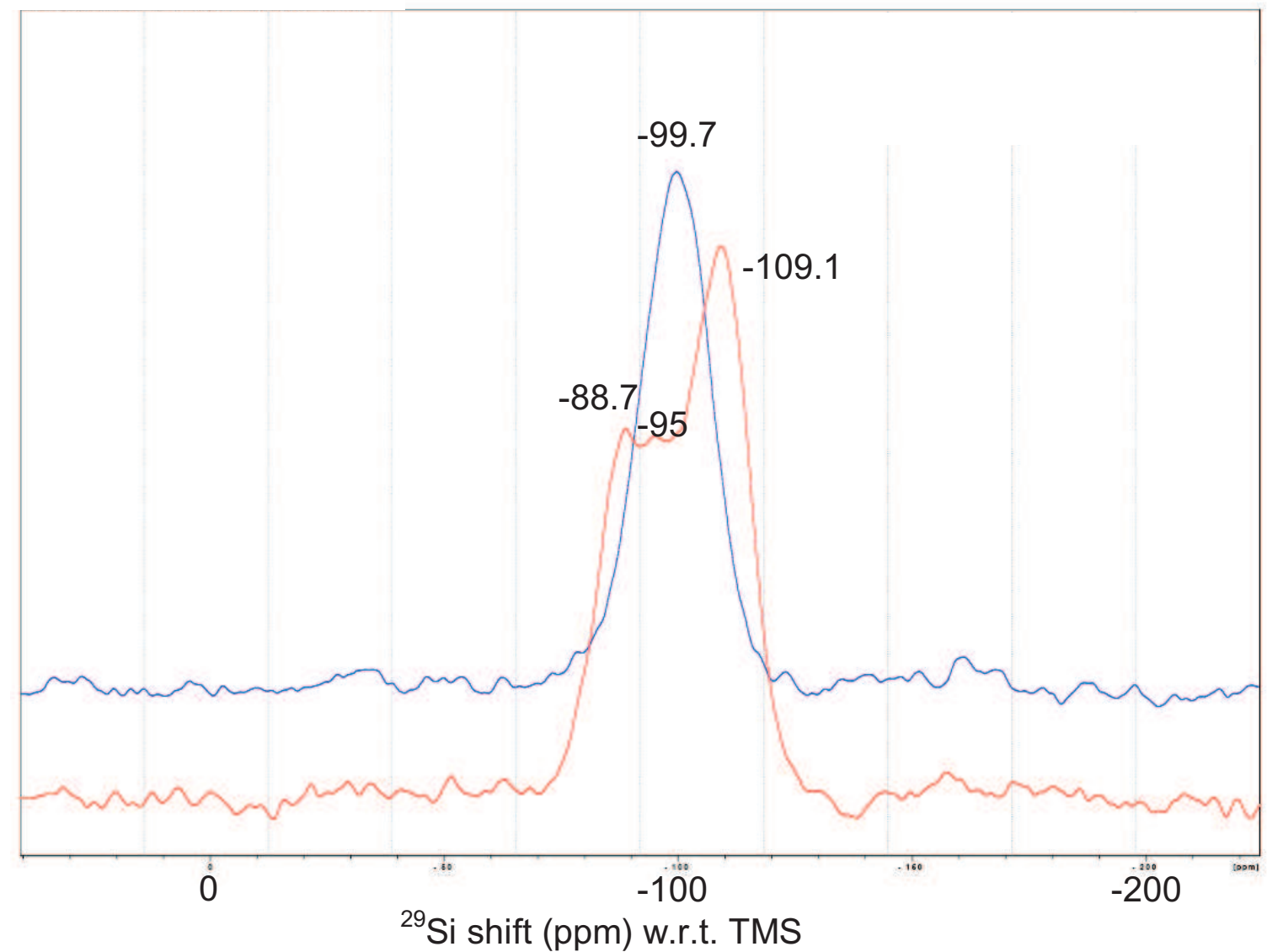

Figure 61: 11.7 $\mathrm{T}^{29} \mathrm{Si}$ MAS NMR of an aluminosilicate sample unfired (red) and fired $1000^{\circ} \mathrm{C}$ (blue). 
A 50:50 gallium aluminosilicate inorganic polymer fired at $1200^{\circ} \mathrm{C}$ shows a single broad resonance at $-98.5 \mathrm{ppm}$ (figure 62).

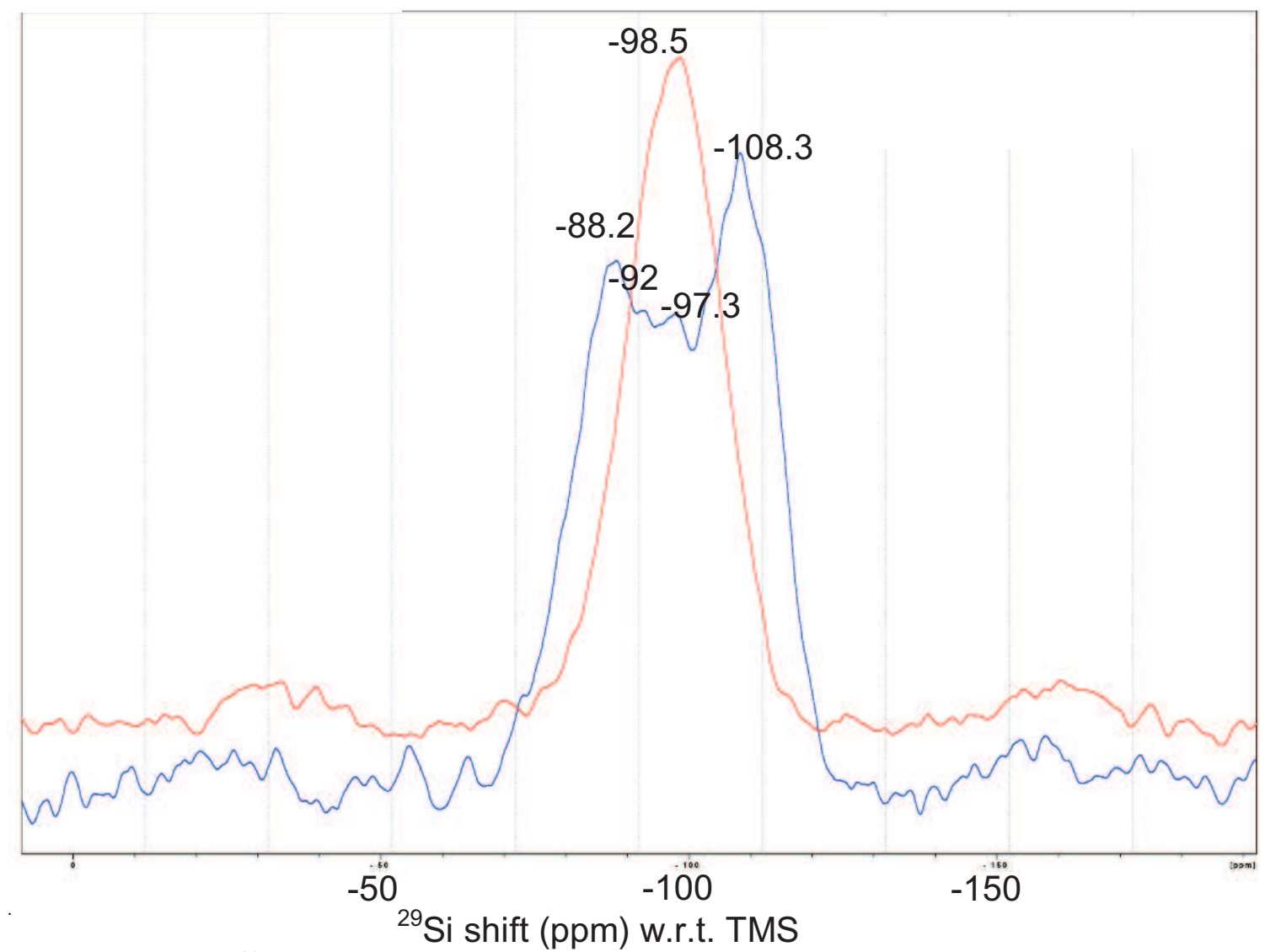

Figure 62: 11.7 T ${ }^{29}$ Si MAS NMR of 50:50 sample unfired (blue) and fired (red)

These results show that the free silica reacts with the inorganic polymer, causing an overall shift to lower ppm. This results in more silicon tetrahedra and fewer gallium or aluminium tetrahedra and the structure alters, with the $\mathrm{Si}(3 \mathrm{Al})$ and $\mathrm{Si}(3 \mathrm{Ga})$ sites of the inorganic polymer changing to $\mathrm{Si}(1 \mathrm{Al})$ and $\mathrm{Si}(1 \mathrm{Ga})$ sites in the fired product. The ${ }^{29} \mathrm{Si}$ chemical shift has been shown to vary systematically with Si-Al ratio.[75] As observed earlier, the increased shielding effects of gallium shift the silicon resonances to higher ppm compared with aluminium. 


\subsection{Aluminium and gallium NMR}

The solid-state ${ }^{27} \mathrm{Al}$ MAS NMR spectrum of a 50:50 sample fired at $1200^{\circ} \mathrm{C}$ shows a broadening of the tetrahedral resonance compared with the unfired sample (figure 63). This may indicate increased site disorder as a result of the aluminium silicate phase melting at this temperature. The small octahedral resonance at $6.5 \mathrm{ppm}$ in the unfired sample disappeared when the sample was fired.

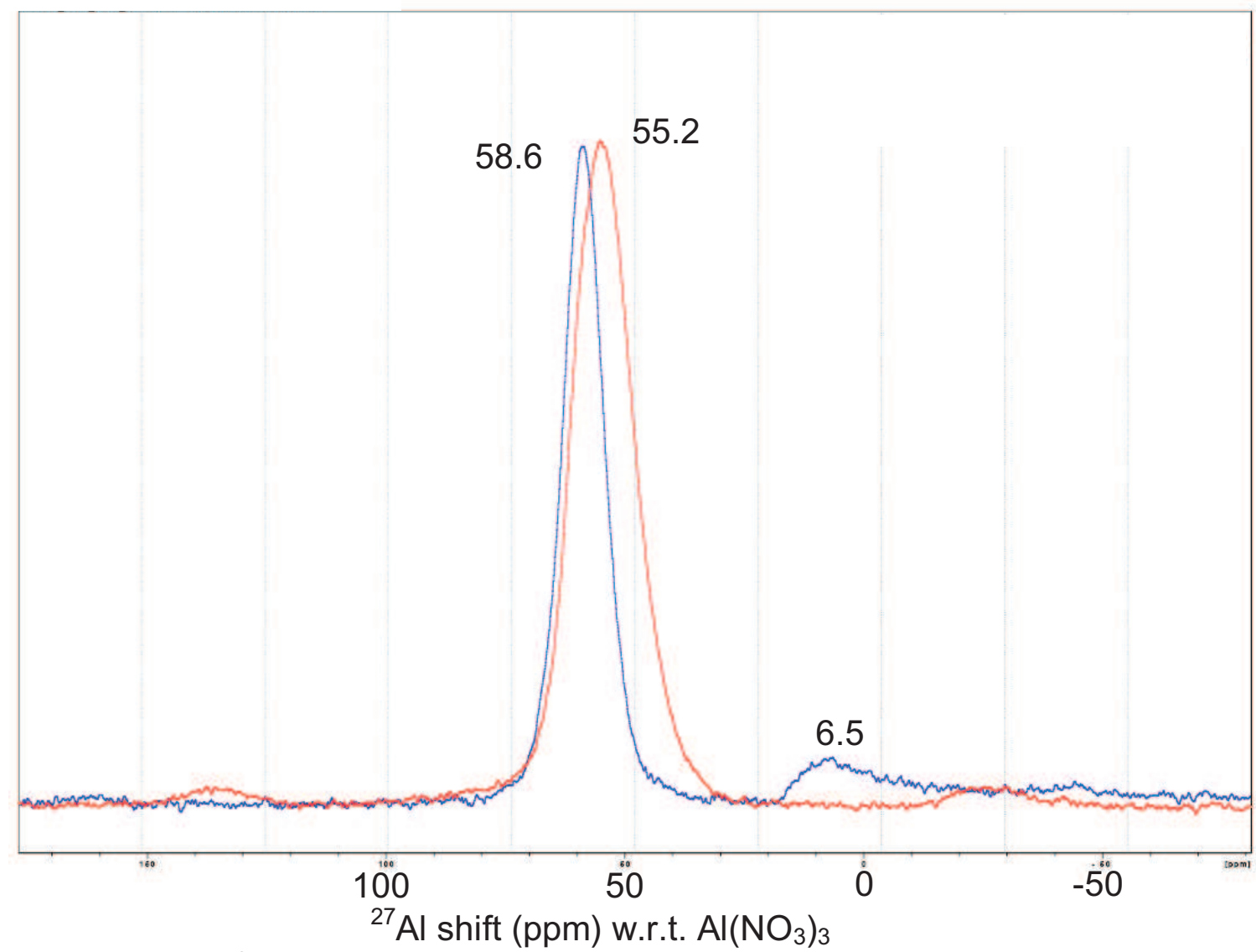

Figure 63: $11.7 \mathrm{~T}^{27} \mathrm{Al}$ MAS NMR spectra of a 50:50 sample unheated (blue) and fired to $1200^{\circ} \mathrm{C}$ (red).

A similar result was observed for an aluminosilicate inorganic polymer sample, with the octahedral peak disappearing and tetrahedral peak broadening (figure 64). In addition the tetrahedral resonance shifted slightly to higher ppm with increasing temperature, from $58.2 \mathrm{ppm}$ in the unfired sample to $56.7 \mathrm{ppm}$ at $1000^{\circ} \mathrm{C}$ to $54.9 \mathrm{ppm}$ when fired at $1200^{\circ} \mathrm{C}$. 


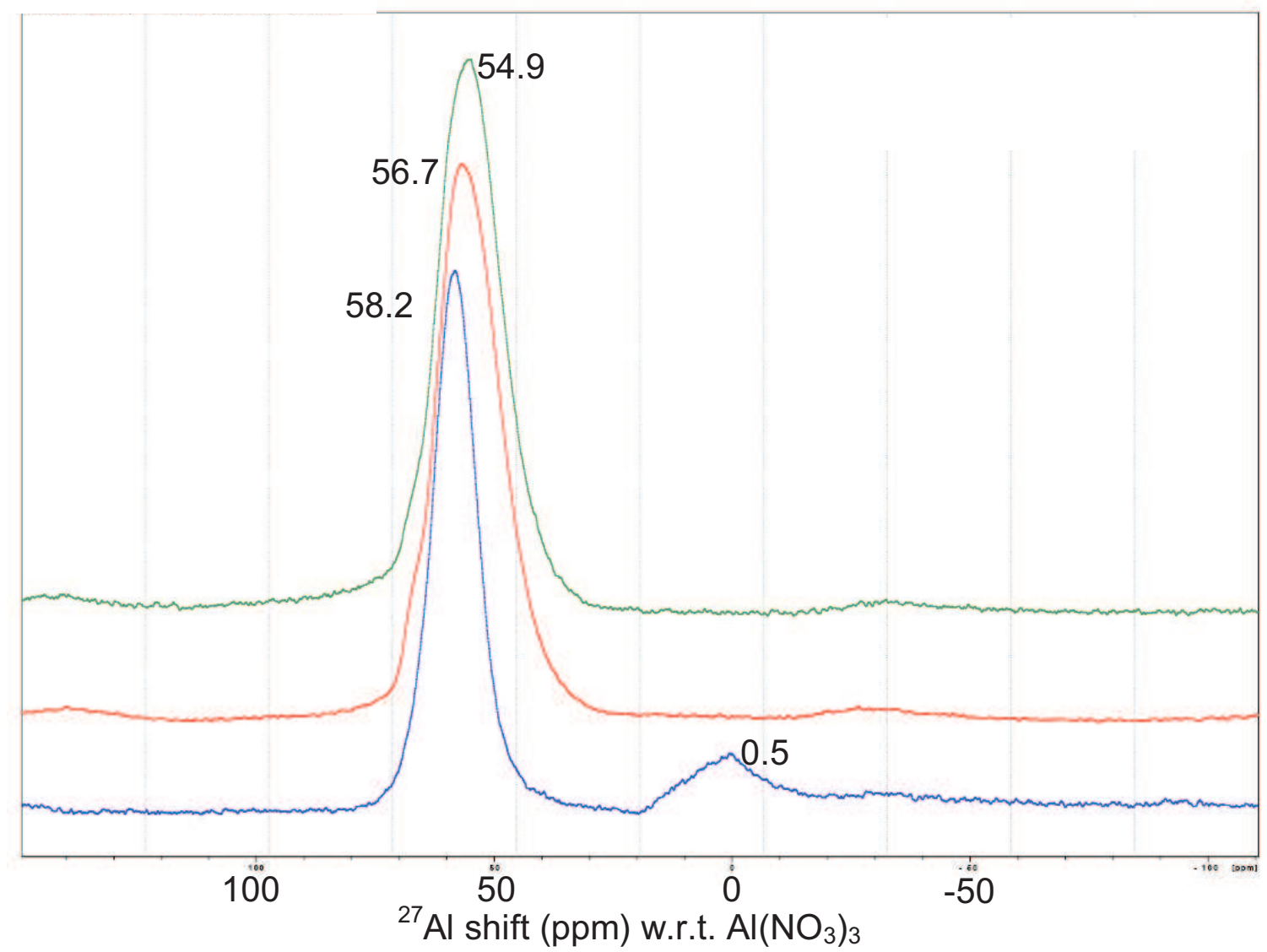

Figure 64: 11.7 $\mathrm{T}^{27} \mathrm{Al}$ MAS NMR spectra of aluminosilicate IP showing change of aluminium coordination as sample is fired from unheated sample (blue) to $1000^{\circ} \mathrm{C}$ (red) to $1200^{\circ} \mathrm{C}$ (green).

The solid-state ${ }^{71} \mathrm{Ga}$ MAS NMR spectra do not show any difference between the unfired gallium silicate inorganic polymer and the $\mathrm{KGaSi}_{2} \mathrm{O}_{6}$ product of firing at $900^{\circ} \mathrm{C}$. Both show a tetrahedral peak at approximately $175 \mathrm{ppm}$ (figure 65). The line-width of these spectra is broad and this may mask a slight shift to higher ppm as observed for samples containing aluminium. 

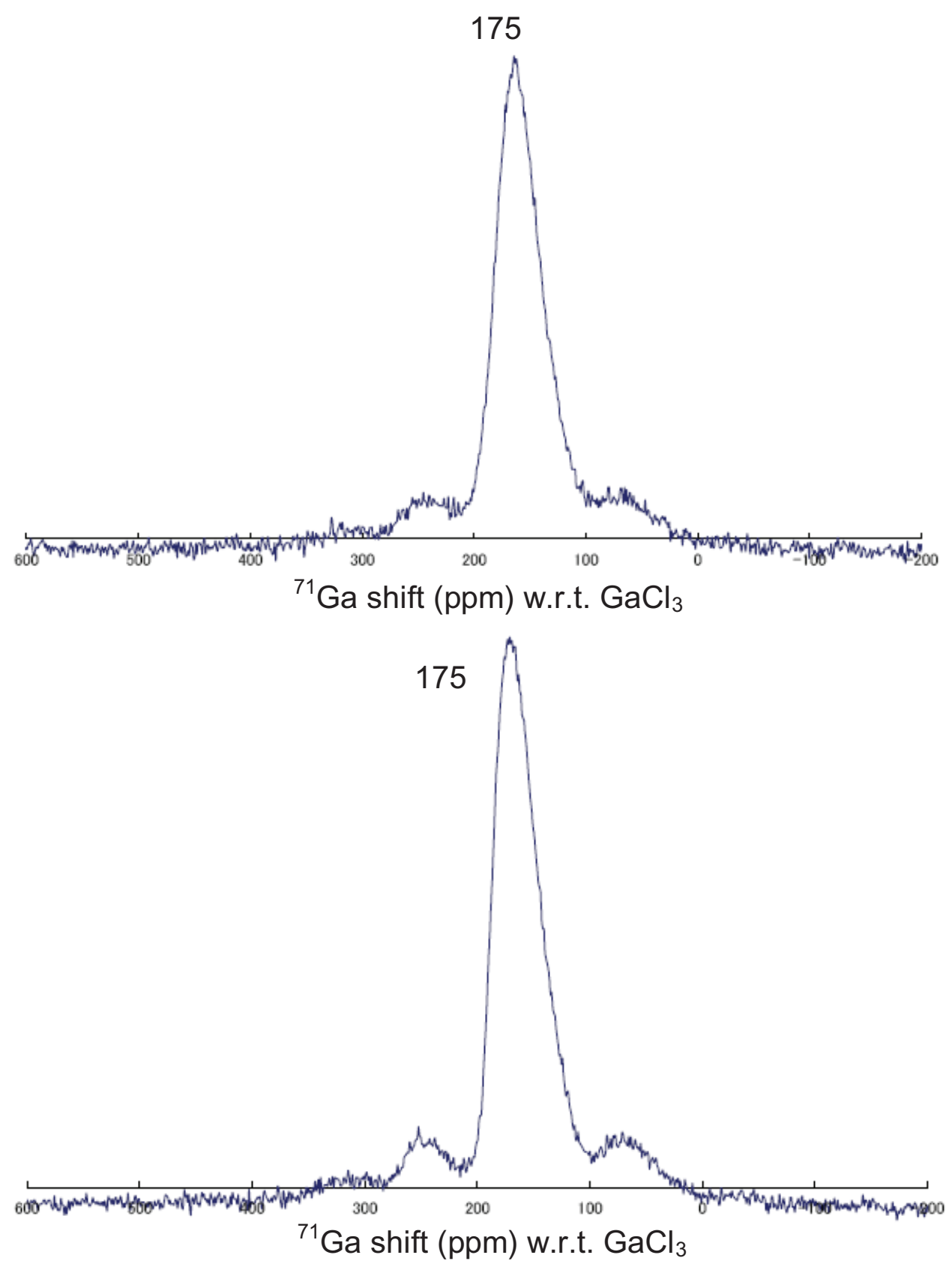

Figure 65: $14.1 \mathrm{~T}^{71} \mathrm{Ga}$ MAS NMR spectra of a gallium silicate inorganic polymer (top) and the same sample fired at $900^{\circ} \mathrm{C}$ to form $\mathrm{KGaSi}_{2} \mathrm{O}_{6}$ (bottom). 


\subsection{Summary}

When the gallium silicate and gallium aluminosilicate inorganic polymers were thermally treated, all samples lost water in stages at around 75 and $160^{\circ} \mathrm{C}$ and then showed a structural transition to a crystalline material at approximately $950^{\circ} \mathrm{C}$. The products were $\mathrm{KGaSi}_{2} \mathrm{O}_{6}$ and $\mathrm{KAISi}_{2} \mathrm{O}_{6}$. The silica particles in the inorganic polymer reacted at this temperature and were no longer observed by ${ }^{29} \mathrm{Si}$ MAS NMR. Any octahedral aluminium present disappeared when the inorganic polymer was fired. When the inorganic polymers were heated to $1200^{\circ} \mathrm{C}$ the gallium silicate sample held its shape and crystallised to $\mathrm{KGaSi}_{2} \mathrm{O}_{6}$, but gallium aluminosilicate and aluminosilicate samples melted. These observations are summarised in table 3.

\begin{tabular}{|l|l|l|l|}
\hline \multicolumn{1}{|c|}{ Temperature } & \multicolumn{1}{c|}{$75-300^{\circ} \mathrm{C}$} & \multicolumn{1}{c|}{$950^{\circ} \mathrm{C}$} & \multicolumn{1}{c|}{$1200^{\circ} \mathrm{C}$} \\
\hline $\mathrm{K}$ gallium silicate IP & water loss & crystallised & remained crystalline \\
\hline $\begin{array}{l}50: 50 \mathrm{~K} \text { gallium } \\
\text { aluminosilicate IP }\end{array}$ & water loss & crystallised & melted \\
\hline K aluminosilicate IP & water loss & crystallised & melted \\
\hline
\end{tabular}

Table 3: Comparison of thermal behaviour of gallium silicate and aluminosilicate inorganic polymers. 


\section{Summary and conclusions}

Gallium was successfully incorporated into the inorganic polymer structure in place of aluminium. Substitution of germanium for silicon was not successful. A number of compounds in this system were synthesised, using newly-developed sol-gel or solid-state techniques, or combinations of both.

Gallium silicate inorganic polymers were successfully synthesised from a solution of $\mathrm{KGaO}_{2}$ and a potassium silicate solution made from $\mathrm{KOH}$, water and silica fume. XRD showed the products of this reaction were X-ray amorphous. Solidstate ${ }^{71} \mathrm{Ga}$ and ${ }^{29} \mathrm{Si}$ MAS NMR showed the gallium to be in solely tetrahedral coordination, and silicon to be in both $\mathrm{Si}(3 \mathrm{Ga})$ and $\mathrm{Si}(2 \mathrm{Ga})$ sites in the inorganic polymer matrix, and also as free silica. SEM showed the presence of spherical silica particles dispersed randomly throughout the inorganic polymer matrix, and EDS mapping showed a homogeneous distribution of elements in the inorganic polymer, and also highlighted silica particles.

A similar synthesis method using a mixture of $\mathrm{KAIO}_{2}$ and $\mathrm{KGaO}_{2}$ allowed the synthesis of gallium aluminosilicate inorganic polymers. The Ga:Al could be varied from $100 \%$ gallium to $100 \%$ aluminium with all ratios in-between producing inorganic polymers. XRD showed all products to be X-ray amorphous, but the incorporation of aluminium caused a small secondary hump in the XRD trace of the amorphous phase in addition to the single hump of the gallium silicate inorganic polymers. The presence of aluminium also increased the viscosity of the mixture before setting, which could be caused by a faster reaction rate compared to the gallium species.

${ }^{27} \mathrm{Al}$ MAS NMR showed the aluminium to be almost entirely tetrahedral, with most samples having a very weak broad octahedral peak in the spectra. ${ }^{71} \mathrm{Ga}$ MAS NMR showed no change in the gallium coordination when aluminium was also included in the material. ${ }^{29} \mathrm{Si}$ MAS NMR showed $\mathrm{Si}(3 \mathrm{Al})$ and $\mathrm{Si}(2 \mathrm{Al})$ sites when 
aluminium was incorporated. The silicon spectra are more complex when both gallium and aluminium are present due to the overlap of resonances, resulting in a broader signal with multiple peaks and shoulders. Unreacted silica is also present in the silicon spectra of the gallium aluminosilicate inorganic polymers. SEM shows the product to be similar to gallium silicate inorganic polymers, with spherical silica partices. The inorganic polymer matrix is chemically homogeneous. The structure of gallium substituted inorganic polymers was thus determined to be analogous to aluminosilicate inorganic polymers.

Thermal treatment of gallium silicate and gallium aluminosilicate inorganic polymers was monitored by DSC-TGA and showed a water loss in two stages at approximately 75 and $160^{\circ} \mathrm{C}$ followed by a broad exotherm at around $950^{\circ} \mathrm{C}$ indicating a structural transition to a crystalline material.

XRD of a gallium silicate inorganic polymer fired sequentially at increasing temperatures showed a thermodynamic transition to crystalline $\mathrm{KGaSi}_{2} \mathrm{O}_{6}$ at $800^{\circ} \mathrm{C}$. The incorporation of aluminium was shown to affect the thermal properties of the inorganic polymer. Gallium silicate, gallium aluminosilicate and aluminosilicate inorganic polymers all synthesised by variations of the sol-gel method were fired to $1200^{\circ} \mathrm{C}$. The gallium silicate sample crystallised to $\mathrm{KGaSi}_{2} \mathrm{O}_{6}$ and retained its shape. The other two samples melted at this temperature and slumped, losing their shape. The resulting melts were X-ray amorphous.

Attempts to synthesise an inorganic polymer analogue where germanium was substituted for silicon were unsuccessful. Many reactions did not set and those that did were always crystalline. Initially $\mathrm{Ga}_{2} \mathrm{O}_{3}$ and $\mathrm{GeO}_{2}$ were used, as these are typical reagents for the synthesis of zeolites containing gallium and germanium. The products of these sol-gel reactions were crystalline potassium gallium germanium oxide hydrate and potassium germanium oxide hydrate. 
The polymerisation behaviour of $\mathrm{GeO}_{2}$ in aqueous solution differs greatly compared to $\mathrm{SiO}_{2}$. The formation of kinetically stable germanium oxide octamers, $\mathrm{Ge}_{8} \mathrm{O}_{12}(\mathrm{OH})_{8}$, which form aggregates in alkaline solutions interfered with the solgel synthesis. The solubility of these starting materials and the low water content of the inorganic polymer synthesis may also have been a cause of the synthesis failure. As a result, different gallium and germanium containing precursors, potassium gallate and potassium germanate were synthesised by solid-state reactions. Sol-gel syntheses using these precursors did not yield X-ray amorphous products, and therefore a solid-state synthesis was tried. $\mathrm{KGaO}_{2}$ and potassium germanate were mixed and heated together to form a partially amorphous mixed-oxide hydraulic precursor powder. On the addition of water this powder formed a paste which did not set. When dried out the paste turned to a crumbly gritty powder, and the product was crystalline. The alkali content was potentially affecting the water stability of the product, and therefore new starting materials with lower alkali content were synthesised by solid-state reactions. $\mathrm{KGa}_{5} \mathrm{O}_{8}$ and potassium germanate were reacted in a solid-state reaction forming a hydraulic precursor, which set on the addition of water to a crystalline product.

The crystalline product of all these reactions, sol-gel and solid-state, was always a potassium gallium germanium oxide hydrate, $\mathrm{K}_{6} \mathrm{Ga}_{6}\left(\mathrm{GeO}_{4}\right)_{6}\left(\mathrm{H}_{2} \mathrm{O}\right)_{7}$. There appears to be a strong driving force for the formation of this product when germanium containing species are used in these syntheses. It is possible that the amount of water added drives the formation of the hydrate product. But the minimum amount of water was always used to form a paste, and could not be reduced.

A sol-gel reaction of $\mathrm{NaAlO}_{2}$ solution and $\mathrm{GeO}_{2}$ with $\mathrm{KOH}$ solution did form a set product that was X-ray amorphous. ${ }^{27} \mathrm{Al}$ MAS NMR showed both tetrahedral and octahedral sites present in the product. If $\mathrm{KOH}$ is not added the $\mathrm{GeO}_{2}$ does not fully react. When $\mathrm{KAIO}_{2}$ and $\mathrm{KGaO}_{2}$ were used in place of $\mathrm{NaAlO}_{2}$ the products were crystalline. 
The reasons for the change in reaction behaviour when these substitutions were made are unknown. The product was brittle and it is uncertain whether it is a true inorganic polymer.

While germanium-containing zeolites have been developed, the differences in conditions of inorganic polymer synthesis compared to that of zeolites are such that it may not be possible to incorporate germanium in significant quantities into the inorganic polymer structure.

Kinetic factors, such as particle size, surface area, reaction temperature, and diffusion rates are all important considerations in synthesising inorganic polymers. These factors will affect scaling of the synthesis to produce larger sample sizes.

\section{Future work}

The gallium silicate and gallium aluminosilicate inorganic polymers synthesised here contained unreacted silica particles. Ideally all the silica should react to form the inorganic polymer product. The particle size of the silica fume used may be affecting this. The particle size may be reduced by mechanochemical grinding.

Alternatively a different silicon source could be used, such as a silica sol. However the high surface area of this may affect the required alkali and water ratios of the inorganic polymers. A commercial alkali silicate 'water glass' solution could be used, but the water content would need to be reduced.

The electronic properties of the new inorganic polymers should be studied, especially the electric conductivity. The product may also have optical properties, as gallium oxide-containing compounds have been shown to exhibit selfactivated luminescence, and also luminesce when activated by manganese, copper, silver and terbium.[39] It should be possible to activate the potassium gallium silicate inorganic polymers, or the crystalline fired products in this way, and to study their optical properties. 
The $\mathrm{NaAlO}_{2}$ and $\mathrm{GeO}_{2}$ sol-gel reaction needs to be further studied. It is unknown whether the amorphous product is an inorganic polymer, and without germanium NMR it may be difficult to elucidate the nature of the product. It might be possible to study the coordination state of the germanium in such a compound by EXAFS or some related technique.

A soluble $\mathrm{NaGaO}_{2}$ species may be able to react with $\mathrm{GeO}_{2}$ in an alkaline solution to form an amorphous product containing gallium and germanium.

Further attempts at synthesising a germanium containing inorganic polymer could be made, and the solid-state method is probably the best approach to this. A solid-state synthesis may also allow lithium to be used as a charge balancing cation, which may have a positive affect on the formation of an amorphous product.

The addition of hydrogen peroxide could help make $\mathrm{GeO}_{2}$ soluble in a basic aqueous solution. This method has been suggested for the preparation of a water-soluble alkali-metal germanium oxide for use as a fertiliser additive.[76] However, the impact of peroxide on the geopolymerisation reaction is unknown and would need to be investigated. 


\section{References}

1. Khale, D. and R. Chaudhary, Mechanism of Geopolymerisation and factors influencing its development: a review. J. Mater. Sci, 2007. 42: p. 729-746.

2. Meinhold, R.H. and K.J.D. MacKenzie, The system $\mathrm{Ga}_{2} \mathrm{O}_{3}\left(\mathrm{Al}_{2} \mathrm{O}_{3}\right)$ $\mathrm{GeO}_{2}\left(\mathrm{SiO}_{2}\right)$ studied by NMR, XRD, IR and DTA. J. Mater. Chem., 2000. 10: p. 701-707.

3. Baker, D.R., Diffusion of silicon and gallium (as an analogue for aluminium) network-forming cations and their relationship to viscosity in albite melt. Geochimica et Cosmochimica Acta, 1995. 59(17): p. 35613571.

4. Fricke, R., H. Kosslick, G. Lischke, and M. Richter, Incorporation of Gallium into Zeolites: Synthesis, Properties and Catalytic Application. Chem. Rev., 2000. 100: p. 2303-2405.

5. Gabelica, Z. and G. Demortier, RBS and PIXE study of gallium depth profiling in ZSM-5 gallo-aluminosilicate zeolites. Nucl. Instr. and Meth. in Phys. Res. B, 1998. 136-138: p. 1312-1321.

6. Berg, L.G., V.A. Demidenko, and M.S. Remiznikova, Unfired finishing building materials based on kaolin. Stroit. Mater., 1970. 10: p. 72.

7. Komnitsas, K. and D. Zaharaki, Geopolymerisation: A review and prospects for the minerals industry. Minerals Engineering, 2007. 20(14): p. 1261-1277.

8. Davidovits, J. in $1^{\text {st }}$ International Conference on Geopolymer. 1988. Compiegne, France.

9. Davidovits, J., Mineral polymers and methods of making them, U.S. Patent, Editor. 1982: United States.

10. Davidovits, J., Synthetic mineral polymer compound of the silicoaluminates family and preparation process, U.S. Patent, Editor. 1984: United States.

11. Davidovits, J., M. Davidovics, and N. Davidovits, Process for obtaining a geopolymeric alumino-silicate and products thus obtained, U.S. Patent, Editor. 1994.

12. Davidovits, J., M. Davidovics, and N. Davidovits, Alkaline alumino-silicate geopolymeric matrix for composite materials with fiber reinforcement and method for obtaining same, U.S. Patent, Editor. 1998.

13. Duxson, P., S.W. Mallicoat, G.C. Lukey, W.M. Kriven, and J.S.J. van Deventer, The effect of alkali and Si/Al ratio on the developement of mechanical properties of metakaolin-based geopolymers. Colloid Surf. APhysicochem. Eng. Asp., 2007. 292: p. 8-20.

14. MacKenzie, K.J.D., M.E. Smith, and A. Wong, 2007: p. 5090-5096.

15. Nicholson, C.L., B.J. Murray, R. Fletcher, D.R.M. Brew, and K.J.D. MacKenzie. in World Congress Geopolymer 2005. 2005. Saint Quentin, France 
16. MacKenzie, K.J.D., S. Komphanchai, and R.J. Vagana, Formation of inorganic polymers (geopolymers) from 2:1 layer lattice aluminosilicates. J. Euro. Ceram. Soc, 2007.

17. De Silva, P., K. Sagoe-Crenstil, and V. Sirivivatnanon, Kinetics of geopolymerisation: Role of $\mathrm{Al}_{2} \mathrm{O}_{3}$ and $\mathrm{SiO}_{2}$. Cement and Concrete Research, 2007. 37: p. 512-518.

18. Provis, J.L., G.C. Lukey, and J.S.J. van Deventer, Chem. of Mater., 2005. 17: p. 3075-3085.

19. Rees, C.A., J.L. Provis, G.C. Lukey, and J.S.J. van Deventer, The mechanism of geopolymer gel formation investigated through seeded nucleation. Colloid Surf. A-Physicochem. Eng. Asp., 2008. 318: p. 97-105.

20. Vail, J.G., Soluble Silicates. Vol. 1 and 2. 1952, New York: Reinhold.

21. Weng, L., K. Sagoe-Crentsil, T. Brown, and S. Song, Effects of aluminates on the formation of geopolymers. Materials Science and Engineering B, 2005. 117: p. 163-168.

22. Barbosa, V.F.F., K.J.D. MacKenzie, and C. Thaumaturgo, Synthesis and characterisation of materials based on inorganic polymers of alumina and silica: sodium polysialate polymers. Int. J. Inorg. Mat., 2000: p. 309-317.

23. Davidovits, J., Geopolymers: Inorganic Polymeric New Materials. Journal of thermal analysis, 1991. 37(8): p. 1633-1656.

24. MacKenzie, K.J.D., What are these things called geopolymers? A physicochemical perspective. Ceramic transactions, 2003. 153: p. 175-186.

25. Fletcher, R., K.J.D. MacKenzie, C.L. Nicholson, and S. Shimada, The composition range of aluminosilicate geopolymers. J. Euro. Ceram. Soc., 2005. 25: p. 1471-1477.

26. O'Connor, S.J., Solid-state synthesis of lithium aluminosilicate geopolymer. 2009, Victoria University of Wellington.

27. Silva, F.J. and C. Thaumaturgo, Fibre reinforcement and frature response in geopolymeric mortars Fatigue Fract. Engng. Mater. Struct., 2003. 26: p. 167-172.

28. Dias, D.P. and C. Thaumaturgo, Fracture toughness of geopolymeric concretes reinforced with basalt fibres. Cement and Concrete Composites, 2005. 27: p. 49-54.

29. Brew, D.R.M. and K.J.D. MacKenzie, Geopolymer synthesis using silica fume and sodium aluminate. J. Mater. Sci., 2007. 42(11): p. 3990-3993.

30. Kolousek, D., J. Brus, M. Urbanova, J. Andertova, V. Hulinsky, and J. Vorel, Preparation, structure and hydrothermal stability of alternative (sodium silicate-free) geopolymers. J. Mater. Sci., 2007. 42: p. 9267-9275.

31. Barbossa, V.F.F. and K.J.D. MacKenzie, Synthesis and thermal behaviour of potassium sialate geopolymers. Materials Letters, 2003. 57: p. 14771482.

32. De Silva, P. and K. Sagoe-Crenstil, Medium-term phase stability of $\mathrm{Na}_{2} \mathrm{O}-$ $\mathrm{Al}_{2} \mathrm{O}_{3}-\mathrm{SiO}_{2}-\mathrm{H}_{2} \mathrm{O}$ geopolymer systems. Cement and Concrete Research 2008. 38: p. 870-876.

33. Gevorkyan, S.V., D.G. Aslanyan, and S.T. Kostanyan, Solubility diagrams of gallium sesquioxide-sodium oxide-water and gallium sesquioxide- 
potassium oxide-water systems at 90 degrees. Armyanskii Khimicheskii Zhurnal, 1972. 25(2): p. 113-116.

34. Wijnen, P.W.J.G., T.P.M. Beelen, J.W. De Haan, C.P.J. Rummens, L.J.M. Van de Ven, and R.A. Van Santen, Silica gel dissolution in aqueous alkali metal hydroxides studied by ${ }^{29}$ Si-NMR. Journal of Non-Crystalline Solids, 1989. 109: p. 85-94.

35. Duxson, P., A. Fernandez-Jimenez, J.L. Provis, G.C. Lukey, A. Palomo, and J.S.J. van Deventer, J. mater. Sci., 2007. 42: p. 2917-2933.

36. Xue-Min, C., Z. Guang-Jian, H. Yao-Cong, S. Feng, and Z. Ji, A study on electrical conductivity of chemosynthetic $\mathrm{Al}_{2} \mathrm{O}_{3}-2 \mathrm{SiO}_{2}$ geopolymer materials. Journal of Power Sources, 2008. 184: p. 652-656.

37. Foster, L.M. and H.C. Stumpf, Analogies in the Gallia and Alumina Systems. The preparation and Properties of some Low-Alkali Gallates. J. Am. Chem. Soc., 1951. 73(4): p. 1590-1595.

38. Escribano, V.S., E.F. Lopez, P.S. Huidobro, M. Panizza, C. Resini, J.M. Gallardo-Amores, and G. Busca, Characterisation of manganese-gallium mixed oxide powders. Solid State Sciences, 2003. 5: p. 1480-1489.

39. Postolov, V.S., Synthesis and luminescence properties of some alkali metal gallates (translated from Russian by J. Temuujin). Izvestia academy nauk SSSR Physical Part, 1974. 38(6): p. 1195-1196.

40. MacKenzie, K.J.D., Personal Communication. A. Durant, Editor. 2007: Wellington, NZ.

41. Haneda, M., Y. Kintaichi, and H. Hamada, Enhanced activity of metal oxide-doped $\mathrm{Ga}_{2} \mathrm{O}_{3}-\mathrm{Al}_{2} \mathrm{O}_{3}$ for $\mathrm{NO}$ reduction by propene. Catalysis Today, 1999(54): p. 391-400.

42. Pelati, J.E. and R.J. Gulotty Jr., Dehydrogenation of alkyl aromatic compound over a gallium-zinc catalyst. 2004: US.

43. Varey, P., Chem. Eng., 1991. 13: p. 491.

44. Katada, N. and S.N. Kuroda, M. , Appl. Catal. A, Gen., 1991. 13: p. 180.

45. Peng, L. and J.F. Stebbins, High resolution ${ }^{17} \mathrm{O}$ MAS and triple-quantum MAS NMR studies of gallosilicate glasses. Journal of Non-Crystalline Solids, 2008. 354: p. 3120-3128.

46. Sun, P. and A. Navrotsky, Formation and dehydration enthalpy of gallosilicate zeolites. Microporous and Mesoporous Materials, 2008. 111: p. 507-516.

47. Gabelica, Z., R. Monque, and G. Gianetto, Method of manufacturing metallosilicates, U.S. Patent, Editor. 1994.

48. Kuhl, G.H., J. Inorg. Nucl. Chem., 1971. 33: p. 3261.

49. Thomas, M. and X. Liu, J. Phys. Chem., 1986. 90: p. 4843.

50. Gianetto, G., A. Montes, N. Gnep, A. Florentino, P. Cartraud, and M. Guisnet, Conversion of Light Alkanes into Aromatic Hydrocarbons; VII. Aromatization of Propane on Gallosilicates: Effect of Calcination in Dry Air. Journal of Catalysis, 1993. 145: p. 86-95.

51. Dartt, C.B. and M.E. Davis, Catal. Today, 1994. 19: p. 151. 
52. Kanai, J. and N. Kawata, Coke formation and aging of Galloaluminosilicate (ZSM-5 type zeolite). Applied Catalysis, 1990. 62: $\mathrm{p}$. 141-150.

53. Guth, J.-L. and Z. Gabelica, Silica/Germanium oxide zeolites, U.S. Patent, Editor. 1994.

54. Lee, Y., S.J. Kim, and J.B. Parise, Synthesis and crystal structures of gallium- and germanium-variants of the fibrous zeolites with the NAT, EDI and THO structure types. Microporous and Mesoporous Materials, 2000. 34: p. 255-271.

55. Johnson, G.M., A. Tripathi, and J.B. Parise, Novel Routes for the Preparation of a Range of Germanium Containing Zeolites. Chem. Mater., 1999. 11(1): p. 10-12.

56. Rimer, J.D., D.D. Roth, D.G. Vlachos, and R.F. Lobo, Self-Assembly and Phase Behavior of Germanium Oxide Nanoparticles in Basic Aqueous Solutions. Langmuir, 2007(23): p. 2784-2791.

57. Corma, A., M.J. Diaz-Cabanas, and H.P. Garcia, E. , Chem Commun. , 2001: p. 2148.

58. Li, Q.H., A. Navtrotsky, F. Rey, and A. Corma, Micropor. Mesopor. Mater., 2003. 64: p. 127.

59. Duxson, P., J.L. Provis, G.C. Lukey, S.W. Mallicoat, W.M. Kriven, and J.S.J. van Deventer, Colloid Surf. A-Physicochem. Eng. Asp., 2005. 269: p. 47-58.

60. Walton, R.I. and D. O'Hare, An X-ray absorption fine structure study of amorphous precursors of a gallium silicate zeolite. Journal of Physics and Chemistry of Solids, 2001. 62: p. 1469-1479.

61. MacKenzie, K.J.D. and M.E. Smith, Multinuclear Solid-State NMR of Inorganic Materials. Pergamon Materials Series, ed. R.W. Cahn. 2002, London: Pergamon.

62. Klinowski, J., S.W. Carr, S.E. Tarling, and P. Barnes, Nature, 1987. 350: p. 56-58.

63. Barbosa, V.F.F. and K.J.D. MacKenzie, Thermal behaviour of inorganic geopolymers and composites derived from sodium polysialate. Materials Research Bulletin, 2003. 38: p. 319-331.

64. Occelli, M.L., H. Eckert, A. Wolker, and A. Auroux, Microporous and Mesoporous Solids, 1999. 30: p. 219.

65. Mortlock, R.F., A.T. Bell, and C.J. Radke, Silicon-29 and gallium-71 NMR investigations of alkylammonium gallosilicate solutions. J. Phys. Chem., 1992. 96(7): p. 2968-2975.

66. Wong, H., Personal Communication. A. Durant, Editor. 2008: Wellington.

67. Jozefaciuk, G. and G. Bowanko, Clay Min., 2002. 50: p. 771-783.

68. Fricke, R. and W. Blencke, Z. Anorg. Chem., 1925. 143: p. 184-199.

69. De la Cuadra, A., On polygermanate ion (review and critical study). Anales de Quimica, 1990. 86(3): p. 221-229.

70. Shagisultanova, G.A., G.I. Kurnevich, and E.M. Loiko, Behavior of germanium dioxide in alkaline solutions. Zhurnal Neorganicheskoi Khimii, 1968. 13(11): p. 3100-3103. 
71. Wijnen, P.W.J.G., T.P.M. Beelen, J.W. de Haan, L.J.M. Van de Ven, and R.A. Van Santen, The structure directing effect of cations in aqueous silicate solutions. A ${ }^{29}$ Si-NMR study. Elsevier Science Publishers, 1990.

72. Bao, Y., C. Kuo, and P.S. Nicholson, Solid-state synthesis of potassium $\beta$ and $\beta$ "-gallates. Solid State Ionics, 2000. 130: p. 293-298.

73. Michiue, Y. and M. Watanabe, Structure of Sodium $\beta$ "-Gallate. Acta Cryst., 1991. C47: p. 495-498.

74. Toropov, N.A. Some rare earth silicates. in 7th Trans. Int. Ceram. Congr. . 1960. London, United Kingdom.

75. Rowles, M.R., J.V. Hanna, K.J. Pike, M.E. Smith, and B.H. O'Connor, ${ }^{29}$ Si, ${ }^{27} \mathrm{Al},{ }^{1} \mathrm{H}$ and ${ }^{23} \mathrm{Na}$ MAS NMR Study of the Bonding Character in Aluminosilicate Inorganic Polymers. Appl. Magn. Reson., 2007. 32: p. 663689.

76. Yoon, J.H., Preparation of a water soluble alkali-metal germanium oxide for fertilizer additive, in Kongkae Taeho Kongbo. 2005: South Korea. 